NBER WORKING PAPER SERIES

WHEN HARRY FIRED SALLY: THE DOUBLE STANDARD IN PUNISHING MISCONDUCT

\author{
Mark L. Egan \\ Gregor Matvos \\ Amit Seru \\ Working Paper 23242 \\ http://www.nber.org/papers/w23242 \\ NATIONAL BUREAU OF ECONOMIC RESEARCH \\ 1050 Massachusetts Avenue \\ Cambridge, MA 02138 \\ March 2017, Revised December 2021
}

Emir Kamenica was the editor for this article. We thank Emir and the anonymous referees for many valuable comments and suggestions. We also thank Sumit Agarwal, Jonathan Berk, Marianne Bertrand, Jules van Binsbergen, Kerwin Charles, Darrell Duffie, Elena Espinoza, Matt Gentzkow, Christopher Hennesey, Laurie Hodrick, Emir Kamenica, Lawrence Katz, Crystal Lam, Edward Lazear, Sendhil Mullainathan, Paige Parker, Paul Oyer, Chris Palmer, Chris Parsons, Joshua Rauh, Paola Sapienza, Anna Scherbina, Andrei Shleifer, Ken Singleton, Vikrant Vig, Luigi Zingales, and the seminar participants at the Eller College of Management, London Business School, NYU Stern, Princeton University, Stanford University, Tepper School of Business, Tuck School of Business, University of Chicago (economics), University of Chicago Booth School of Business and participants at the American Finance Association Meetings, Bank of England conference, Berkeley-Stanford joint seminar, HBS-MIT Financial Economics conference, NBER Summer Institute and RCFS conference. We also thank Daniel Neagu for his excellent research assistance. The views expressed herein are those of the authors and do not necessarily reflect the views of the National Bureau of Economic Research.

NBER working papers are circulated for discussion and comment purposes. They have not been peer-reviewed or been subject to the review by the NBER Board of Directors that accompanies official NBER publications.

(C) 2017 by Mark L. Egan, Gregor Matvos, and Amit Seru. All rights reserved. Short sections of text, not to exceed two paragraphs, may be quoted without explicit permission provided that full credit, including $\odot$ notice, is given to the source. 
When Harry Fired Sally: The Double Standard in Punishing Misconduct

Mark L. Egan, Gregor Matvos, and Amit Seru

NBER Working Paper No. 23242

March 2017, Revised December 2021

JEL No. D18,G24,G28,J71

\begin{abstract}
$\underline{\text { ABSTRACT }}$
We examine gender differences in misconduct punishment in the financial advisory industry. We find evidence of a "gender punishment gap": following an incident of misconduct, female advisers are $20 \%$ more likely to lose their jobs and $30 \%$ less likely to find new jobs relative to male advisers. Females face harsher outcomes despite engaging in misconduct that is $20 \%$ less costly and having a substantially lower propensity towards repeat offenses. The gender punishment gap in hiring and firing dissipates at firms with a greater percentage of female managers at the firm or local branch level. The gender punishment gap is not driven by gender differences in occupation (type of job, firm, market, or financial products handled), productivity, misconduct, or recidivism. We extend our analysis to explore the differential treatment of ethnic minority men and find similar patterns of "in-group" tolerance. Our evidence is inconsistent with a simple Bayesian model with profit maximizing firms and suggests instead that managers are more forgiving of missteps among members of their own gender/ethnic group.

Mark L. Egan

Harvard Business School

Baker Library 365

Soldiers Field

Boston, MA 02163

and NBER

megan@hbs.edu

Gregor Matvos

Kellogg School of Management

Northwestern University

2211 Campus Drive

Global Hub 4361

Evanston IL, 60208

and NBER

gregor.matvos@kellogg.northwestern.edu

Amit Seru

Stanford Graduate School of Business

Stanford University

655 Knight Way

and NBER

aseru@stanford.edu
\end{abstract}




\section{Introduction}

Labor markets compensate productive activities with higher wages and non-wage compensation such as promotions and perks. Conversely, employees who engage in unproductive or even destructive activities are punished, for example, through job loss and lack of employment opportunities in the market. The existing research on the differential treatment of men and women has generally focused on gender differences in the compensation of productive activities. Firms pay female employees less than comparable male employees (Altonji and Blank, 1999). Firms are also less likely to hire and promote female employees relative to their male counterparts with similar credentials or output (Goldin and Rouse, 2000); and these gaps differ across states (Charles et al. 2018). In this paper we explore whether the differential treatment of men and women carries over to the punishment of undesirable activities as well. In other words, are labor markets more forgiving of missteps made by men than of missteps made by women? A priori, gender differences in punishment may be as important as gender differences in hiring and compensation; roughly $60 \%$ of lawsuits alleging discrimination in the workplace concern discriminatory firings (Siegelman 2016). This paper documents the "gender punishment gap": gender differences in the punishment of similar undesirable activities. We study the punishment gap in the context of financial adviser misconduct and document that this punishment gap is not driven by gender differences in occupation (type of job, firm, market, or financial products), productivity, type of misconduct, or recidivism. We then explore the mechanisms driving the gap.

Gender differences in punishment speak to the broader idea that female employees are given less leniency for missteps than their male counterparts. This aspect of gender differences has received little attention in academia or in policy relative to differences in hiring and compensation. One possible explanation is that a punishment gap is less likely to draw attention than a wage gap. For instance, when we observe a financial adviser losing her job following misconduct, the appeal that the termination was unfair or discriminatory may sound hollow. In fact, the firing may be justified. It is only after observing that, on average, male advisers were not fired for similar transgressions that one can detect a gender punishment gap. In such cases, gender differences may be a priori more difficult to detect, both by the legal system and regulators, and possibly by the employers who themselves may be unaware of their own biases (Bertrand et al., 2005).

A gender punishment gap also differs from gaps in hiring and wages with respect to the information that the employer has about the employee. One view is that the differential treatment between men and women in the workplace mostly takes place before the employer has screened potential employees, at the CV evaluation stage. An extensive literature using correspondence and audit studies has evaluated such differences (see Bertrand and Duflo, 2017; Charles and Guryan, 2011), examining differences in treatment across groups while reducing the potential employee to a bundle of characteristics that can be captured in a CV. During the hiring process and employment, the employer learns substantially more about the employee, reducing the potential for "attention discrimination" (Bartos et al., 2016; Reuben, Sapienza, and Zingales, 2014). One might therefore imagine that discrimination disappears conditional on employment. In contrast, we observe the gender punishment gap among employees with several years of tenure, suggesting that a potentially different mechanism is at play. Moreover, methodologically studying these types of gender differences does not lend itself toward audit and correspondence studies which, by design, reduce an employee to characteristics captured in a CV.

Ours is the first study to investigate the gender punishment gap in an important setting, the financial advisory industry. Undesirable outcomes are generally difficult to measure, especially across firms. We over- 
come this obstacle by exploiting a novel panel data on all financial advisers (about 1.2 million) registered in the United States from 2005 to 2015, representing approximately 10\% of total employment in the finance and insurance sector. Regulators require that financial advisers disclose misconduct-related career events such as customer disputes, regulatory infractions, and criminal offenses. We also observe detailed information on the nature of misconduct, ${ }^{1}$ the monetary cost of misconduct in terms of the associated settlement (which averages several hundred thousand dollars), consequent actions taken by the firm and the regulator following misconduct, and employee movement across firms. ${ }^{2}$ The financial advisory industry is highly regulated with comprehensive licensing requirements, which determine advisers' job tasks. These features of the data allow us to account for differences across advisers in terms of job role, productivity, and misconduct, and to study gender differences in punishment at both the firm and industry level.

Researching gender differences in the financial sector is also interesting per se. Finance is a large and highly compensated industry, which consistently ranks among the bottom industries in terms of gender equality. Personal financial advisers, for example, have among the largest gender earning gaps across occupations (Census, 2008). Recent survey evidence found that nearly $88 \%$ of female financial service professionals believe that gender discrimination exists within the financial services industry (Tuttle, 2013). Consequently, concerns about the lack of diversity and discrimination in the financial industry have become an important policy issue. Our work speaks to this issue since it suggests that the harsher punitive measures taken against women (such as termination) for similar missteps might inherently contribute to the glass ceiling they face. ${ }^{3}$

This paper has two goals. First, we document key differences in the punishment of similar misconduct across male and female financial advisers at both the firm and industry level: the gender punishment gap. We show that the gap is not driven by gender differences in occupation (type of job, firm, market, or financial products), productivity, type of misconduct, or recidivism. Rather, we find that this punishment gap is strongly correlated with the gender composition of the managerial team; more female managers and executives on the team help mitigate the gender punishment gap. Moreover, we find evidence of a similar punishment gap and mitigating factors for ethnic minority men. Second, we examine the mechanism behind the gender punishment gap. We begin with a benchmark that the gap is simply a product of firms' Bayesian profit maximizing behavior, i.e. statistical discrimination (Phelps, 1972; Arrow, 1973). This line of explanation has a difficult time reconciling the collage of evidence we document. We then explore the alternative that the punishment gap is driven by managers' biases. Such biases could be either taste-based (Becker, 1957) or because market participants hold miscalibrated/incorrect beliefs about misconduct across the two groups (Bordalo et al., 2016; Arnold et al, 2018; Sarsons, 2017). While we are not able to conclusively tease out the specific bias driving our findings, our empirical evidence is consistent with a simple model of managerial bias.

We first document gender differences in the financial advisory industry. Male financial advisers make up $75 \%$ of the financial advisory industry and are responsible for a disproportionately large amount of the misconduct in the industry. Moreover, male advisers engage in more severe misconduct in terms of the corresponding monetary damages to the firm. These differences are partially a result of somewhat different

\footnotetext{
${ }^{1}$ Common misconduct allegations include activities such as unauthorized trading, churning accounts to generate excess commissions, misrepresenting the risks associated with a financial product, and committing outright fraud.

${ }^{2}$ Roughly $7 \%$ of financial advisers have a past record of misconduct, and the average settlement is in excess of several hundred thousand dollars.

${ }^{3}$ Consulting firm Oliver Wyman (2016) lists the glass ceiling as the number one cause for concern for women in the industry. Former FDIC chairwomen Sheila Bair (2016) writes that the glass ceiling in finance is "barely cracked" for women.
} 
allocations to jobs and tasks—-males are more likely to be managers with longer industry tenures and hold more qualifications. Nevertheless, the gender differences in misconduct persist after comparing male and female advisers working at the same firm, in the same location, at same point of time, and in the same job role, and even after accounting for a rich set of adviser characteristics and productivity measures. ${ }^{4}$ Our finding that men have a higher propensity to commit more nefarious activities has been supported in other contexts and is "universal" across violent and nonviolent criminal activity (Steffensmeier and Allen, 1996). ${ }^{5}$

Next, we turn to our first main result. We find that, despite having a lower incidence of misconduct and engaging in less severe misconduct, female advisers face more severe punishment in the labor market. Female advisers are $20 \%$ more likely to experience a job separation following misconduct relative to male advisers with similar offenses. Conditional on separation, female advisers face longer out-of-the-industry spells and are $30 \%$ less likely to find a new position in the industry within one year. This finding is robust across longer time horizons and is particularly striking because we find no gender differences in job turnover rates for advisers without misconduct. Our results suggest that firms, and the industry as a whole, discipline female advisers more severely relative to male advisers following misconduct. We term these differences in labor market outcomes the "gender punishment gap."

The central concern is that the gender punishment gap is driven by gender occupational segregation across firms, markets, or job roles. Several pieces of evidence in the data suggest that this is not the case. We compare the career outcomes of male and female advisers who are working at the same firm, in the same location, and at the same point in time. In addition, as noted before, because the market for financial advice is highly regulated, advisers are legally required to hold a particular set of licenses to sell certain classes of products and perform certain job tasks. For example, the Series 6 License authorizes financial advisers to sell mutual funds and variable annuities, the Series 11 License (Registered Sales Assistant License) allows an individual to work as a sales assistant in the industry, and the Series 24 allows an individual to work as a manager who oversees other advisers. We account for 61 different professional licenses. In particular, we effectively compare the career outcomes of male and female advisers who are working for the same firm, in the same branch, at the same time, and in the same role (firm $\times$ year $\times$ county $x$ license fixed effects). These fixed effects allow us to control for differences across firms, branches, and jobs, such as whether advisers engage with institutional investors, retail investors, and/or investment banking activities. We also bound our estimates using tests that account for unobservable selection (Oster, 2019) and the results suggest that unobservable selection cannot explain the gender punishment gap. Finally, for a smaller subset of the data, we also observe an individual adviser's assets under management (AUM) and productivity. Accounting for these dimensions also helps condition on other aspects of the job function of the adviser. After controlling for these differences, the gender punishment gap remains virtually unchanged.

Our second main result is that there is substantial heterogeneity in the gender punishment gap across firms. At firms with no female representation at the executive/ownership level, women are 14pp more likely to experience an employment separation following misconduct than their male colleagues. Conversely, there is no gap in firms with an equal representation of male and female executives/owners. We find similar results when exploiting within-firm variation in the share of female branch-level managers. While the gender punishment gap varies with the gender composition of a firm's management, it does not vary with the

\footnotetext{
${ }^{4}$ In the specifications we include, firm $\times$ year $\times$ county $\times$ license fixed effects.

${ }^{5}$ With the exception of prostitution, men are more likely to be arrested for all FBI offense categories, including violent, non-violent, and small crimes (Steffensmeier and Allen, 1996). Steffensmeier and Allen (1996) write "Criminologists agree that the gender gap in crime is universal: Women are always and everywhere less likely than men to commit criminal acts."
} 
composition of a firms' junior employees. Our results suggest that male executives and managers seem to be more forgiving of misconduct by men than by women. Using novel data on sexual harassment claims filed against the financial advisory firms, we also find that the gender punishment gap is roughly twice as large at financial advisory firms with a history of sexual harassment.

We extend our analysis to minority men and show that the punishment gap and patterns of "in-group" tolerance are not limited to gender. Males with names from traditionally discriminated minorities face a punishment gap relative to non-minority men. The punishment gap is lower in firms with a larger share of managers from their ethnic group. These results also suggest that the "in-group" tolerance we observe is not driven solely by gender specific factors. In addition, we find no evidence that male minority managers decrease the gender punishment gap. In other words, managers only mitigate the punishment gap within their own gender and ethnic group. This evidence is important because it rules out several potential alternatives, under which firms with female or minority male executives attract a pool of individuals with selected misconduct propensities.

We next document that the gender punishment gap is robust to different measures of misconduct and misconduct severity. Firms might be less willing to tolerate misconduct among female advisers if female advisers engage in more severe or more costly misconduct. The data suggest the exact opposite. Male advisers engage in misconduct that is $20 \%$ more costly to settle for firms. We also experiment with a variety of misconduct measures and find robust results across those alternative measures. These results suggest that the gender punishment gap does not arise because female advisers engage in different types, or more egregious misconduct. Another explanation could be that female advisers are more likely to be repeat offenders. Again, the opposite is true. Male advisers are more than twice as likely to be repeat offenders in the future. These results suggest that, all else equal, firms should punish male advisers more severely than female advisers. In other words, even if job separation rates following misconduct were identical, these results would still suggest that the punishment of misconduct is biased against women.

Similarly, the gender punishment gap does not appear to be driven by gender differences in productivity. An advantage of the financial adviser setting is that the productivity of financial advisers can be broadly encapsulated by the amount of assets they attract (i.e., AUM). As noted before, we observe AUM and other measures of productivity for a smaller subset of the data. Controlling for productivity measures has no effect on the gender punishment gap in this sample. We also control for other measures, which indirectly reflect expected productivity. For example, the gender punishment gap persists across different levels of experience, and exists even for advisers whose abilities are well known to the market (15+ years experience). Career interruptions, which explain a large part of the earnings gap in finance (Bertrand et al, 2010) correlate with turnover, but not with the punishment gap. Lastly, if female advisers who engage in misconduct have less desirable characteristics, we would expect these characteristics to also lead to higher turnover prior to misconduct. However, we find no signs of elevated turnover for female advisers who eventually engage in misconduct prior to their initial misconduct offense.

In the last part of the paper, we explore two potential mechanisms generating the gender punishment gap. First, we consider a benchmark mechanism, in which the gender punishment gap arises from profitmaximizing, Bayesian updating behavior of firms (i.e. statistical discrimination; Phelps, 1972; Arrow, 1973). A profit maximizing, Bayesian firm may find it optimal to punish women more severely if - given the lower misconduct of female advisers relative to male ones in general -misconduct by female advisers is predictive of more frequent subsequent misconduct or lower adviser skill. Alternatively, the gender punishment gap 
could instead be driven by managerial biases. The biases could be the result of either an inherent firm prejudice against women or favoritism towards men (i.e. taste-based discrimination; Becker, 1957) and/or could be due to miscalibrated beliefs held by firms (i.e. stereotyping; Bordalo et al., 2016). We then contrast these two mechanisms and their associated predictions with the data.

We present several results which are difficult to reconcile with Bayesian updating by profit maximizing firms. As discussed above, we find little evidence that female advisers with recent misconduct records have lower expected productivity or more severe misconduct than similar male advisers. Second, Bayesian updating has a difficult time reconciling the ethnic minority punishment gap we document. The existence of the minority punishment gap and the fact that it diminishes in the presence of minority male managers suggests that it is driven by the same mechanism as the gender punishment gap. A key distinction in the data is that, compared to non-minority male advisers, male minority advisers are more likely to engage in misconduct. Thus, following the logic of Bayesian updating, it should be the case that misconduct by male minority advisers would therefore be predictive of less frequent subsequent misconduct or higher adviser skill. Consequently, profit maximizing firms would update less and punish less harshly after observing misconduct by these advisers. In other words, given high average misconduct rates of male minority advisers relative to non-minority ones, we should find the "reverse" punishment gap for minority males. The existence of the male minority punishment gap therefore suggests that Bayesian updating by profit maximizing firms is not likely driving the gender punishment gap.

Third, it is difficult to rationalize why the gender punishment gap is higher in branches with more male managers, but is not correlated with the gender composition of junior employees in a Bayesian, profit maximizing, framework. If female advisers are more productive in female managed firms, this productivity should also be reflected in junior employees. Moreover, a similar sorting would have to take place among male advisers along the dimension of ethnicity. The facts do not support these arguments. Finally, since we find that male minority managers do not mitigate the gender punishment gap, the sorting would have to be multi-dimensional. In sum, a simple benchmark model in which Bayesian firms maximize profits has a difficult time explaining a wide range of facts about the gender punishment gap.

We also consider the alternative that firms are biased: firms either prefer non-minority male advisers or have biased beliefs about productivity/misconduct across genders and minority status. Such a model could explain the existence of a gender punishment gap, and why it varies with the composition of firms' management but not other employees. It is difficult to determine whether biased beliefs or the managers' preferences drive the gap, since the predictions are similar once one allows for sufficient heterogeneity of beliefs or preferences. The evidence of a larger gender punishment gap in firms with sexual harassment claims is somewhat more consistent with the taste (ethics/morals) based explanation, rather than managers' beliefs (either rational or biased). While we think this is the most plausible explanation of our findings, we cannot rule out alternatives based on a sufficiently rich set of beliefs or underlying heterogeneity across advisers and firms.

Our findings contribute to the large literature on gender discrimination. We document a new type of gender gap in a large industry: gender differences in job separation and reemployment for similar missteps. More broadly, our analysis indicates that the absence of a gender gap in compensation or hiring rate at the entry level does not imply the absence of differential treatment across gender — such differences can emerge long after employees are working inside a firm. In establishing this novel mechanism, we connect to the vast literature on discrimination dating back to the theoretical work of Becker (1957; rev. 1971), Phelps (1972), 
Arrow (1973), and Aigner and Cain (1977).

Our paper contributes to the empirical literature documenting gender differences in the workplace. A large literature finds gender differences in hiring decisions, such as such as Neumark (1996), Goldin and Rouse (2000), Booth and Leigh (2010), Carlsson (2011), and Moss-Racusin et al. (2012), and in promotions and compensation (Altonji and Blank, 1999; Blackaby et al., 2005; Blau and Kahn, 1997; and Ginther and Kahn, 2004). ${ }^{6}$

While the existing research on gender has generally focused on gender differences in the compensation of productive activities, we explore whether such gender differences carry over to the punishment of undesirable activities as well. In the criminal system, females are frequently punished less severely for similar crimes (Goulette et al., 2015). This contrasts with our finding of a gender punishment gap in the labor market. Sarsons (2017) documents similar patterns in the medical industry: female surgeons experience a larger drop in patient referrals relative to male surgeons following a patient death. At the same time, male surgeons experience a greater increase in patient referrals relative to female surgeons following positive surgical outcomes. Sarsons finds limited evidence suggesting that these asymmetric referrals patterns are generated by rational/Bayesian physician behavior, where physicians maximize patient outcomes. We, similarly, find limited evidence that the gender punishment gap is generated by rational/Bayesian firm behavior, where firms maximize profits. We also document differences at the firm at which the issue occurred (current employer) and other firms in the labor market (re-hiring). Landsman (2018) finds evidence of a gender punishment gap among S\&P 1500 executives for poor firm performance. Following negative firm performance, female executives are 5pp more likely to leave their position relative to male executives. Consistent with our findings, Landsman (2018) concludes that the gender differences in executive departure rates are best explained by an attribution bias.

We also contribute to the growing literature documenting that significant male/female participation and wage gaps exist in competitive, high paying jobs (Bertrand and Hallock, 2001; Bell, 2005; Wolfers, 2006; Niederle and Vesterlund, 2007; Sapienza et al. 2009; Bertrand, Goldin, and Katz, 2010). We complement this literature by focusing on a large population of financial advisers, who are perhaps more representative of the high-skilled labor population, rather than the tail of the population represented by CEOs or directors of corporate boards.

Our work also relates to the literature on the effect of females in management and evaluation positions. The evidence in the literature is mixed, finding no effect (Hamermesh and Abrevaya, 2013; Bertrand et al., 2014; Jayasinghe et al., 2003); that female evaluators are harsher towards females (Broder, 1993); and that the consequences are not always straightforward (Zinovyeva and Bagues, 2011). For example, Bagues et al. (2017) find that female evaluators are not significantly more favorable towards female candidates but that male evaluators discriminate against female candidates upon female evaluators joining. Our findings suggest that female evaluators and leaders mitigate the gender punishment gap, consistent with the results of Beaman et al. (2012), De Paola and Scoppa (2015), and Cardoso and Winter-Ebmer (2007).

After documenting the gender punishment gap in the financial advisory industry, we empirically examine whether the observed pattern is consistent with a simple statistical discrimination model or with a model with firm biases driven due to tastes or miscalibrated beliefs (Bordalo et al., 2016). In doing so, we closely relate to work of Altonji and Pierret (2001), Barres (2006), Knowles et al. (2001), Charles and Guryan (2008),

\footnotetext{
${ }^{6}$ For extensive surveys, see Altonji (1999), Bertrand (2011), Bertrand and Duflo (2017), Blau and Kahn (2017).
} 
Arnold et al. (2018), Sarsons (2017), and Landsman (2018). Our paper is also related to Lavy (2008) and Beaman et al. (2009) who provide evidence of the importance of stereotypes in driving discrimination but focus on compensation as the labor outcome rather than job separations and hiring.

Finally, our work also relates to the literature on financial misconduct and punishment. The framework of our analysis relates closely to the work of Becker on crime and punishment (1968). Our paper relates to the recent literature on fraud and misconduct among financial advisers (Egan, Matvos, and Seru, 2019a; Dimmock et al., 2018; Qureshi and Sokobin, 2015) and in the mortgage industry (Piskorski, Seru, and Witkin, 2013; Griffin and Maturana, 2016). The paper also relates to the literature on corporate fraud, including: Povel et al. (2007), Dyck et al. (2010; 2014), Wang et al. (2010), Khanna et al. (2015), and Parsons et al. (2018).

The rest of the paper is structured as follows. Section II describes the data, describes how we measure misconduct, and presents the basic facts about gender differences among financial advisers. Section III documents the gender punishment gap in the labor market for financial advisers. Section IV explores the economic mechanisms underlying the gap. Section V concludes.

\section{Gender and Financial Advisers}

\section{II.A Data Set}

Our data set contains the universe of financial services employees registered with the Financial Industry Regulatory Authority (FINRA) from 2005 to 2015. The data comes from FINRA's BrokerCheck database. Additional details describing the data set are in Egan, Matvos, and Seru (2019a) (also available at http://egan matvoserru.stanford.edu). Throughout the paper, we refer to a financial adviser as any individual who is registered with FINRA, but are careful to make distinctions about additional registrations or qualifications a financial adviser may hold, such as being a registered investment adviser or a general securities principal. A broker (or stockbroker) is registered with FINRA and the SEC and is defined in the Securities and Exchange Act 1934 as "any person engaged in the business of effecting transactions in securities for the account of others." An investment adviser provides financial advice rather than transaction services. Although both are often considered "financial advisers," brokers and investment advisers differ in terms of their registration, duties, and legal requirements. Throughout the paper, we will use terminology consistent with FINRA and refer to both investment advisers and brokers as "financial advisers." Our data includes all brokers and the vast majority of investment advisers. The data set also contains additional information on the universe of currently active financial firms.

Our sample contains a monthly panel of all registered advisers from 2005 to 2015 . For each of the roughly 1.2 million advisers in the data set, we observe the adviser's registrations, licenses, employment history, and

whether or not she has any disclosures on her record. We observe each adviser's complete employment history in the industry which often dates back substantially further than 2005.

We observe detailed data on the adviser's complete employment history in the financial advisory industry including the employer, location and tenure. We also observe information on each adviser's role and job function within their firm. Relative to many other industries, the financial advisory industry is highly regulated. Financial advisers are legally required to hold regulatory licenses (i.e., pass specific exams called series exams) in order to engage in particular activities and to hold certain positions within a firm. For example, the Investment Company Products/Variable Life Contracts Representative License (Series 6 exam) 
authorizes an individual to sell mutual funds and variable annuities. The Futures Managed Fund Exam (Series 31) is required to sell managed futures funds. The licenses also provide detail on the adviser's specific job role. An Assistant Representative (Series 11) License allows an individual to work as an assistant, while a General Securities Representative (Series 24) License is required to work as a manager. In Appendix A3 we list the 61 different types of licenses we observe in the data. These detailed, specific, and granular occupational licensing requirements allow us to compare female and male advisers with the same qualifications and engaged in the same job roles within a firm.

Measuring Misconduct: The regulatory data also provides details on whether an adviser has ever engaged in misconduct and the specific details of each offense. By rule (4530), the regulator FINRA requires that financial advisers and firms "disclose customer complaints and arbitrations, regulatory actions, employment terminations, bankruptcy filings, and criminal or judicial proceedings" within thirty days. ${ }^{7}$ The rule is designed to remove a firm's discretion in what gets reported to FINRA, and firms would be subject to fines and penalties for misreporting. The rule helps alleviate concerns that there is any systematic gender bias in misconduct reporting.

We observe the full set of such disclosures for each financial adviser in our data. A disclosure indicates any sort of dispute, disciplinary action, or other financial matter concerning the adviser. Because not all disclosures are indicative of misconduct (i.e. personal bankruptcy), we classify only the disclosures that are indicative of fraud or wrongdoing as misconduct. Specifically, following Egan, Matvos, and Seru (2019a), we restrict our classification of disclosures indicating misconduct to include only six of the twenty-three disclosure categories reported by FINRA: Customer Dispute-Settled, Regulatory-Final, Employment Separation After Allegations, Customer Dispute - Award/Judgment, Criminal - Final Disposition, Civil-Final. To summarize, misconduct includes customer disputes, internal investigations, and regulatory/criminal events that were resolved against the adviser. Roughly $7 \%$ of the financial advisers in our data set have a past record of misconduct.

An advantage of our data set is that we observe granular data for each misconduct disclosure, including the specific allegations, products involved, and costs. Table 1c displays the most commonly reported allegations reported against financial advisers broken down by gender. The allegations vary in terms of their severity and potential opacity/ambiguity. Several of the common allegations are relatively clear-cut in terms determining guilt such as unauthorized trading, churning, misrepresentation, and outright fraud. Unauthorized trading, for instance, involves trading in a client's account without their consent. This type of activity is easily verifiable because account activity, client activity, and legal consent are tracked and well documented. Other allegations are more vague. For example, a common allegation is that the adviser made unsuitable investments. This is not surprising. By law, brokers are required to only sell "suitable" investments to their clients. However, the exact dimension on which a given product might be unsuitable for a given client is less clear. In our analysis, we explicitly account for these differences by examining the type and extent of misconduct.

Misconduct is costly for the advisory firm. Our data set provides details on the dollar awards/ settlements advisers are forced to pay out to clients as a result of misconduct. The median settlement is $\$ 40,000$, and the mean settlement is approximately $\$ 550,000$, suggesting substantial damages to the household. We use data on the associated awards/settlements to examine the severity of misconduct by male and female advisers.

\footnotetext{
${ }^{7}$ Regarding customer complaints, firms must report all written customer complaints, where written is broadly defined to include all emails, text messages, tweets, etc.
} 
Gender Data: The BrokerCheck data set does not provide information on the gender of the financial adviser. We use data from GenderChecker to match the gender of each adviser based on the first name of the adviser. GenderChecker uses data from the UK Census in conjunction with other proprietary data sources to match the first names of individuals to gender. GenderChecker takes a conservative approach to assigning genders from names. If a name appears in the census (or one of GenderChecker's other data sources) as both male and female even once, the name is classified as being unisex. We assign a specific gender to $82 \%$ of the advisers in our database: $62 \%$ of the advisers in our data set are classified as male, $20 \%$ are classified as female. Of the remaining $18 \%$ of advisers, $15 \%$ are classified as unisex and $3 \%$ are unmatched in the GenderChecker database. In our main analysis, we restrict our data set to those advisers we classify as either male or female, dropping all unisex and unmatched observations. Females therefore comprise approximately $25 \%$ of the matched data. As an additional robustness check, we use name/gender data from Meridian IQ's database on financial advisers and find similar results as with the former classification. We report these robustness tests in Appendix A1. Summary statistics for the complete data set are reported in Table 1. Central to our purposes, $15 \%$ of male advisers and $8 \%$ of female advisers in our data set have disclosures on their records. These statistics are in line with previous work (Egan, Matvos, Seru 2019a and cites therein).

Meridian IQ Data: For a subset of active advisers, we observe detailed adviser-level productivity data from Meridian IQ as of 2016. Meridian IQ contains data on an adviser's self-reported production (revenues brought to a firm), self-reported assets under management (AUM), and internal "quality" rating as defined by Meridian IQ. We report the productivity summary statistics for male and female advisers in the bottom panel of Table 1a. The summary statistics suggest that male advisers are marginally more productive and manage more assets. On average, male advisers are $6 \%$ more productive than female advisers ( $\$ 532 \mathrm{k}$ vs $\$ 503 \mathrm{k})$.

We use the Meridian IQ data to perform several robustness checks corresponding to our main analysis. The advantage of the Meridian IQ data is that it provides granular adviser-level productivity data which is a potentially important input for understanding employment turnover. The disadvantage of this data is that we observe productivity data as for a subset of advisers. Table A1 compares the sample of advisers for which we observe Meridian IQ productivity data with the full sample. In general, the Meridian sample is similar to the full sample in terms of adviser experience, qualifications, disclosures, and gender. The biggest differences are in terms of adviser turnover. Because we only observe Meridian data for advisers who were active as of 2016, advisers in this sample are less likely to leave their firm in a given year relative to the full sample ( $10 \%$ vs $19 \%$ ) and, conditional on leaving their firm, they almost always join a new firm within a year (93\% vs 53\%). We discuss these potential sample selection issues in the context of our findings in Section III.

Arbitration Awards Data: Customer and employment disputes, including claims of sexual harassment and discrimination, in the financial advisory industry are typically subject to mandatory arbitration. Arbitration is an alternative dispute resolution mechanism for resolving disputes outside of the court system. Financial adviser employment (customer) contracts typically include a mandatory arbitration clause which means that any disputes between a firm and an adviser (customer) will be resolved through arbitration rather than through the court system. FINRA governs the arbitration rules and proceedings (Further details of the FINRA arbitration proceedings are described in Egan, Matvos and Seru (2019b)).

We collect data on the arbitration cases from FINRA's Arbitration Awards Online database. The FINRA Arbitration Awards database contains case-level information for the universe of arbitration cases $(50,000+)$ 
overseen by FINRA over the period 1988-2015. For each arbitration case, FINRA provides a pdf document that describes the nature and outcomes of the arbitration cases. Central to our analysis, we observe the firm named in the case and whether the arbitration dispute involved claims of sexual harassment. We parse through each document to determine the firm involved in the case and whether the case includes claims of sexual harassment. We observe 259 harassment cases in total and 120 sexual harassment cases. The claimant in sexual harassment cases is typically an adviser who was subject to sexual harassment from his/her firm, but the claimant can also be a customer who was subject to sexual harassment from his/her firm. We use this data to examine how the gender punishment gap is correlated with sexual harassment at the firm level.

\section{II.B Gender Composition of Advisers and Misconduct}

\section{II.B.1 Gender Composition}

The advisers in our data account for roughly $10 \%$ of employment in the Finance and Insurance sector (NAICS 52). $25 \%$ of financial advisers are female. Simple cuts of the data in Table 1 suggest that male financial advisers have more experience, more extensive qualifications, and are more likely to be in managerial and supervisory positions than their female counterparts. Male advisers average three additional years of experience relative to female advisers. Similarly, male advisers have passed a somewhat larger number of qualification exams. Male and female advisers also differ in the types of qualification exams they have passed. ${ }^{8}$ Female advisers are more likely to have completed the Series 6 qualification exam, which allows an adviser to sell open-end mutual funds and variable annuities, while male advisers are more likely to hold a Series 65 qualification, which allows them to act in an investment adviser capacity. Among currently registered advisers, $54 \%$ of male advisers and $45 \%$ of female advisers are also registered as investment advisers.

In addition to having more seniority, male advisers are more likely to be in managerial and supervisory positions than their female counterparts. The Series 24 exam qualifies an individual to operate in a supervisory capacity. Male advisers are 7pp more likely to have completed the Series 24 exam. Similarly, female advisers are underrepresented among executives/owners of the financial advisory firms. Figure 1 displays the distribution of female owner/executives across active financial advisory firms. Female advisers represent $16 \%$ of the owners and executives and $17 \%$ of managers, even though they account for $25 \%$ of all financial advisers. To summarize: male and female financial advisers differ on observables, that might be related to job tasks, financial products, or firms that employ them. It is therefore important to account for these differences when comparing advisers across genders.

\section{II.B.2 Gender Differences in Misconduct Propensity}

Approximately $7 \%$ of financial advisers have records of past misconduct (Egan, Matvos, and Seru, 2019a). Here, we examine how misconduct varies across male and female advisers. Similar to the literature on white collar crime, and crime in general, we find that men are significantly more likely to engage in misconduct than women (Daly, 1989; Steffensmeier and Allen, 1996; Holtfreter, 2005; Steffensmeier et al., 2013). Table $1 \mathrm{~b}$, columns (3) and (4) display the share of advisers with at least one record of past misconduct at a given point in time. The results indicate that $9 \%$ of male and $3 \%$ of female financial advisers have at least one incident of misconduct on their record. ${ }^{9}$ Columns (1) and (2) of Table $1 \mathrm{~b}$ show that the probability

\footnotetext{
${ }^{8}$ Details of each qualification exam are available in Appendix A3 and from FINRA online: http://www.finra.org/industry/qualification-exams?bc=1

${ }^{9}$ Because many financial advisers have multiple disclosures pertaining to misconduct, the subcategories of disclosure that we classify as misconduct in Table $1 \mathrm{~b}$ add up to more than $9 \%$ and $3 \%$.
} 
that an adviser engages in new misconduct during a given year is $0.72 \%$ for males and $0.29 \%$ for females. The incidence of misconduct among male advisers is more than twice the rate among female advisers. Conditional on receiving a misconduct disclosure, the distributions of the types of misconduct are similar across male and female advisers, but there are some subtle differences. Customer initiated misconduct, i.e., customer disputes, accounts for roughly half of all misconduct (57\% for men and $48 \%$ for women). Regulatory and criminal offenses account for $20 \%$ and $17 \%$ of misconduct disclosures received by men and women. Lastly, firm initiated misconduct, accounts for $28 \%$ of misconduct disclosures received by men and $41 \%$ received by women. ${ }^{10}$

Beyond the type of disclosure, we also observe details on the nature of the misconduct. Tables 1c and $1 \mathrm{~d}$ display the most commonly reported types of allegations and financial products in the misconduct disclosures. In general, the distributions of complaint types received by male and female advisers are similar. These simple summary statistics suggest that male and female advisers engage in similar types of misconduct even though the incidence of misconduct is higher among male advisers.

One potential explanation for the differences in misconduct among the two genders is that the job functions of male advisers are, on average, different from those of female advisers. For example, men may be more likely to work in a client-facing role, where they give explicit investment and financial planning advice to consumers. Conversely, women may be more likely to work in non-client facing positions, such as compliance or risk management. Customer disputes account for about one-half of all misconduct (Table 1b), so occupational segregation along these lines could well explain differences in misconduct across genders. To account for these concerns, we examine gender differences in misconduct more systematically using the following linear probability model:

$$
\text { Misconduct }_{i q j l t}=\alpha \text { Female }_{i}+\beta X_{i t}+\mu_{q j l t}+\varepsilon_{i q j l t} .
$$

Observations are at the adviser-by-year level; $i$ indexes an adviser with qualifications/occupational licenses $q$ who worked for firm $j$, at time $t$, and in county $l$. The dependent variable Misconduct $_{i q j l t}$ is a dummy variable indicating that adviser $i$ received a misconduct disclosure at time $t$. The independent variable of interest is the dummy variable Female $_{i}$, which indicates the gender of the adviser. Our full specification includes firm $\times$ year $\times$ county $\times$ license fixed effects $\mu_{q j l t}$. In other words, we include a fixed effect for each set of possible licenses an adviser potentially holds within a firm, location, and time. These sets of controls allow us to compare male and female advisers who work for the same firm, in the same branch, at the same time, and in the same job role. The fixed effects also account for aggregate shocks such as the financial crisis, variation in regulatory conditions (subsuming any state- or county-level regulatory variation), and any differences in firm business models or types of clients serviced across locations. We also account for other adviser level observables such as their experience in the industry in the vector $X_{i t}$.

Table 2a displays the results. In each specification, we estimate a negative and statistically significant relationship between the dummy variable $\mathrm{Female}_{i}$ and the probability that the adviser engages in misconduct. The estimates in column (3) indicate that the probability a female adviser engages in misconduct in a given year is $0.32 \mathrm{pp}$ lower than that of a male adviser. Therefore, relative to male advisers $(0.72 \mathrm{pp}$ from Table 1b), female advisers within the same firm, at the same time, and in the same county (column 3) are roughly

\footnotetext{
${ }^{10}$ Firms must report whether or not adviser experienced an "Employment Separation after Allegations." For these cases where the firms report an "Employment Separation after Allegations," firms report whether or not the adviser was fired/discharged, permitted to resign, or if it was a voluntary separation. Among male advisers with this type of disclosure, $75 \%$ were discharged, $13 \%$ were permitted to resign, and $11 \%$ left voluntarily. Among female advisers with this type of disclosure, $83 \%$ were discharged, $7 \%$ were permitted to resign, and $9 \%$ left voluntarily.
} 
half as likely to engage in misconduct. Most importantly, in our specification with the full set of fixed effects (column 4), we find that women are $0.27 \mathrm{pp}$ less likely to engage in misconduct.

Columns (5) and (6) of Table 2a present our results in which we restrict the data set to advisers for whom we observe productivity in Meridian IQ in 2016. An important caveat is that we only observe advisers productivity for a selected subset of advisers who were active in 2016. We find that, even after controlling for differences in adviser productivity, female advisers are $0.33 p p$ less likely to engage in misconduct in a given year (column 6). The results also suggest that more productive advisers are also more likely to engage in misconduct, but the economic magnitudes are very small. The results in column (6) indicate that a $100 \%$ increase in an adviser's assets under management is associated with a $0.03 p$ increase in misconduct. Collectively the results displayed in Table 2a suggest that gender differences in misconduct can be partially, but not fully explained by occupational segregation across genders.

\section{II.B.3 Gender Differences in Misconduct Severity}

Female advisers engage in less misconduct than male advisers. We now document that, conditional on misconduct, female advisers also engage in less costly misconduct. If firms pay investors for damages resulting from adviser misconduct, all such settlements and awards are recorded with FINRA. The settlements are either negotiated between the firm and customer or awarded through arbitration. Table 1e reports the summary statistics corresponding to the settlements paid out as a result of misconduct among male and female advisers. The median settlement is $\$ 40 \mathrm{k}$ for male advisers and $\$ 32.5 \mathrm{k}$ for female advisers. Furthermore, the average settlement for male advisers is more than double that of female advisers ( $\$ 549 \mathrm{k}$ versus $\$ 263 \mathrm{k}$; See Figure A2 for the distribution of settlements).

We examine the differences in the settlements paid out on behalf of male and female advisers using the following regression specification:

$$
\ln \left(\text { Settlement }_{i j l t}=\alpha \text { Female }_{i}+\beta X_{i t}+\mu_{j}+\mu_{l}+\mu_{t}+\varepsilon_{i j l t} .\right.
$$

The sample is restricted to instances of misconduct in which settlements were paid to the customer. The dependent variable is $\ln \left(\right.$ Settlement $_{i j l t}$, which measures the settlements paid out on behalf of advisers following an incident of misconduct. The key independent variable of interest is the dummy variable Female . $_{\text {. }}$ We control for adviser characteristics in $X_{i t}$ and firm, county, and year fixed effects $\mu_{j}, \mu_{l}, \mu_{t}$. The results in Table $2 \mathrm{~b}$ confirm that misconduct committed by male advisers is more costly than misconduct committed by female advisers. On average, settlements associated with female adviser misconduct are $11-20 \%$ lower than settlements associated with male adviser misconduct. ${ }^{11}$ Thus, male advisers engage in more misconduct, and, conditional on engaging in misconduct, misconduct by male advisers is costlier for the firm.

\section{Labor Market Consequences of Misconduct: “The Gender Punish- ment Gap"}

Egan, Matvos, and Seru (2019a) show that the financial industry punishes misconduct, both through employment separations at the firm level and through worse employment opportunities at the industry

\footnotetext{
${ }^{11}$ One potential concern is that settlements could be endogenous and/or biased across gender. Given that women are less likely to engage in misconduct, arbitrators and firms may underestimate how costly misconduct is by women. In Appendix A1 we examine potential gender biases in the settlement process by examining the settlement/award granted relative to the amount requested by the customer. We do not find any evidence of a gender bias in the settlement process.
} 
level. Here, we document gender differences in the labor market consequences of misconduct - the gender punishment gap - at the firm and industry level. We also establish that this gender punishment gap is not driven by gender differences in job role or in types of firms, markets, or financial products handled by the adviser.

\section{III.A Gender Differences in Job Separation Following Misconduct}

We first document that, relative to male advisers, female advisers face worse job separation prospects following misconduct. We start with a simple cut of the data in Table 3. Both male and female advisers are likely to experience job separations following misconduct, but female advisers face harsher consequences. While $46 \%$ of male advisers experience job separations following misconduct, $55 \%$ of female advisers do so. In other words, female advisers are $20 \%$ more likely to lose their jobs following misconduct than male advisers. For ease of terminology, we call gender differences in job separation rates following misconduct the "gender punishment gap." The gap does not arise because female advisers, on average, face larger job turnover. Turnover rates among male and female advisers (excluding those with recent misconduct) are remarkably similar. On average, $19 \%$ of male and 19\% of female advisers leave their firm in a given year. Annual turnover rates among male and female advisers are nearly identical over the period 2005-2015, with a correlation of 0.98 . However, following misconduct, female advisers are substantially more likely to lose their jobs.

The nearly identical turnover rates among male and female advisers without misconduct suggests that the gender punishment gap is not driven by the sorting of male and female advisers across different firms or locations. Nevertheless, it may be possible that female advisers are matched with firms that punish misconduct more severely or provide services in markets where consumers or regulators are particularly sensitive to misconduct. To evaluate this alternative, we compare female and male advisers working at the same firm, at the same location, and at the same point in time, with the same qualifications, experience, and other observable characteristics, by estimating the following linear probability model:

$$
\text { Separation }_{i q j l t+1}=\beta_{1} \text { Female }_{i}+\beta_{2} \text { Misc.iqjlt }+\beta_{3} \text { Misc }_{\text {iqjlt }} \times \text { Female }_{i}+\beta_{4} X_{i t}+\mu_{q j l t}+\varepsilon_{i q j l t} .
$$

Observations are at the adviser-by-year level; $i$ indexes an adviser with qualifications/occupational licenses $q$ who worked for firm $j$ at time $t$ in county $l$. The dependent variable Separation $_{\text {iqj } j t+1}$ is a dummy variable indicating that the adviser is not employed at firm $j$ in year $t+1 .^{12}$ The independent variable Misconduct iqjlt $_{\text {i }}$ (abbreviated as $M i s c_{\text {.iqjlt }}$ ) is a dummy variable indicating that the adviser received a misconduct disclosure in year $t$. The independent variable of interest is Misconduct $_{i q j l t} \times$ Female $_{i}$, which measures the gender punishment gap. We control for other advisers' characteristics such as experience in $X_{i t}$. These capture the type of advising the adviser engages in. Like before, our full specification includes firm $\times$ year $\times$ county $\times$ license fixed effects $\mu_{q j l t}$, i.e. a fixed effect for each set of possible qualifications an adviser potentially holds within a firm, location, and time. As mentioned earlier, these sets of controls allow us to compare male and female advisers who work for the same firm, in the same branch, at the same time, and in the same job role. Thus the effects we identify are driven neither by firms' product characteristics, attitudes towards misconduct, or different turnover rates, nor by demographics differences, local labor market conditions,

\footnotetext{
${ }^{12}$ In our baseline analysis, we examine whether an adviser experiences an employment separation within one year $\left(\right.$ Separation $\left._{i q j l t+1}\right)$. As a robustness check, we also examine whether an adviser experiences an employment separation within two years Separation iqjlt+2 $_{\text {and }}$ aport the corresponding results in Appendix A1. We find quantitatively similar estimates of the gender punishment gap when we examine whether an adviser experiences an employment separation within one or two years.
} 
types of clients serviced across locations, or differences in job roles.

We present the estimates in columns (1)-(5) of Table 4. In each specification, we estimate a positive and statistically significant relationship between misconduct in year $t$ and job separation in year $t+1$. The coefficient on misconduct measures the probability that a male adviser experiences a job separation following misconduct. The results in column (4) indicate that male advisers are 26pp more likely to experience an employment separation following misconduct relative to male advisers without recent misconduct. More importantly, we find evidence of a gender punishment gap. In each specification, we estimate a positive and statistically significant coefficient on Misconduct $_{i q j l t} \times$ Female $_{i}$ between 8pp and 10pp. The estimated gender punishment gap changes little as we include the firm $\times$ year $\times$ county fixed effects $\mu_{j l t}$ or firm $\times$ year $\times$ county $\times$ license fixed effects $\mu_{q j l t}$. The estimates in column (1) indicate that, following misconduct, male advisers have a 28pp higher chance of a job separation, while female advisers have a 28pp $+8 \mathrm{pp}=36 \mathrm{pp}$ higher chance of a job separation. Relative to male advisers, female advisers are $20 \%$ more likely to lose their jobs following a misconduct.

In column (5) we control for the specific misconduct allegations. While the summary statistics displayed in Table 1c suggest that the types of misconduct that men and women engage in are similar in terms of the associated allegations, one might still be concerned that the gender punishment gap is driven by genderspecific differences in misconduct. We find evidence of a gender punishment gap after controlling for the specific type of misconduct. The results in column (5) indicate that, following misconduct, female advisers are $7.5 \mathrm{pp}$ more likely to experience a job separation relative to their male colleagues. The results also indicate that the type of misconduct impacts the probability of an employment separation, but does not drive the gender punishment gap. ${ }^{1314}$

While we control for each adviser's adviser's qualifications, experience, firm, location, and other characteristics, one might still be concerned that the gender punishment gap is driven by some unobservable adviser characteristic. As an additional robustness check, we bound our estimate of the gender punishment gap where we account for the potential impact of unobservables (such as unobserved productivity) following Oster (2019) and Altonji, Elder, and Taber (2005a, 2005b, 2008). The Oster framework allows the researcher to bound a coefficient estimate by examining how the coefficient and $R^{2}$ change as controls are added to the regression model. Following Oster (2019) we bound the gender punishment gap between 8.66pp and 7.08pp by comparing the estimated gap in our specification without any additional controls (Table 4, column 1) to our specification with the full set of controls (Table 4, column 5), where we keep the sample the same. ${ }^{15}$ Intuitively, as we increase the number of additional controls, the amount of explained

\footnotetext{
${ }^{13}$ For each misconduct disclosure we observe a short description of the misconduct offense in the BrokerCheck data. To further control the specific nature of each misconduct effect, we use standard textual analysis tools, Bag of Words (Gentzkow, Kelly, and Taddy, 2019; Bodoh-Creed, Boehnke, and Hickman 2018) and Latent Dirichlet Allocation (Blei et al. 2003) to classify each misconduct disclosure. We find that the gender punishment gap is robust when we control for these different misconduct classifications. We discuss and present these results in Appendix A5.

${ }^{14}$ In our analysis we control for the type of misconduct in terms of the allegations rather than controlling for the specific disclosure category. Disclosure categories indicate not only misconduct but can also indicate how misconduct was punished. For example, the allegation "adviser fraud" could be reported as any of the six disclosure categories. If it is reported as an "Employment Separation After Allegations" that indicates not only did the adviser engage in fraud but he/she was forced to leave his/her firm. Because we are interested how misconduct is punished, controlling for disclosure category would already mechanically control for the outcome.

${ }^{15}$ Following Oster (2019), we calculate the lower bound using $R_{\max }^{2}=1.3 \times \tilde{R}^{2}$ and $\delta=1$, where $\tilde{R}^{2}=0.4$ (Table 4 column 5). We estimate that the gender punishment gap is 7.50 (4, column 5) in our controlled regression and estimate that the gender punishment gap is 8.66 in the uncontrolled regression where we keep the sample the exact same as in our controlled regression. Note that we follow the baseline approach in Oster (2019) by comparing the estimate corresponding to the specification with the fewest controls (column 1) to the estimate corresponding to the specification with the most controls (column 5). If one assumes that some set of the control variables do not share covariance properties with the unobservables but correlate with the punishment gap, one could bound the gender punishment gap by examining how the gap and $R^{2}$ change as control variables are sequentially added.
} 
variation in turnover $\left(R^{2}\right)$ increases substantially in Table 4, but the estimated gender punishment gap does not change much, decreasing slightly. While we cannot completely rule out selection on unobservables, the methodology from Oster (2019) helps provide some bounds on how unobservables could impact the gender punishment gap.

We also use our additional productivity data from Meridian IQ to help show that observable productivity differences across genders cannot explain the gender punishment gap. We re-estimate our employment separation specifications (eq. 3) using our Meridian IQ sample and report the corresponding results in columns (6)-(8) of Table 4. Controlling for productivity differences, the punishment gap remains statistically significant, and even slightly increases. This does not imply that productivity has no effect on job separation rates; advisers that are more productive, manage more assets, and have high quality ratings are less likely to experience employment separations. This validates the view that productivity offsets turnover. Similarly, the results in column (8) suggests that firms are more tolerant of misconduct among advisers that manage more assets and have high quality ratings. However, as is clear, the observed differences in productivity do not explain, and slightly increase the estimated gender punishment gap. ${ }^{16}$

An important caveat with the subsample with additional productivity data in columns (6)-(8) of Table 4 is that we only observe productivity for advisers who were active at the start of 2016 . To the extent that the gender punishment gap exists in the population, the women with records of misconduct in this sample are likely to have better unobservable characteristics, because they survived in the industry as of 2016. The potential selection therefore likely biases us against finding a gender punishment gap this sample. Nevertheless, we find strong evidence of a gender punishment gap after controlling for productivity in light of the potential sample selection issue. As an additional robustness check, we collect additional BrokerCheck adviser data covering the period 2016-2017. We re-estimate the baseline specification and study separations occurring in 2017 conditional on adviser's productivity and misconduct in 2016 and present the results in Table 5. This data does not suffer from the selection issue noted above. Despite a substantially smaller sample, we continue to find evidence of the gender punishment gap although we have less statistical power. ${ }^{17}$ Depending on the sample, the estimated gender punishment gap ranges from 4-9 percentage points after controlling for productivity and is similar to our main effects.

Overall, our results are consistent with the notion that firms are more tolerant of misconduct among male advisers. ${ }^{18}$ In addition to the alternatives ruled out in this section, we additionally show that this result is robust to different measures of misconduct in Section IV.A.

\section{III.B Gender Differences in Reemployment Following Misconduct}

In this section we document that the punishment gap extends to firms' hiring decisions. In addition to being more tolerant towards misconduct by their own male employees, firms are more tolerant of misconduct committed by males at other firms. This gender punishment gap in hiring provides additional insight into what might be driving the punishment gap more generally. One reason why the punishment gap may arise

\footnotetext{
${ }^{16}$ One might be concerned that adviser productivity is correlated with the severity of the misconduct and this may vary across genders. As an additional robustness check, we also simultaneously control for adviser productivity and the severity of the misconduct offense (as measured by the settlement amounts). We report the corresponding results in Appendix A1. We find that the gender punishment gap is robust when we simultaneously control for productivity and misconduct severity.

${ }^{17}$ Given that the industry is predominately male and that female advisers are less likely to engage in misconduct, the sample in column (8) contains just over 50 female advisers who engaged in misconduct in 2016.

${ }^{18}$ As an extension, in Table A23 in Appendix A1, we show that female advisers are also less likely to be promoted following misconduct. The economic magnitudes in the table suggest that a female adviser with a past record of misconduct is $25 \mathrm{bps}$ (40\%) less likely to be promoted in a given year relative to a male adviser with a past record of misconduct (column 1).
} 
is because of differences in favoritism towards current employees, because they know them from daily interactions. This is not the case with advisers from other firms. Therefore, the existence of the punishment gap at reemployment suggests that favoritism towards existing employees is unlikely the sole driver of the phenomenon.

Simple cuts of the data displayed in Table 3 indicate that women face worse reemployment prospects following misconduct. Almost one half (47\%) of male advisers who lose their jobs following misconduct find new jobs in the industry within a year. Conversely, only one third (33\%) of female advisers who lose their jobs following misconduct find reemployment within a year. This difference in reemployment partially arises because female advisers are less likely to be reemployed, even if job separations are not preceded by misconduct. To account for this difference, we compute the decrease in reemployment probabilities due to misconduct across genders. For female advisers, the reemployment rate declines from $48 \%$ to $33 \%$ following misconduct, or $15 p p$. For male advisers, the decline is substantially smaller, from $54 \%$ to $47 \%$, or $7 p p$. Taking a difference in differences approach, the turnover rates in Table 3 indicate female advisers are $8 p p$ less likely to find new employment following misconduct relative to male advisers $(-8 \%=(33 \%-48 \%)-(47 \%-54 \%))$.

To ensure that the gender differences in reemployment following misconduct are not confounded by differences in regulation and demographics across markets, in previous employment, or in activities that advisers engage in, we estimate the following linear probability model:

$$
\text { New_Empl.iqjlt+1 }=\beta_{1} \text { Female }_{i}+\beta_{2} \text { Misc. } i q j l t_{1}+\beta_{3} \text { Misc. }_{\text {iqjlt }} \times \text { Female }_{i}+\beta_{4} X_{i t}+\mu_{q j l t}+\varepsilon_{i q j l t} .
$$

We restrict the sample to advisers who were separated from their jobs in the previous year. New_Employment ${ }_{i q j l t+1}$ (abbreviated as $N e w_{-} E m p l_{\text {.iqjlt+1 }}$ ) is equal to one if the adviser $i$ with qualifications/occupational licenses $q$ who had been employed at firm $j$ in location $l$ has found new employment in the industry between time $t$ and $t+1$. The independent variable of interest is Misconduct $_{i q j l t} \times$ Female $_{i}$, which measures the differential reemployment prospects of male and female advisers following misconduct. As before, our full specification includes firm (original firm at time $t$ ) $\times$ year $\times$ county $\times$ license fixed effects $\mu_{q j l t}$, i.e. a fixed effect for each set of possible qualifications an adviser potentially holds within a firm (original firm at time $t$ ), location, and time. In effect, we compare the outcomes of male and female financial advisers who had been previously employed at the same firm, at the same time, in the same county, and who are licensed to engage in same activities, and examine how their reemployment depends on whether they engaged in misconduct.

The corresponding results are reported in Table 6 . We estimate a negative and significant relationship between misconduct and new employment. The negative coefficient on the interaction term Misconduct $_{i q j l t} \times$ Female $_{i}$ suggests that female advisers face more severe punishment at the industry level; they are $2.5-7 p p$ less likely to find a new job than a male financial adviser who engaged in misconduct. ${ }^{19}$ Given that male advisers who lose their jobs following misconduct are 7.5-12pp less likely to find a new job in the next year, this magnitude is substantial. Relative to male advisers', the decline in reemployment opportunities following misconduct is 30\% larger for female advisers. One important caveat is that an advisers' reemployment depends on both on the firm's desire to hire the adviser and the adviser's willingness to find a new job in the

\footnotetext{
${ }^{19}$ Note that the magnitude of the effect falls when we include previous employer effects. As discussed further in Section , we find that the gender punishment gap varies across firms. A larger gender punishment gap could imply a larger difference in the (unobservable) quality of female and male advisers who were terminated following misconduct. Specifically, women fired from firms with larger punishment gap may have better unobservable characteristics (and as a result better prospects) than women fired from firms with smaller punishment gap. When we measure the reemployment punishment gap, we are estimating based only on advisers who lost their job following misconduct. Therefore, controlling for firm differences at previous employment but conditional on separation may in fact partially control for gender differences in quality at reemployment.
} 
industry. Thus, one potential explanation for the reemployment gap is that after losing their job following misconduct, female advisers are less likely than male advisers to look for new employment in the advisory industry. While this behavior could contribute to or magnify the reemployment gap, we do not believe this behavior is likely at the core of the reemployment gap. In Appendix A1, we show that firms with a greater share of female executives are more likely to employ female advisers with past records of misconduct, which suggests that employer demand may play an important role in the reemployment gap. Furthermore, we find a similar reemployment gap for male ethnic minority advisers (Section III.D).

As before, we use Oster (2019) to bound our estimates of the gender differences in reemployment prospects following misconduct. The results in Table 6 indicate that conditional on experiencing an employment separation following misconduct, female advisers are $3.54 \mathrm{pp}$ less likely to find reemployment in the industry relative to their male colleagues. Following Oster (2019) we bound the effect to be between 11.14pp and -1.03pp by comparing the estimates corresponding to those reported in column (1) to column (5) in Table 6, where we keep the sample size the same. ${ }^{20}$ Intuitively, the estimates provided by the bound are relatively large because we find that including our control variables has a large impact on the gender punishment gap relative to the increase in $R^{2}$. While these additional tests do not provide a tight bound on the punishment gap, they still help provide insight into how unobservables could impact the gender punishment gap.

Another way to measure differences in reemployment prospects across genders is to examine the time an adviser spends out of the industry. In Appendix A4, we estimate a Cox proportional hazards model and find that among advisers with recent misconduct, female advisers are $25 \%$ less likely to find reemployment relative to male advisers. Our hazard model estimates indicate that a female adviser's chances of finding reemployment are 8pp smaller than that of comparable male advisers following misconduct (26pp-16pp). The results from this section suggest that firms are more tolerant of misconduct by male financial advisers in other firms in their hiring decisions.

\section{III.C Gender Punishment Gap Across and Within Firms}

We now delve deeper into the source of the gender punishment gap by examining its relationship with the gender composition of decision makers in firms. Recent survey evidence suggests that $88 \%$ of female financial service professionals believe that gender discrimination persists within their industry (Tuttle, 2013). If the source of the gender punishment gap is indeed the firm, then it is plausible that there is heterogeneity in how firms treat male and female advisers following misconduct. We first document that such firm differences exist. Then, we illustrate that the differences between firms, such as the gender composition of management, can explain differences in the gender punishment gap across firms and across branches within firms.

We first compute differences in the gender punishment gap across firms using the following specification:

$$
\text { Separation }_{i t+1}=\beta_{j 0}+\beta_{j 1} \text { Female }_{i}+\beta_{j 2} \text { Misc } i t_{\cdot}+\beta_{j 3} \text { Misc }_{\cdot i t} \times \text { Female }_{i}+\beta_{4} X_{i t}+\varepsilon_{i t} .
$$

The firm-specific coefficients of interest $\beta_{j 3}$ measure the difference between the probability a female adviser experiences an employment separation following misconduct relative to male advisers in a given firm $j$. Note that we also allow the turnover rates for male advisers, female advisers, and advisers with misconduct to vary across firms by including firm specific coefficients $\beta_{j 1}, \beta_{j 2}$, and $\beta_{j 3}$. Figure 2 a displays the dispersion in

\footnotetext{
${ }^{20}$ Again, following Oster (2019), we calculate the lower bound using $R_{\max }^{2}=1.3 \times \tilde{R}^{2}$ and $\delta=1$, where $\tilde{R}^{2}=0.46$ (Table 6 column 4). We estimate that the gender punishment gap is 2.47 (4, column 5) in our controlled regression and estimate that the gender punishment gap is 11.14 in the uncontrolled regression where we keep the sample the exact same as in our controlled regression.
} 
the gender punishment gap $\left(\beta_{j 3}\right)$ across firms, and Figure $2 \mathrm{~b}$ displays the firms with the highest gap. ${ }^{21}$ We restrict our analysis to firms in which at least twenty female advisers receive misconduct disclosures such that we have enough observations for each firm to precisely measure the gender punishment gap within the firm. The estimated distribution of firm coefficients $\left(\beta_{3}\right)$ are jointly significantly different from each other, confirming differences in the gender punishment gap across firms. In terms of magnitudes, for example, the gender gap at Wells Fargo Advisers ${ }^{22}$ is $18 p p$ higher than the average gap. ${ }^{23}$ Overall, the results suggest that the gender punishment gap varies substantially across firms. ${ }^{24}$

\section{III.C.1 Female Managers Mitigate the Gender Punishment Gap at Job Separation}

If the gender punishment gap arises because of employer bias, it is probably driven by the bias of the decision makers in the firm. One proposal to limit discrimination in firms is to increase the share of women in positions of power. The idea is that decision makers in organizations can directly affect policies leading to discrimination. The members from the discriminated group (women) are more likely to recognize discrimination and less likely to support discriminatory practices. Figures $1 \mathrm{a}$ and $1 \mathrm{~b}$ illustrate the substantial differences in gender composition of branch management and firm executives in our sample. We first show that differences in the gender composition of branch management can explain differences in the punishment gap across different branches within the same firm. We then show that differences in the gender composition of the executive teams across firms can also explain across-firm differences in the gender punishment gap. We start by examining whether the gender punishment gap is smaller in branches with more female branch mangers using the following linear probability model:

$$
\begin{aligned}
& \text { Separation }_{\text {iqjlt }+1}=\beta_{1} \text { Misc. }_{\text {iqjlt }}+\beta_{2} \text { Female }_{i}+\beta_{3} \text { Pct Female Mgmt } \text { Flt }+\beta_{4} \text { Misc }_{\text {iqjlt }} \times \text { Female }_{i} \\
& +\beta_{5} \text { Misc.iqjlt } \times \text { Pct Female Mgmt } \text { Flt }+\beta_{6} \text { Female }_{i} \times \text { Pct Female } \text { Mgmt }_{j l t} \\
& +\beta_{7} \text { Misc.iqjlt }_{\text {. }} \times \text { Female }_{i} \times \text { Pct Female } \text { Mgmt }_{j l t} \\
& +\beta_{8} X_{i t}+\mu_{q j l t}+\varepsilon_{i q j l t} .
\end{aligned}
$$

Observations are at the adviser-by-year level; $i$ indexes an adviser with qualifications/occupational licenses $q$ who worked for firm $j$ at time $t$ in county $l$. The dependent variable Separation $_{i q j l t+1}$ is a dummy variable indicating that the adviser is not employed at firm $j$ in year $t+1$. The variable Pct Female Mgmt $t_{j l t}$, measures the percentage of managers that are female at the firm $\times$ county $\times$ year level; the level effect $\left(\beta_{3}\right)$ is absorbed by the fixed effect $\mu_{q j l t} .{ }^{2526}$ The independent variable of interest is Misconduct $_{\text {qqjlt }} \times$ Female $_{i} \times$ Pct Female Mgmt $_{j l}$, which measures how the differences in punishment across genders depends on the

\footnotetext{
${ }^{21}$ The distribution of gender differences $\left(\beta_{j 3}\right)$ reported in Figure 2a includes measurement error. To account for measurement error, we construct an empirical Bayes estimate of firm gender differences by shrinking $\widehat{\beta_{j 3}}$. Under the assumption that the variance of the estimation error is homoskedastic (Cassella, 1992) the estimated scaling factor suggests that underlying differences across firms accounts for $78 \%$ of the variation in the distribution of the OLS estimated coefficients $\widehat{\beta_{j 3}}$.

${ }^{22}$ Firms are defined by the corresponding CRD identification number. Firms with distinct CRD numbers can share the same parent company. For instance, Wells Fargo, operates several financial services businesses under separate numbers. In particular, Wells Fargo has several operations such as Wells Fargo Advisors Financial Network (CRD\# 11025), Wells Fargo Advisors (CRD\# 19616), and Wells Fargo Securities (CRD\# 126292).

${ }^{23}$ The results Table 3 find a gender gap of $9 p p$, which is $27 p p$ at Wells Fargo Advisers.

${ }^{24}$ In Appendix A1 we find that gender differences in the rate of misconduct also vary across firms. For example, we find that the difference in misconduct between male and female advisers is larger at firms with a past record of sexual harassment.

${ }^{25}$ We classify those advisers holding a Series 24 License as managers. A Series 24 License is required to act in a supervisory role in financial advisory firm.

${ }^{26}$ We define the gender composition of branch management (Pct Female $M g m t_{j l t}$ ) at the firm-by-county-by-year level and thus the variable varies over time. As a robustness check, in Appendix A1 we replicate our analysis where we define $\left(\right.$ Pct Female Mgmt $\left._{j l t}\right)$ in the pre-period 2005 and examine how it impacts future separations.
} 
share of female branch managers. As before, our most stringent specification accounts for differences in firms' attitudes towards misconduct or turnover rates, demographics differences, local labor market conditions, and activities that advisers engage in by including firm $\times$ year $\times$ county $\times$ license fixed effects $\mu_{q j l t}$. We also control for advisers' characteristics, such as experience, in $X_{i t}$.

Columns (1)-(4) of Table 7a display the corresponding estimates. The results indicate that female advisers are more likely to experience employment separations after receiving misconduct disclosures relative to male advisers at branches with more male management. At branches with no female representation at the management level, female advisers are 10-14pp more likely to experience an employment separation following misconduct relative to their male counterparts.

We next examine how the gender punishment gap varies with the gender composition of the executive teams at the firm level. We measure the gender composition of executives in the variable Pct Female Exec , $_{j}$ which measures the share of executives that are female as of 2015 . We re-estimate eq. (6) where we allow the gender punishment gap to vary with the gender composition of a firm's executives and report the corresponding results in columns (5)-(8). Here, we restrict our sample to the period 2014-2015 because we only observe executive composition as of 2015. ${ }^{27}$ The results indicate that firms with a greater share of female executives exhibit a smaller gender punishment gap. In firms in which females comprise one-third of the executive team, there is almost no differential punishment for misconduct between genders. ${ }^{28}$ In firms without any female executives, on the other hand, female advisers are 14pp more likely to experience employment separations relative to their male counterparts following misconduct (Table 7a, column 5).

\section{III.C.2 Junior Female Advisers do not Mitigate the Punishment Gap}

We find that the presence of female advisers in senior management and executive positions helps mitigate the gender punishment gap. One potential explanation for these findings is that female advisers are more productive at these firms, which is why they are less likely to experience an employment separation following misconduct. Here, we attempt to distinguish between firms with more female executives and managers, i.e. decision makers, and firms that hire more female advisers in general. To ensure that the latter female advisers do not have decision making power, we focus on the junior female employees of the firm. For each firm, we calculate the share of its junior employees defined as those with less than 3 years industry experience, that are female at the county-by-year level (Pct Jr Female $j l t)$. We examine how the gender punishment gap varies with the gender composition of a firm branch using the following linear probability model:

$$
\begin{aligned}
& \text { Separation }_{\text {iqjlt+1 }}=\beta_{1} \text { Misc. }_{\text {iqjlt }}+\beta_{2} \text { Female }_{i}+\beta_{3} \text { Pct JrFemale } \text { Flt }_{1}+\beta_{4} \text { Misc }_{\text {iqjlt }} \times \text { Female }_{i} \\
& +\beta_{5} \text { Misc.iqjlt } \times \text { Pct Jr Female } \text { Flt }_{1}+\beta_{6} \text { Female }_{i} \times \text { Pct Jr Female } \text { Flt } \\
& +\beta_{7} \text { Misc.iqjlt } \times \text { Female }_{i} \times \text { Pct Jr Female } j \text { jlt } \\
& +\beta_{8} X_{i t}+\mu_{q j l t}+\varepsilon_{i q j l t} .
\end{aligned}
$$

Observations are at the adviser-by-year level. The dependent variable Separation $_{\text {iqj } j t+1}$ is a dummy variable indicating that adviser $i$ is not employed at firm $j$ in year $t+1$, where $q$ indexes the adviser's qualifications and $l$ indexes the adviser's location/county. The coefficient of interest is the triple interaction term

\footnotetext{
${ }^{27}$ In untabulated results we find similar estimates if we estimate the model over the full sample period. Also as an additional robustness check, in Appendix A1 we replicate our analysis using additional BrokerCheck data covering the period 2016-2018. We examine how the composition of executives in 2015 impact the gender punishment gap in 2016-2018 and find similar effects.

${ }^{28}$ The results in column (5) of Table $7 \mathrm{a}$ indicate that estimated coefficient on the interaction term Misconduct $\times$ Female $\times$ Pct_Female_Exec is -41.4 and estimated coefficient on the term Misconduct $\times$ Female is 14.0. There is no differential in job separation probabilities for male and female advisers following misconduct if Pct_Female_Exec $=\frac{14.0}{41.4}=0.34$.
} 
${\text { Misc. } \text {.qjit } \times \text { Female }_{i} \times \text { Pct Jr Female }}_{\text {jlt }}$ which measures how the gender punishment gap varies with the gender composition of the junior employees at a firm.

We present the corresponding results in Table 7b. We find little relationship between the gender composition of a firm's junior employees and the gender punishment gap. In each specification, the coefficient on the triple interaction term is statistically insignificant and very close to zero, even when one accounts for the standard errors. These test results suggest that the gender punishment gap does not decline in firms that see junior female advisers as more valuable. What matters for the gender punishment gap is the gender composition of executives and managers, the decision makers in the firm, rather than the gender composition of the firm as a whole.

\section{III.C.3 Gender Punishment Gap and Sexual Harassment Claims}

We now document a link between two related but potentially distinct phenomena: the gender punishment gap, and sexual harassment. Studying this link is useful for thinking about the causes of gender punishment gap. For instance, as we discuss in Section IV, if the gender punishment gap arises as a result of Bayesian updating on productivity across genders by profit maximizing firms, then it is unlikely to be related to sexual harassment incidents. To explore this link, we collect novel data on the sexual harassment claims filed against the financial advisory firms in our data. We examine how the gender punishment gap varies with the incidence of sexual harassment claims at a firm. Specifically, we assess how the gender punishment gap varies across firms in the following triple difference-and-differences specification:

$$
\begin{aligned}
& \text { Separation }_{i q j l t+1}=\beta_{1} \text { Misc }_{\text {iqjlt }}+\beta_{2} \text { Female }_{i}+\beta_{3} \text { Harassment }_{j}+\beta_{4} \text { Misc }_{\text {iqjlt }} \times \text { Female }_{i}
\end{aligned}
$$

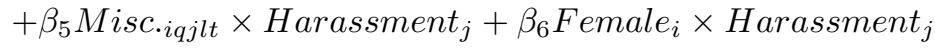

$$
\begin{aligned}
& +\beta_{7} \text { Misc }_{\text {iqjlt }} \times \text { Female }_{i} \times \text { Harassment }_{j} \\
& +\beta_{8} X_{i t}+\mu_{q j l t}+\varepsilon_{i q j l t} .
\end{aligned}
$$

Observations are at the adviser-by-year level. The dependent variable Separation $_{i q j l t+1}$ is a dummy variable indicating whether adviser $i$ with qualifications $q$ working for firm $j$ in county $l$ in year $t$ experienced an employment separation between year $t$ and $t+1$. The variable Harassment $_{j}$ is a dummy variable indicating whether or not the firm has ever had a sexual harassment claim resolved through arbitration. Roughly $25 \%$ of our adviser-year level observations involve an adviser working for a firm with a record of harassment (i.e. Harassment $_{j}=1$ ). The control variable Harassment $_{j}$ is absorbed by the qualifications-by-firm-by-countyby-year fixed effect $\mu_{q j l t}$. The coefficient of interest is the triple interaction term Female $_{i} \times$ Misc $_{i q j l t} \times$ Harassment $_{j}$ which measures how the gender punishment gap varies with the firm's sexual harassment claims.

Columns (1)-(4) of Table 8 presents the corresponding estimates. In each specification, we estimate a positive and significant relationship between employment separation and the triple interaction term Female $_{i} \times$ Misc $_{i q j l t} \times$ Harassment $_{j}$. A positive coefficient on the triple interaction term indicates that the gender punishment gap is larger at firms with a record of sexual harassment. The estimated coefficient on the triple interaction term Female $_{i} \times$ Misc $_{i q j l t} \times$ Harassment $_{j}$ is more than twice as large as the estimated coefficient on the term Misc $_{i q j l t} \times$ Female $_{i}$, which suggests that the gender punishment gap is more than twice as large at firms with a record of sexual harassment. The results in column (2) indicate that at firms with a record of sexual harassment, female advisers following misconduct are $13.82 \mathrm{pp}(=4.10 \mathrm{pp}+9.72 \mathrm{pp})$ more likely to 
experience an employment separation relative to their male colleagues. As we will discuss in Section IV, this evidence is consistent with the gender punishment gap being at least partially related to preferences and tastes of the firm and its managers.

In the arbitration awards database, we also observe non-sexual harassment discrimination claims. The discrimination claims often refer to age discrimination but can also refer to other forms of discrimination. As an additional robustness check, we examine how the gender punishment gap varies with whether the firm has a history of discrimination. Specifically, we augment our specification (eq. 8) where we interact the gender punishment gap with the Discrimination $_{j}$, which is a dummy variable indicating whether a firm has ever had a discrimination claim resolved though arbitration. This additional test tells us whether the gender punishment gap is correlated specifically with harassment or more generally with firm discrimination.

We report the corresponding estimates in columns (5)-(8) of Table 8. We find that the gender punishment gap is $7.1 \mathrm{pp}$ larger at firms with a record of sexual harassment after controlling for whether the firm has a record of discriminating against employees (Table 8, column 8). Conversely, we do not find evidence that, after conditioning on whether the firm has a history of sexual harassment, the gender punishment gap is larger at firms with a record of discrimination. The results suggest that the gender punishment gap is specifically related to sexual harassment rather than firm discrimination or firm dysfunction more generally.

As an additional robustness check, in Appendix A1 we also explore how the gender punishment gap varies with other non-gender related firm/branch characteristics such as branch size or share of advisers with past misconduct. We find little relationship between these other non-gender related firm characteristics and the gender punishment gap, while the female composition of management mitigates the gender punishment gap. $^{29}$

\section{III.D Is Punishment Gap Gender Specific? Punishment Gap for Minority Men}

Several theories explaining gender differences in labor outcomes are gender specific. For example, genders exhibit differences in the value of home production and risk aversion, which can explain several important phenomena that might look like discrimination across gender (Bertrand et al. 2010). ${ }^{30}$ Gender identity norms (Bertrand, Kamenica, and Pan, 2015) could also drive this behavior. In this section, we show that the punishment gap extends to minority men, who have also traditionally faced discrimination in the labor market. Consequently, it is unlikely that the mechanism behind it is gender specific. Instead, the results here are more consistent with a pattern of "in-group" tolerance or favoritism towards the members of one's own group.

We examine the labor market consequences following misconduct for male advisers of African or Hispanic ethic origin. To ensure that our results are not driven by gender differences, we limit our sample to men. We determine the ethnicity of each adviser using the name-ethnicity classifier developed in Ambekar et al. (2009) and used in the literature (Dimmock et al. 2018; Pool et al 2014). ${ }^{31}$ We are able to classify the

\footnotetext{
${ }^{29}$ We find some evidence that the gender punishment gap is relatively smaller at financial advisory firms set up as corporations and relatively larger at financial advisory firms set up as limited liability companies and partnerships. Our results (reported in Appendix A1) suggest that the gender punishment gap is about $40 \%$ smaller at corporations relative to non-corporations. One potential explanation for this result is that scrutiny could be higher at corporations because they are often publicly traded firms whereas LLCs and partnerships are privately held.

${ }^{30}$ See Croson and Gneezy (2009) for a review on the literature documenting differences in risk tolerance among males and females. Croson and Gneezy find robust differences in risk preference among men and women, with women being more risk averse than men. Sapienza, Zingales and Maestripieri (2009) find that even among MBA students at the University of Chicago, women have higher risk aversion than men.

${ }^{31}$ The name-ethnicity classifier developed by Ambekar et al. (2009) is available online at http://www.textmap.org/ethnicity.
} 
ethnicity of $99 \%$ of the male advisers in our sample. Roughly $4 \%$ of male advisers are classified as having Hispanic ethnic origins and $2 \%$ are classified as having African ethnic origins.

We measure the punishment gap of minority men by re-estimating eq. (3) but replacing female advisers with minority men. We include additional controls for the adviser's ethnicity (African or Hispanic) and the interaction of misconduct and the adviser's ethnicity. We report the corresponding estimates in the columns (1)-(4) of Table 9b. In each specification, the estimated coefficients on the interaction terms Misconduct $\times$ African Origins and Misconduct $\times$ Hispanic Origins are positive and significant, suggesting African origin and Hispanic advisers are more likely to experience job separations following misconduct. In other words, minority men experience a punishment gap similar to female advisers. We find similar results for reemployment following misconduct (Table 9b, columns 5-8). These results suggest that Hispanic advisers face relatively worse employment prospects following misconduct than non-African and non-Hispanic advisers. We do not find much evidence suggesting that African advisers face worse reemployment prospects following misconduct relative to non-African origin and Hispanic advisers. Overall, the results suggest that following misconduct, African advisers face more severe punishment at the firm level but not at the industry level while Hispanic advisers face more severe punishment at both the firm and industry level.

The existence of a punishment gap for minority men suggests that a similar mechanism generates the gender and the minority (male) punishment gap. There is one difference between the groups, which speaks to the potential mechanism: female and minority male advisers differ in the average rate of misconduct. Female advisers engage in substantially less misconduct than their male counterparts. African and Hispanic advisers, on the other hand, are 9bp more likely to receive misconduct disclosures in a given year relative to other male advisers (Table 9a). One potential reason why female advisers could be treated more harshly following misconduct is precisely because of their low average rates of misconduct: firms might tradeoff lower average misconduct for lower productivity and update more severely about female misconduct propensity after observing misconduct, given their low average misconduct rates. If such a mechanism were at play for minority men, it would suggest milder punishment, because, given their higher rates of misconduct, these advisers would be expected to be more productive and firms would update less harshly after observing misconduct by such advisers. However, the existence of male minority punishment gap suggests that updating from low average misconduct rates is not driving the gender punishment gap. We discuss this mechanism in more detail in Section IV.

\section{III.D.1 Minority Male Managers Mitigate the Minority (Male) Punishment Gap}

We find that firms with a larger share of female managers have a smaller gender punishment gap. Here, we document that minority male managers mitigate the minority punishment gap among male advisers.

Specifically, we re-estimate the analog of eq. (6) where we separately control for the branch level composition of manager ethnicity (Pct African Mgmt and Pct Hispanic Mgmt). The variable Pct African Mgmt (Pct Hispanic Mgmt) measures the percentage of managers that are of African (Hispanic) origin at the firm in a county in a given year. We report the corresponding estimates in Tables 10a and 10b. In each specification, we estimate a negative coefficient on the minority triple interaction terms. Given that there are relatively few African and Hispanic origin advisers and managers in our data set, we start to lose statistical power in columns (4) and (5) when we include firm $\times$ year $\times$ county $\times$ license fixed effects. The results in column (1) of Table 10a suggest that African origin advisers working at a branch with no African origin branch managers are 10pp more likely to experience employment separations following misconduct. However, the 
estimates also imply that there would be no punishment gap in branches where $50 \%(=10.2 / 20.3)$ of the branch managers are of the same minority as the adviser (Table 10a, column 1). We find similar patterns for Hispanic advisers and managers as displayed in Table 10b. Overall, our results are most consistent with in-group tolerance of executives of financial advisory firms. Male executives seem to be more forgiving of misconduct by men rather than by women, and non-minority managers are more forgiving of misconduct from members within their own group.

\section{III.D.2 Minority Male Managers do not Mitigate the Gender Punishment Gap}

Given that female managers mitigate the gender punishment gap and ethnic minority male managers mitigate the minority punishment gap, we now ask whether managers from disadvantaged groups lower the punishment gap in general. This test allows us to distinguish between two alternative reasons for why minority managers - gender or ethnic - matter. One alternative is that minority managers better understand that there is a punishment gap and seek to avoid it. If so, we would expect minority male managers to reduce the gender punishment gap. Alternatively, the mechanism may be related to specific group membership. For example, managers of a group only understand that the stereotypes about their own group are incorrect but share stereotypes about other groups, or because of simple in-group favoritism. Under this alternative, we would find that minority male managers do not mitigate gender gap.

As reported in Appendix A1, we find that the gender punishment gap does not vary systematically with the ethnic composition of the firm's branch management. We find no evidence that managers of African descent mitigate the gender punishment gap and only very modest and noisy evidence suggesting that managers of Hispanic descent mitigate the gender punishment gap. ${ }^{32}$ Thus, minority male managers do not appear to systematically mitigate the gender punishment gap. These results suggest that while managers in power can potentially mitigate punishment gap among any group, they typically only do so only within their gender or ethnic group. Group membership seems to play an important role in understanding the punishment gap of advisers across different genders and ethnicities.

\section{What explains the Punishment Gap?}

We find a punishment gap for female and minority-male advisers. This gap is smaller in firms with a larger share of managers (not junior employees) from the specific minority group. In this section, we first provide additional evidence, which suggests that the gender punishment gap does not proxy for female advisers' lower productivity or more severe misconduct. We then discuss which types of models can explain the evidence in the paper. Consider a benchmark model in which the joint distribution of misconduct and productivity is the only difference across genders. Furthermore, firms update their beliefs about adviser misconduct and productivity using Bayes rule with correct beliefs and hire/fire advisers to maximize profits. We argue that such a model would have a difficult time explaining the totality of evidence we have gathered up to this point; doing so would require additional complexity with more degrees of freedom. We also

\footnotetext{
${ }^{32}$ Specifically we examine regressions of the form:

Separation $_{i j l t+1}=\beta_{1}$ Misc $_{i j l t}+\beta_{2}$ Female $_{i}+\beta_{3}$ Pct African Mgmt $_{j l t}+\beta_{4}$ Misc $. i t \times$ Female $_{i}$ $+\beta_{5}$ Misc. $_{i j l t} \times$ Pct African Mgmt Plt $_{j}+\beta_{6}$ Female $_{i} \times$ Pct African Mgmt f $_{j l t}$$$
+\beta_{7} \text { Misc }_{i j l t} \times \text { Female }_{i} \times \text { Pct African Mgmt } \text { Ilt }_{j}
$$$$
+\beta_{8} X_{i t}+\mu_{j l t}+\varepsilon_{i j l t} \text {. }
$$ 
consider a model in which the punishment gap is generated by biases of market participants. We then discuss the types of biases that may more adequately generate the patterns we observe.

\section{IV.A Gender does not Proxy for Misconduct or Productivity}

The gender punishment gap is smaller in firms with more female managers, but not in firms with more female junior advisers; the punishment gap also exists for ethnic minority men. Therefore it is unlikely that the punishment gap arises solely because group membership proxies for productivity or misconduct severity. Nevertheless, we provide additional evidence against this possibility.

\section{IV.A.1 Gender Does Not Proxy for Misconduct}

Recidivism: We find that men unconditionally have higher rates of misconduct. However, it is possible that female advisers with misconduct records are more likely to re-engage in misconduct than their male counterparts. If so, it would be optimal for firms to fire female advisers with a higher probability. In this section, we show that instead, male advisers are more likely to re-offend.

We find that $41 \%$ of men with misconduct records are repeat offenders, while only $22 \%$ of female advisers are repeat offenders. ${ }^{33}$ Male advisers are therefore roughly twice as likely to be repeat offenders than female advisers. To ensure that these gender differences in recidivism are not driven by differences in other adviser characteristics, we more formally examine recidivism using a linear probability model:

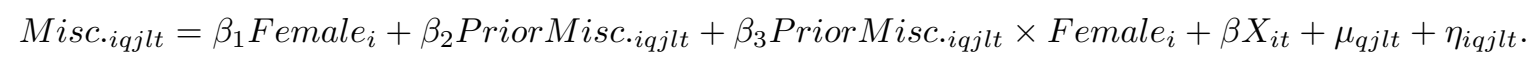

The dependent variable Misconduct $_{i q j l t}$ is a dummy variable indicating that the adviser was disciplined for misconduct at time $t$. The variable Prior Misconduct ${ }_{i q j l t}$ (abbreviated as PriorMisc.) is a dummy variable indicating whether the adviser was ever reprimanded for misconduct prior to time $t$. The main independent variable of interest is PriorMisconduct ${ }_{\text {iqjlt }} \times$ Female $_{i}$. The interaction measures the difference in propensity between male and female advisers to engage in repeat offenses. We also control for the adviser's gender to account for any differences in the baseline misconduct rate across the two genders. Our most stringent specification controls for firm $\times$ year $\times$ county $\times$ license fixed effects $\mu_{q j l t}$. We also control for the adviser's characteristics, such as experience in the industry in $X_{i t}$.

We report the corresponding estimates in columns (1)-(4) of Table 11. Similar to Egan et al. (2019a), the

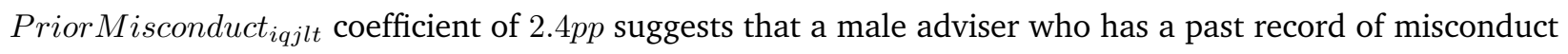
is $2.4 p p$ more likely to receive a new misconduct disclosure in the upcoming year (Table 11, column 1 ). More importantly, the negative coefficient of $-0.7 p p$ on PriorMisconduct ${ }_{i q j l t} \times$ Female $_{i}$ suggests that women are significantly less likely to be repeat offenders. The financial advisory industry may find it optimal to punish female advisers more severely if they engage in more repeated misconduct. However, the evidence presented in Table 11 indicates the exact opposite; male advisers are substantially more likely to be repeat offenders than female advisers.

We next show that men have higher recidivism rates relative to females, both in the sample of advisers whose previous misconduct was punished with a job separation, and in the sample of advisers who were allowed to keep their job following misconduct. In other words, differential separation rates across genders following misconduct are not driving the different recidivism rates. We extend our previous regression specification (10) by including the dummy variable PriorDiscipline $e_{i q j l t}$, which indicates whether an adviser

\footnotetext{
${ }^{33}$ Figure A6 displays the frequency of misconduct among male and female advisers. Male advisers are more likely than female advisers to be both repeat offenders and multiple repeat offenders.
} 


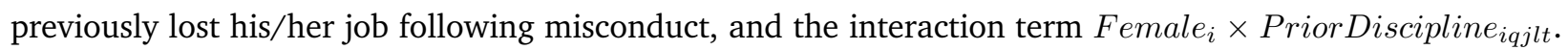
Columns (5)-(8) in Table 11 display the corresponding estimates. The results suggest that firms are shedding advisers that are more likely to engage in misconduct in the future (coefficient on PriorDiscipine is positive). Among those who suffered a job separation following misconduct, male advisers are 2.5pp $(\approx 0.56+1.70+0.27)$ more likely to engage in misconduct in a given year than female advisers (column 5). Similarly, among advisers who kept their job following misconduct, male advisers are roughly $1 p p$ $(\approx 0.5+0.27)$ more likely to engage in misconduct than female advisers (column 5$)$. Overall, these results suggest that past misconduct is actually more predictive of future misconduct for male advisers than for female advisers.

One important caveat when looking at recidivism in the data is that there is a selection issue. We only observe repeat offenses for those advisers who gain new employment in the industry. Thus, our estimates of recidivism may suffer from a selection bias. Given that women face a gender punishment gap, its possible that the women who would have had the highest rates of recidivism are pushed out of the industry. Consequently, it could be the case that, in absence of the gender punishment gap, men and women would have the same rates of recidivism. A simple back of the envelope calculation suggests that in order for the average male and female adviser to have the same rates of recidivism, the female who left the industry as a result of the gender punishment gap would need to be 10x more likely to engage in misconduct than the average adviser and 20x more likely to engage in misconduct than the average female adviser. ${ }^{34}$ As a further robustness check, in Appendix A6 we address the selection issue using a semi-parametric control function similar to the original parametric approach in Heckman (1979) and find that male advisers are more likely to be repeat offenders.

Type of Misconduct: Another reason why firms would want to punish female advisers more harshly is if they engaged in costlier or more severe misconduct. In Section II.B.3, we show the opposite is true: male advisers' misconduct is $11-20 \%$ more costly to the firm. Similarly, in Section III, we control for the specific type of misconduct an adviser engages in when initially measuring the gender punishment gap. Here, we separately focus on one specific type of misconduct, unauthorized activity, and show our results within that narrowly defined setting. We examine unauthorized activity because it is a relatively common offense, accounting for roughly $15 \%$ of misconduct disclosures. Moreover, unauthorized activity generally represents unauthorized trading and/or forgery, making its definition and measurement relatively precise.

We re-estimate gender differences in job separation and reemployment following unauthorized activity (similar to eq. 3 and 4) and report the corresponding estimates in Appendix A1. Consistent with our previous results we find that, relative to their male counterparts, female advisers experience significantly higher job separation rates following misconduct related to unauthorized activity. ${ }^{35}$ We also find that female advisers

\footnotetext{
${ }^{34}$ Under the assumption that in absence of the gender punishment gap recidivism would be the same across men and women, we can write the following relationship:

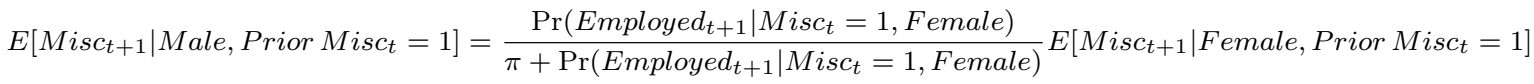

$$
\begin{aligned}
& +\frac{\pi}{\pi+\operatorname{Pr}\left(\text { Employed }_{t+1} \mid \text { Misc }_{t}=1, \text { Female }\right)} r
\end{aligned}
$$

where $\pi$ denotes the fraction of women that leave the industry as result of the gender punishment gap and $r$ denotes the probability of misconduct among this marginal population of women. From the data we have that: $E[$ Misc $t+1 \mid$ Male, Prior Misct $=1]=2.42 \%$ (Table 7, column 1), E[Misct+1 $\mid$ Female, Prior Misct $=1]=1.73 \%$ (Table 7, column 1), $\operatorname{Pr}\left(\right.$ Employed $_{t+1} \mid$ Misct $_{t}=1$, Female $)=$ $63 \%$, and $\pi=12 \%$ (Table 3a). Thus, the implied probability of misconduct among the marginal population that leave the industry as a result of the punishment gap would have to be $6 \%$.

${ }^{35}$ Our baseline result (column 3 of Table A14 indicate that, conditional on receiving unauthorized activity related misconduct disclosures, female advisers are 14pp more likely to experience job separation relative to their male counterparts, a $52 \%$ increase.
} 
are less likely to find new employment relative to their male counterparts following such a disclosure. These results suggest that the gender punishment gap is not driven by differences in the type of misconduct across genders.

In addition to examining just unauthorized activity, we use our detailed data to further categorize the different types of misconduct that appear in the data. BrokerCheck reports descriptions of each misconduct offense, ranging from a sentence to a few paragraphs. As an additional robustness check, we use two standard natural language processing methods to categorize the types of misconduct allegations. First we use a Bag of Words approach (Gentzkow, Kelly, and Taddy, 2019; Bodoh-Creed, Boehnke, and Hickman 2018) where we construct dummy variables for the common words reported in the misconduct descriptions. Second, we categorize the misconduct events using Latent Dirichlet Allocation (LDA) following Blei et al. (2003). LDA is a popular machine learning topic model that helps cluster text documents into topics. Full details of are in Appendix A5. Importantly, one piece of data we do not control for are misconduct disclosure categories. The reason is that some disclosure categories, especially "Employment Separation After Allegations", indicate not only misconduct but also punishment, which is the outcome variable of interest. We want to control for whether an adviser engaged in a specific type of misconduct, such as fraud, which could be reported in any of the six misconduct disclosure categories. However, we do not want to control for whether the adviser was let go, because doing so would be akin to controlling for our outcome variable of interest, i.e., punishment. Conditioning on types of misconduct allegations using methods above allows us to circumvent this issue. ${ }^{36}$ As described in Appendix A5 and in the corresponding tables, the results suggest that the punishment gap in employment separations and re-employment opportunities is not driven by differences in the type of misconduct across genders.

\section{IV.A.2 Gender Does Not Proxy for Productivity}

Our analysis up to this point accounts for much of the differences among financial advisers by controlling for each adviser's qualifications such as licensing, experience, the firm and location at which they work, and other characteristics. The stringent reporting and licensing requirements in the securities industry help us compare male and female advisers working in the same firm, branch, and job role. For a selected subset of active advisers, we are able to directly control for an adviser's productivity and assets under management using data from Meridian IQ. Our results also indicate that the punishment gap is positive after accounting for selection on unobservables using the methodology developed by Oster (2019) and Altonji, Elder, and Taber (2005a, 2005b, 2008). We now present several additional tests which suggest that the gender punishment gap does not proxy for productivity differences across genders.

Career Interruptions: Bertrand et al. (2010) find that career interruptions, which can impact productivity, explain about one-third of the gender wage gap in young professionals in the financial and corporate sectors. We show that the gender punishment gap is not explained by career interruptions. Following Bertrand et al. (2010), we define a career interruption as an out of the industry spell lasting six months or longer. Roughly $19 \%$ of the advisers in our data set have experienced career interruptions. After controlling for observable characteristics, female advisers are 1.26pp more likely to experience a career interruption. In Appendix A1 we re-estimate the gender punishment gap in separation and reemployment while controlling

\footnotetext{
${ }^{36}$ This relates to the critique in Johnson and Neal (1996). When studying discrimination one does not want to include control variables that are affected by discrimination. If the gender discrimination results in more formal female terminations, which are captured in "Employment Separation" disclosures, then this is one clear outcome of gender discrimination that should not be included as a control variable.
} 
for career interruptions. Career interruptions do little to explain gender punishment gap. This does not imply that career interruptions have no effect on labor market outcomes. An interruption is correlated with a $4 \mathrm{pp}$ increase in job separation rate and a 2pp decrease in reemployment rates, which is consistent with observations in Bertrand et al. (2010).

Pre-misconduct Turnover: To further illustrate that the punishment gap is unlikely driven by gender differences in unobserved characteristics (including unobserved productivity), we focus on job separation rates of financial advisers before they engage in misconduct. That is, we focus on advisers who eventually engage in misconduct. If the punishment gap arises because female advisers who eventually engage in misconduct have worse unobservable characteristics than male advisers (such as productivity), one would expect these characteristics to result in higher turnover rates even before misconduct appears. We present the results in Appendix A1 and find no evidence of differential turnover rates in the periods before misconduct appears.

Turnover Following Large Shocks: Are Females Marginal Productivity Employees?: As discussed earlier in Section III, the turnover rates of male and female advisers are remarkably similar among advisers without recent misconduct and only differ following misconduct. As an additional robustness check, we examine the employment decisions of financial advisory firms that are hit with a negative shock. A firm that decides to downsize will find it optimal to lay off the least productive (marginal) employees first. If women are less productive on the margin, then firms should lay off women at a higher rate than men. In Appendix A1, we separately examine turnover at firms that downsize by more than $5 \%, 10 \%$, and $25 \%$ in a given year. When we compare male and female advisers within the same firm, at the same time, and in the same county, we find no evidence that distressed firms downsize more extensively among females.

Human Capital Accumulation and Expected Productivity: The career paths of male and female advisers may evolve differently over time. For example, male and female advisers may acquire human capital and develop career networks on the job at different rates, or female advisers may be more likely than male advisers to experience career interruptions. Here, we show that the punishment gap exists across adviser experience levels. Previous research suggests that gender differences in pre-market human capital among men and women are negligible (Blau and Kahn 1997; Altonji and Blank 1999). If we find that the gender punishment gap exists for advisers with little experience, this suggests that our results are not due to differences in human capital acquisition over time. Similarly, after 15 years in the industry, the difference between realized and future productivity should be small. If we find the same gender punishment gap for more experienced advisers, this suggests that differences in future productivity growth are not likely to be a source of the gap.

In Appendix A1, we separately examine the gender punishment gap for those less experienced advisers ( 5 or fewer years' experience) and those more experienced advisers (15 or more years of experience). The results indicate that the gender punishment gap exists for less experienced advisers: relative to male advisers, female advisers are 9pp more likely to experience employment separations following misconduct, and 2pp less likely to find new jobs following misconduct relative to male advisers (on average, $24 \%$ of male advisers with five or fewer years of experience experience an employment separation in a year). We find similar patterns for more experienced advisers: female advisers are 4pp more likely to experience employment separations following misconduct. In both sub-samples we find weaker evidence suggesting that female advisers face worse reemployment prospects following misconduct relative to male advisers. However, this is likely due to a statistical power given the smaller sample sizes. Our conclusion from this analysis is that the gender punishment gap documented in Section III is persistent regardless of the female adviser's level of 
experience.

\section{IV.B Profit Maximization versus Bias}

Here, we consider two broad classes of explanations for the existence of the gender punishment gap, which are commonly explored in the literature. First, we consider that the gender punishment gap is the result of standard statistical discrimination (Phelps, 1972; Arrow, 1973). Males and females differ in their joint distribution of productivity and misconduct, and firms' profit maximization decisions are made under unbiased beliefs generated through Bayesian updating. In other words, the punishment gap arises because female advisers with recent misconduct are either less productive and/or more likely to be repeat offenders relative to male advisers with recent misconduct. Second, discrimination could be driven by firm biases. These biases could either be a result of implicit tastes (Becker 1957), firms simply prefer to employ male advisers, or firms have biased beliefs, firms systematically over-estimate the probability of recidivism among women (Bordalo et. al 2016).

\section{IV.B.1 Statistical Discrimination/Profit Maximizing Bayesian Firms}

We first consider our findings in the context of a statistical discrimination framework. In this framework, the joint distribution of productivity and misconduct differ across gender. A profit-maximizing Bayesian firm may find it optimal to punish women more severely if - given the lower misconduct of female advisers relative to male advisers in general - misconduct by female advisers is predictive of more frequent subsequent misconduct or lower adviser skill. We find little evidence supporting either alternative in the data along several dimensions. First, the productivity differences across male and female advisers are small and the gender punishment gap persists even after controlling for these productivity differences. In terms of misconduct, male advisers engage in misconduct that is $20 \%$ more costly and are almost $2 \mathrm{x}$ more likely to be repeat offenders.

Second, we find evidence that the gender punishment gap decreases in firms with a greater share of female managers, but not female junior advisers. A statistical discrimination model would imply that at firms with a greater share of female managers, female advisers with recent misconduct are either less likely to be repeat offenders or have higher productivity than male advisers with recent misconduct. This situation could arise if firms with female managers employ a production technology, which favors female advisers. While such a technology is beyond the scope of a benchmark statistical discrimination model, it is nevertheless possible. However, if the mechanism is about gender-specific production technologies, then we would expect to find a smaller gender punishment gap at firms that employ a greater share of female advisers at the junior level as well. This is not the case in the data. It would be even more difficult to extend the standard statistical discrimination model to accommodate sexual harassment and its correlation with a gender punishment gap.

Lastly, we document a similar punishment gap for male minority advisers. In the context of a statistical discrimination model, this would suggest that the joint distributions of misconduct and productivity are similar across female and minority male advisers. However, the distributions of misconduct among male minority advisers and female advisers are drastically different. Minority male advisers are more likely to engage in misconduct than non-minority male advisers. Female advisers, on the other hand, are roughly $50 \%$ less likely to engage in misconduct than male advisers. Following the logic of Bayesian updating, it should be the case that misconduct by male minority advisers would therefore be predictive of less frequent subsequent misconduct or higher adviser skill. Consequently, profit maximizing firms would update less 
and punish less harshly after observing misconduct by these advisers. In other words, given high average misconduct rates of male minority advisers relative to non-minority advisers, we should find the "reverse" punishment gap for minority males.

Overall, the collage of evidence we have documented suggests that it is unlikely that the gender punishment gap arises as a result of a simple statistical discrimination model with profit maximizing firms that use Bayesian updating on productivity across genders. Rationalizing our findings in a model of statistical discrimination would require numerous very specific assumptions about the distributions of productivity and misconduct across male, female, and minority advisers, and those distributions would need to vary with the composition of management but not junior employees and with the firm's sexual harassment record.

\section{IV.B.2 Model with Firm Biases}

We also consider the alternative that firms are biased: managers either prefer non-minority male advisers, or have biased beliefs about productivity/misconduct across genders and minority status. For example, one could rationalize our findings if managers exhibit in-group favoritism towards or are overly optimistic about members of their own group. Such a model could explain the existence of a gender punishment gap on average, and why it varies with the composition of firm management.

Whether the mechanism is driven by biased beliefs or the preferences of the managers is difficult to disentangle in the data. On many dimensions, these two mechanisms are observationally equivalent, especially once one allows for enough flexibility in preferences or beliefs. We do find some evidence suggesting that the tastes of managers play at least some role in the gender punishment gap since the gap is greater at firms with a record of sexual harassment. We interpret sexual harassment as being more likely to be driven by the tastes (ethics/morals) of the firm's employees than by employees' beliefs.

\section{Conclusion}

We find evidence of a "gender punishment gap" following an incident of misconduct. Female advisers are $20 \%$ more likely to lose their jobs relative to similar male advisers. Females are also punished more severely for misconduct committed at other firms and are 30\% less likely to find new jobs following misconduct. Females face harsher outcomes despite engaging in misconduct that is $20 \%$ less costly and having a substantially lower propensity towards repeat offenses. A plethora of tests suggest that the gender punishment gap is not likely driven by gender differences in occupation (type of job, firm, market, or financial products handled), productivity, misconduct, or recidivism. The punishment gap is not limited to gender but also extends to minority men, suggesting that a non-gender specific mechanism is driving the gap.

We find evidence that the punishment gap is likely driven by in-group favoritism. The gap decreases when a larger share of managers are from the specific disadvantaged group: the gender punishment gap decreases with a larger share of female managers, and the punishment gap for minority men decreases with a larger share of minority male managers. Minority male managers, on the other hand, do not mitigate the gender punishment gap. In other words, specific group membership seems to play an important role in understanding the punishment gap of advisers across different genders and ethnicities. We also find that the gender punishment gap is more than twice as large at firms with a history of sexual harassment, which suggests that firm biases/tastes may play a role in the gender punishment gap.

Our findings provide new insight into the gender gap in the workplace. We examine an inconspicuous and potentially costly channel: punishment following cause. This aspect has received little attention 
in academia, despite generating approximately $60 \%$ of lawsuits alleging discrimination in the workplace (Siegelman 2016). A natural next step would be to explore the long-term consequences of the gender punishment gap. Since females face a narrower margin for error, the gender punishment gap may be partially responsible for the glass ceiling observed in the industry. Exploring this argument in detail remains a fruitful area of research. 


\section{References}

Aigner, Dennis J. and Glenn G. Cain. 1977. "Statistical Theories of Discrimination in Labor Markets." Industrial and Labor Relations Review, 30(1): 175-187.

Altonji, Joseph. 1999. "Race and Gender in the Labor Market," In Orley and Ashenfelter and David Card, eds. Handbook of labor economics, Vol. 30. Amsterdam: North-Holland.

Altonji, Joseph G., Todd E. Elder, and Christopher R. Taber. 2005a. "An evaluation of instrumental variable strategies for estimating the effects of catholic schooling." Journal of Human Resources, 40(4): 791-821.

Altonji, Joseph G., Todd E. Elder, and Christopher R. Taber. 2005b. "Selection on observed and unobserved variables: Assessing the effectiveness of Catholic schools." Journal of Political Economy, 113(1): 151-184.

Altonji, Joseph G., Todd E. Elder, and Christopher R. Taber. 2008. "Using selection on observed variables to assess bias from unobservables when evaluating swan-ganz catheterization." The American Economic Review, 98(2): 345-350.

Altonji, Joseph G., and Charles R. Pierret. 2001. "Employer learning and statistical discrimination." The Quarterly Journal of Economics, 116(1): 313-350.

Arnold, David, Will Dobbie and Crystal S. Yang. 2018. "Racial Bias in Bail Decisions." The Quarterly Journal of Economics, 133(4): 1885-1932.

Arrow, Kenneth, J. 1973. "The Theory of Discrimination," in Orley Ashenfelter and Albert Rees eds., Discrimination in labor markets. Princeton, NJ: Princeton University Press.

Ayres, Ian, and Peter Siegelman. 1995. "Race and gender discrimination in bargaining for a new car." The American Economic Review 304-321.

Bair, Sheila. 2016. "BankThink The Glass Ceiling in Finance: Barely Cracked." American Banker, https://www.americanbanker.com/opinion/the-glass-ceiling-in-finance-barely-cracked. Accessed 6 March 2017.

Bagues, Manuel F, and Berta Esteve-Volart. 2010. "Can gender parity break the glass ceiling? Evidence from a repeated randomized experiment." The Review of Economic Studies, 77(4): 1301-1328.

Bagues, Manuel, Mauro Sylos-Labini, and Natalia Zinovyeva. 2017. "Does the gender composition of scientific committees matter?" The American Economic Review, 107(4): 1207- 1238.

Barres, Ben A. 2006. "Does gender matter?" Nature, 442(7099): 133-136.

Bartoš, Vojtěch, Michal Bauer, Julie Chytilová, and Filip Matějka. 2016. "Attention Discrimination: Theory and Field Experiments with Monitoring Information Acquisition." The American Economic Review, 106(6): 1437-1475.

Beaman, Lori, Raghabendra Chattopadhyay, Esther Duflo, Rohini Pande, and Petia Topalova. 2009. "Powerful women: does exposure reduce bias?" The Quarterly Journal of Economics, 124(4): 1497-1540.

Beaman, Lori, Esther Duflo, Rohini Pande, and Petia Topalova. 2012. "Female leadership raises aspirations and educational attainment for girls: A policy experiment in India." Science, 335(6068): 582-586.

Becker, Gary S. 1957. The Economics of Discrimination. University of Chicago Press.

Becker, Gary S. 1968. "Crime and Punishment: An Economic Approach." Journal of Political Economy, 76: 169-217

Bell, Linda A. 2005. "Women-led firms and the gender gap in top executive jobs."

Bertrand, Marianne. 2011. "New Perspectives on Gender," in O. Ashenfelter and D. Card eds, Handbook of Labor Economics, Volume 4B, 1543-1590. 
Bertrand, Marianne, and Esther Duflo. 2017. "Field Experiments on Discrimination," in Abhijit Banerjee and Esther Duflo eds., Handbook of Field Experiments, Vol. 1. Amsterdam: NorthHolland.

Bertrand, Marianne, Claudia Goldin and Lawrence F. Katz. 2010. "Dynamics of the Gender Gap for Young Professionals in the Financial and Corporate Sectors." American Economic Journal: Applied Economics, 2(3): 228-255.

Bertrand, Marianne, and Kevin F. Hallock. 2001. "The Gender Gap in Top Corporate Jobs." Industrial and Labor Relations Review, 55(1): 3-21.

Bertrand, Marianne, Sandra E Black, Sissel Jensen, and Adriana Lleras-Muney. 2014. "Breaking the glass ceiling? The effect of board quotas on female labor market outcomes in Norway."Technical report, National Bureau of Economic Research.

Bertrand, Marianne, Emir Kamenica, and Jessica Pan. 2015. "Gender identity and relative income within households." The Quarterly Journal of Economics, 130(2): 571-614.

Blackaby, David, Alison L Booth, and Jeff Frank. 2005. "Outside offers and the gender pay gap: Empirical evidence from the UK academic labour market." The Economic Journal, 115(501): F81-F107.

Blau, Francine D. and Lawrence M. Kahn. 1997. "Swimming upstream: trends in the gender wage differential in the 1980s." Journal of Labor Economics 15(1):1-42.

Blau, Francine D. and Lawrence M. Kahn. 2017. "The Gender Wage Gap: Extent, Trends, and Explanations," Journal of Economic Literature, vol 55(3), pages 789-865

Blei, David M., Andrew Y. Ng, and Michael I. Jordan. 2003. "Latent dirichlet allocation." Journal of Machine Learning Research, 3(Jan): 993-1022.

Bodoh-Creed, Aaron, Jörn Boehnke, and Brent Hickman. 2018. "Using Machine Learning to Explain Price Dispersion." Working Paper.

Bohnet, Iris, Alexandra Van Geen, and Max Bazerman. 2015. "When performance trumps gender bias: Joint vs. separate evaluation." Management Science, 62(5): 1225-1234.

Booth, Alison, and Andrew Leigh. 2010. "Do employers discriminate by gender? A field experiment in female-dominated occupations." Economics Letters, 107(2): 236-238.

Bordalo, Pedro, Katherine Coffman, Nicola Gennaioli, and Andrei Shleifer. 2016. "Stereotypes." Quarterly Journal of Economics, 131(4): 1753-1794.

Boschini, Anne, and Anna Sjögren. 2007. "Is team formation gender neutral? Evidence from coauthorship patterns." Journal of Labor Economics, 25(2): 325-365.

Broder, Ivy E. 1993. "Review of NSF economics proposals: Gender and institutional patterns." The American Economic Review, 83(4): 964-970.

Cardoso, Ana Rute, and Rudolf Winter-Ebmer. 2007. "Mentoring and segregation: female-led firms and gender wage policies."

Carlsson, Magnus. 2011. "Does Hiring Discrimination Cause Gender Segregation in the Swedish Labor Market?" Feminist Economics, 17(3): 71-102.

Casella, George. 1992. "Illustrating empirical Bayes methods." Chemometrics and Intelligent Laboratory Systems, 16(2): 107-125

Charles, Kerwin Kofi and Jonathan Guryan. 2008. "Prejudice and Wages: An Empirical Assessment of Becker's the Economics of Discrimination." Journal of Political Economy, 116(5): 773-809.

Charles, Kerwin Kofi, and Jonathan Guryan. 2011. "Studying discrimination: Fundamental challenges and recent progress." Annual Review of Economics, 3(1): 479-511.

Charles, Kerwin Kofi, Jonathan Guryan, and Jessica Pan. 2018. "The Effects of Sexism on American Women: The Role of Norms vs. Discrimination.” NBER Working Paper No. w24904. 
Croson, Rachel, and Uri Gneezy. "Gender Differences in Preferences." Journal of Economic Literature, 47(2): 448-474.

Daly, Kathleen. 1989. "Gender and Varieties of White-Collar Crime." Criminology, 27: 769-794.

De Paola, Maria, and Vincenzo Scoppa. 2015. "Gender discrimination and evaluators' gender: evidence from Italian academia." Economica, 82(325): 162-188.

Dimmock, Stephen G., William C. Gerken and Nathaniel P. Graham. 2018. "Is Fraud Contagious? Coworker Influence on Misconduct by Financial Advisors." Journal of Finance, 73(3): 14171450.

Dyck, Alexander, Adair Morse and Luigi Zingales. 2010. "Who Blows the Whistle on Corporate Fraud." Journal of Finance, 65(6): 2213-2253

Dyck, Alexander, Adair Morse and Luigi Zingales. 2014. "How Pervasive is Corporate Fraud?" Rotman School of Managment Working Paper No. 2222608

Egan, Mark, Gregor Matvos, and Amit Seru. 2019a. "The Market for Financial Adviser Misconduct." Journal of Political Economy, 127(1): 233-295.

Egan, Mark, Gregor Matvos, and Amit Seru. 2019b. "Arbitration with Uninformed Consumers." NBER Working Paper No. w25150.

Esteve-Volart, Berta, and Manuel Bagues. 2012. "Are women pawns in the political game? Evidence from elections to the Spanish Senate." Journal of Public Economics, 96(3): 387-399.

Gennaioli, Nicola, and Andrei Shleifer. 2010. "What Comes to Mind." Quarterly Journal of Economics, 125(4): 1399-1433.

Gentzkow, Brian T. Kelly and Matt Taddy. 2019. "Text as Data." Journal of Economic Literature, 57(3): 535-574.

Ginther, Donna K, and Shulamit Kahn. 2004. "Women in economics: moving up or falling off the academic career ladder?" The Journal of Economic Perspectives, 18(3): 193-214.

Goldin, Claudia and Cecilia Rouse. 2000. "Orchestrating Impartiality: The Impact of Blind Auditions on Female Musicians." American Economic Review, 90(4): 715-741.

Gompers, Paul A., Vladimir Mukharlyamov, Emily Weisburst, and Yuhai Xuan. 2020. "Gender Gaps in Venture Capital Performance." Journal of Financial and Quantitative Analysis, Forthcoming.

Goulette, Natalie, John Wooldredge, James Frank, and Lawrence Travis III. 2015. "From Initial Appearance to Sentencing: Do Female Defendants Experience Disparate Treatment?" Journal of Criminal Justice, 43 (5): 406-417.

Griffin, John M. and Gonzalo Maturana. 2016. "Who Facilitated Misreporting in Securitized Loans?" Review of Financial Studies, 29(2): 384-419.

Hamermesh, Daniel S, and Jason Abrevaya. 2013. "Beauty is the promise of happiness?" European Economic Review, 64 351-368.

Heckman, James. 1979. "Sample selection bias as a specification error." Econometrica 47(1): 153-161.

Heckman, James, Sergio Urzua, and Edward Vytlacil. 2006. "Understanding Instrumental Variables in Models with Essential Heterogeneity." Review of Economics and Statistics, 88(3):389432.

Holtfreter, Kristy. 2005. "Is Occupational Fraud 'Typical' White-Collar Crime? A Comparison of Individual and Organizational Characteristics." Journal of Criminal Justice, 33: 353-365.

Jayasinghe, Upali W, Herbert W Marsh, and Nigel Bond. 2003. "A multilevel crossclassified modeling approach to peer review of grant proposals: the effects of assessor and researcher attributes on assessor ratings." Journal of the Royal Statistical Society: Series A (Statistics in Society), 166(3): 279-300. 
Khanna, Vikramaditya S., E. Han Kim and Yao Lu. 2015. "CEO Connectedness and Corporate Fraud." Journal of Finance, 70(3): 1203-1252.

Knowles, John, Nicola Persico, and Petra Todd. 2001. "Racial Bias in Motor Vehicle Searches: Theory and Evidence." Journal of Political Economy, 109(1): 203-232.

Landsman, Rachel. 2018. "Gender Differences in Executive Departure." Bucknell University Working Paper.

Lavy, Victor. 2008. "Do gender stereotypes reduce girls' or boys' human capital outcomes? Evidence from a natural experiment." Journal of public Economics, 92(10): 2083-2105.

Moss-Racusin, Corinne A, John F Dovidio, Victoria L Brescoll, Mark J Graham, and Jo Handelsman. 2012. "Science faculty's subtle gender biases favor male students." Proceedings of the National Academy of Sciences, 109(41): 16474-16479.

Neal, Derrick A. and William R. Johnson. 1996. "The Role of Premarket Factors in Black-White Wage Differences.” Journal of Political Economy, 104(5): 869-895.

Neumark, David. 1996. "Sex Discrimination in Restaurant Hiring: An Audit Study." Quarterly Journal of Economics, 111(3): 915-942.

Niederle, Muriel, and Lise Vesterlund. 2007. "Do Women Shy Away from Competition? Do Men Compete too Much?" Quarterly Journal of Economics, 122(3): 1067-1101.

Oliver Wyman. 2016. "Women in Financial Services." http://www.oliverwyman.com/ content/dam/oliverwyman/global/en/2016/june/WiFS/WomenInFinancialServices_2016.pdf. Accessed 6 March 2017.

Oster, Emily. 2019. "Unobservable Selection and Coefficient Stability." Journal of Business Economics and Statistics, 37(2): 187-204.

Parsons, Christopher A., Johan Sulaeman and Sheridan Titman. 2018. "The Geography of Financial Misconduct." Journal of Finance, 73(5): 2087-2137.

Phelps, Edmund S. 1972. "The statistical theory of racism and sexism." American Economic Review, 62(4): 659-661.

Piskorski, Tomasz, Amit Seru and James Witkin. 2015. "Asset Quality Misrepresentation by Financial Intermediaries: Evidence from the RMBS Market." Journal of Finance, 70(6): 26352678.

Povel, Paul, Rajdeep Sign and Andrew Winton. 2007. "Booms, Busts, and Fraud." Review of Financial Studies, 20(4): 1219-1254.

Price, Joseph, and Justin Wolfers. 2010. "Racial Discrimination Among NBA Referees." Quarterly Journal of Economics, 125(4): 1859-1887.

Qureshi, Hammad and Jonathan Sokobin. 2015. "Do Investors Have Valuable Information About Brokers?" FINRA Office of the Chief Economist Working Paper.

Reuben, Ernesto, Paola Sapienza, and Luigi Zingales. 2014. "How stereotypes impair women's careers in science." Proceedings of the National Academy of Sciences, pnas-201314788.

Sapienza, Paola, Luigi Zingales, and Dario Maestripieri. 2009. "Gender differences in financial risk aversion and career choices are affected by testosterone." Proceedings of the National Academy of Sciences, pnas-0907352106.

Sarsons, Heather. 2017. "Interpreting Signals in the Labor Market: Evidence from Medical Referrals." Working paper.

Steffensmeier, Darrell, and Emilie Allan. 1996. "Gender and crime: Toward a gendered theory of female offending." Annual Review of Sociology, 22(1): 459-487.

Steffensmeier, Darrel J., Jennifer Schwartz, and Michael Roche. 2013. "Gender and Twenty-FirstCentury Corporate Crime: Female Involvement and the Gender Gap in Enron-Era Corporate Frauds." American Sociological Review, 78(3):448-476. 
Tuttle, Beecher. 2014. "How female bankers react to gender bias today." eFinancialCareers, http://news. efinancialcareers.com/us-en/184541/female-bankers-recommend-gender-biasedfirm-women-colleagues/. Accessed 6 March 2017.

Tversky, Amos and Daniel Kahneman. 1983. "Extensional versus Intuitive Reasoning: the Conjunction Fallacy in Probability Judgment." Psychological Review, 90(4): 293-315.

Wang, Tracy Yu, Andrew Winton and Xiaoyun Yu. 2010. "Corporate Fraud and Business Conditions: Evidence from IPOs." Journal of Finance, 65(6): 2255-2291.

Wolfers, Justin. 2006. "Diagnosing Discrimination: Stock Returns and CEO Gender." Journal of the European Economic Association, 4(2-3): 531-41.

Zinovyeva, Natalia, and Manuel Bagues. 2011. "Does Gender Matter for Academic Promotion? Evidence from a Randomized Natural Experiment." 
Figure 1: Female Representation at Financial Advisory Firms

(a) Branch Management

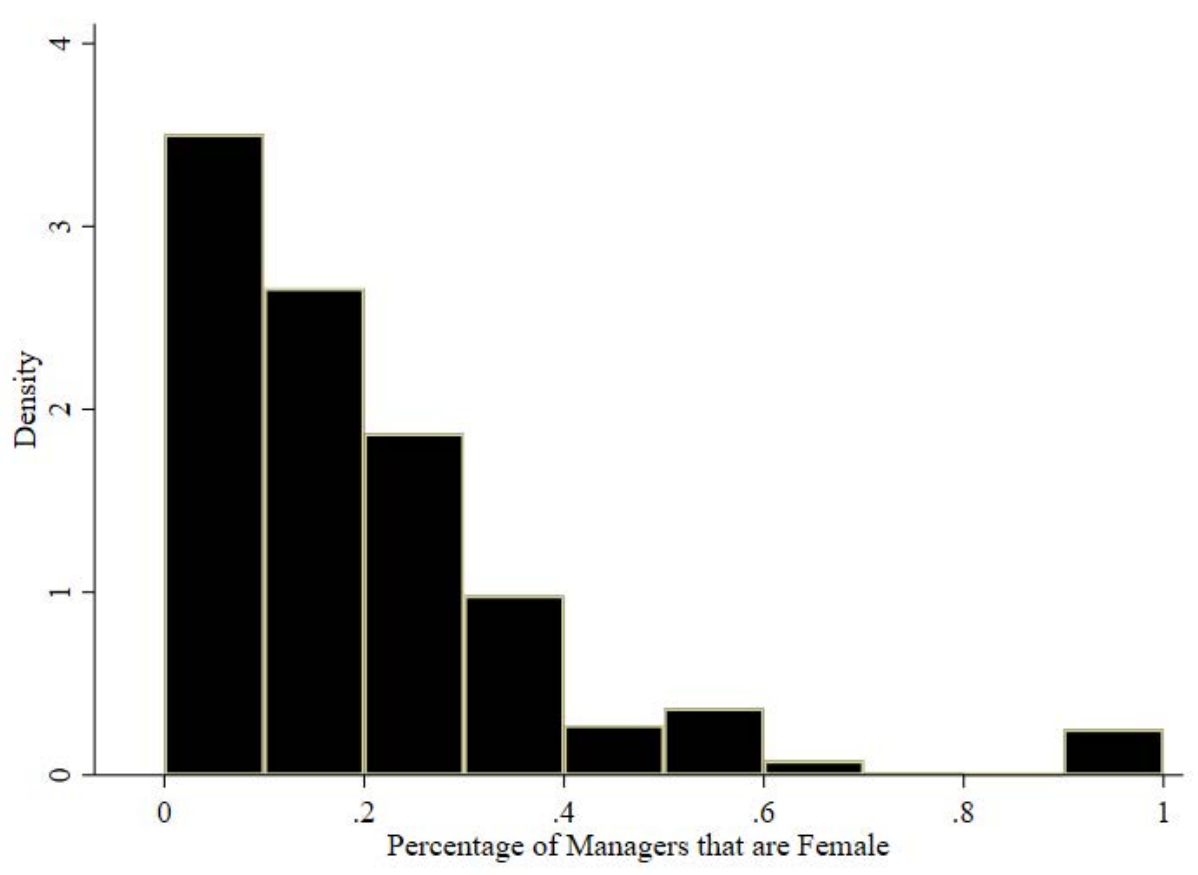

(b) Firm Executives/Ownership

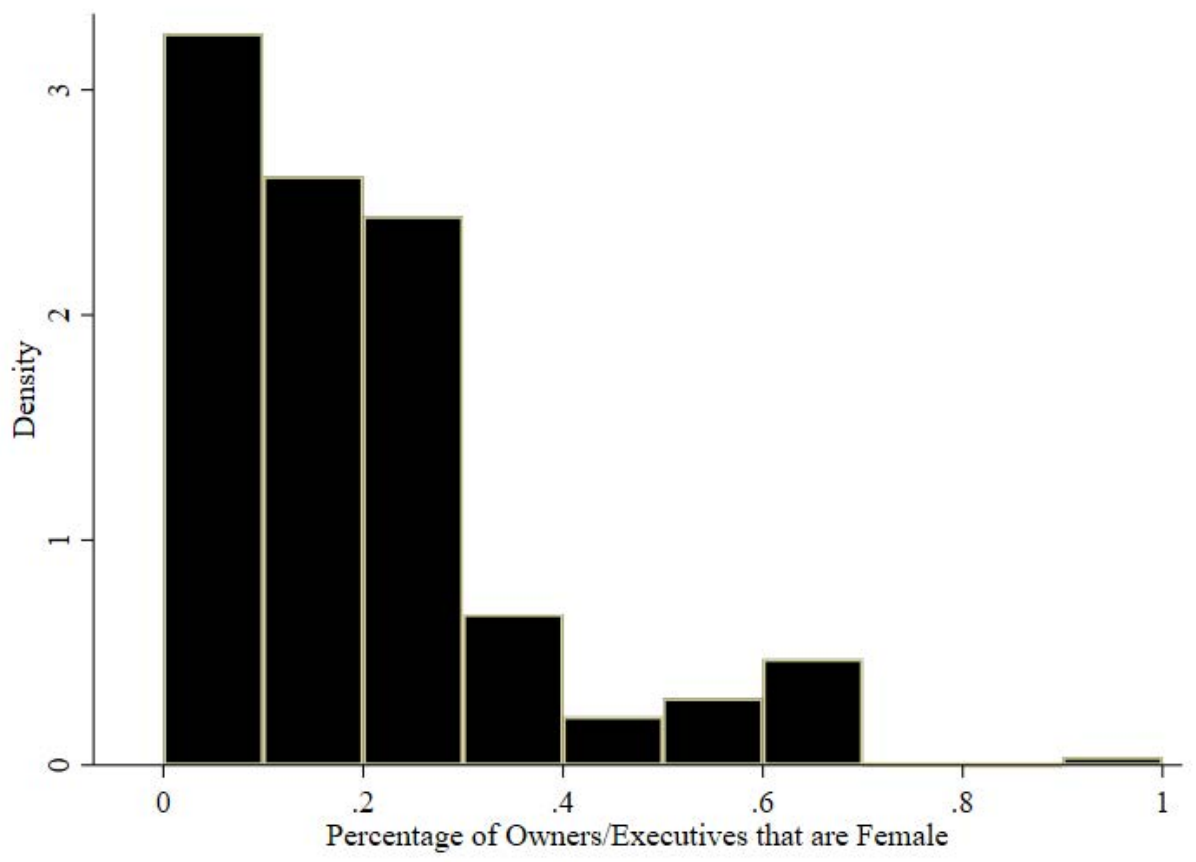

Figure 1a displays the share of managers that are female within a firm branch. Figure $1 \mathrm{~b}$ displays the share of owners or executives that are female as of 2015. Observations in Figure 1a are at the adviser-by-year level over the period 2005-2015. Observations in $1 \mathrm{~b}$ are at the adviser level as of 2015. 
Figure 2: Firm Differences in the Gender Punishment Gap

(a) Distribution of the Gender Punishment Gap

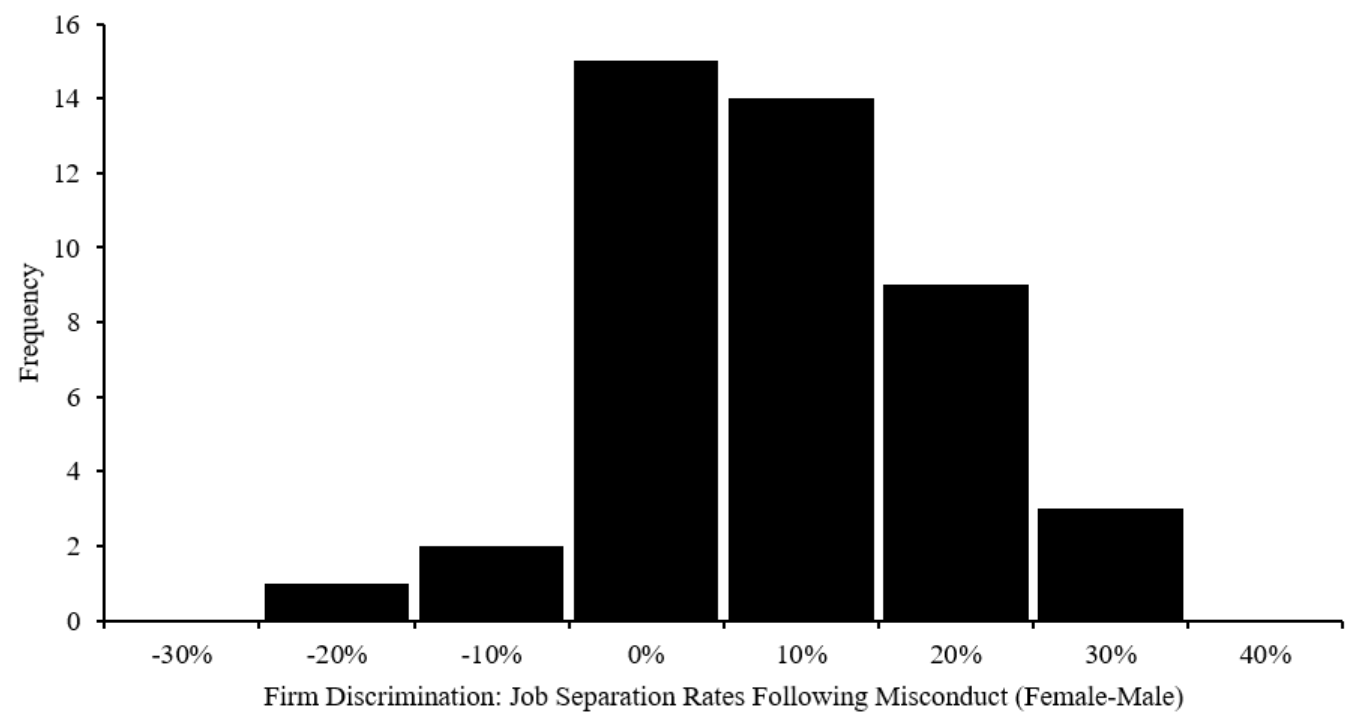

(b) Firms with the Largest Gender Punishment Gap

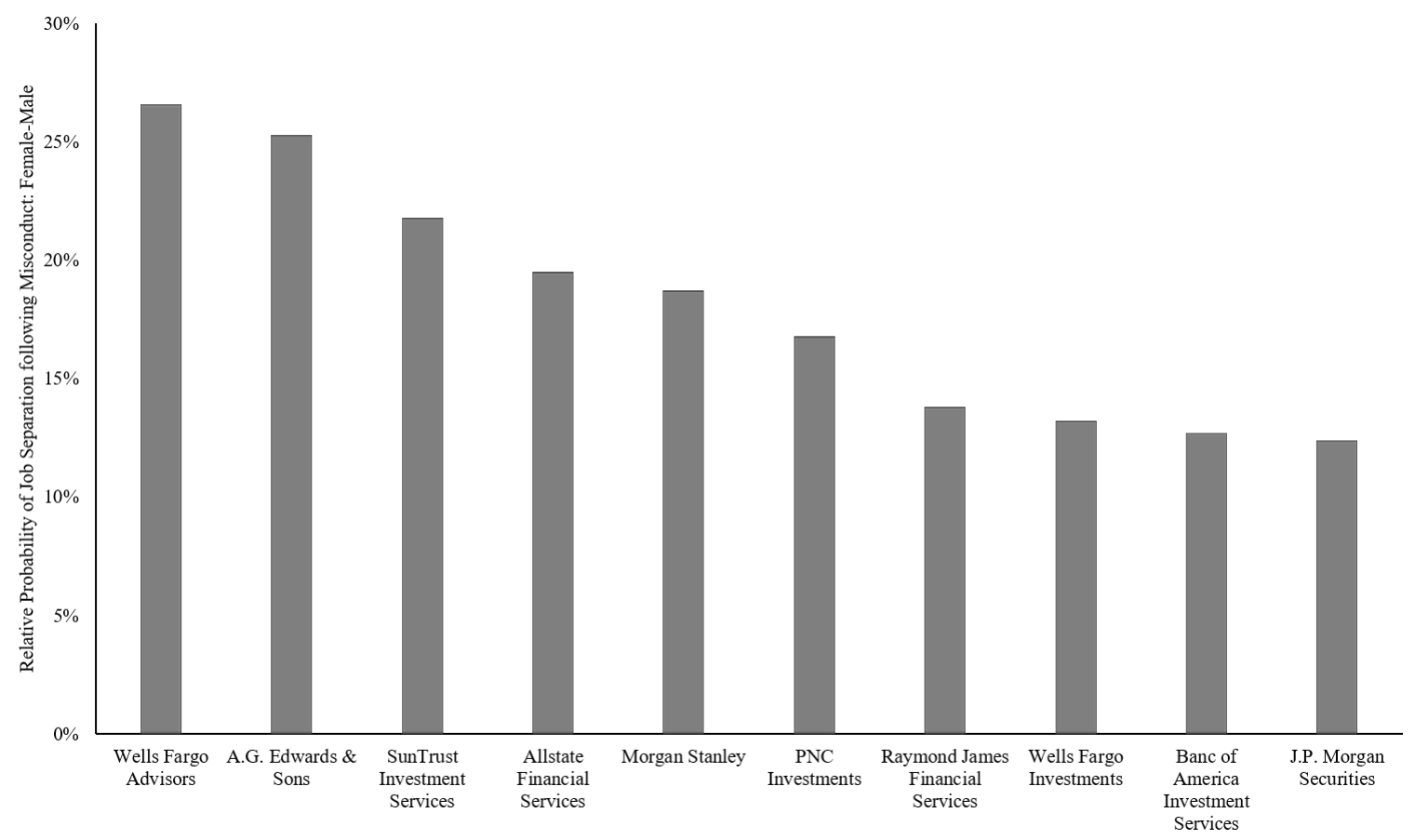

Figures $2 \mathrm{a}$ and $2 \mathrm{~b}$ display the distribution of the gender punishment gap across firms. The figures plot the distribution of the coefficient $\beta_{j 3}$ from eq. (5), which captures the differential probability that female advisers experience employment separations following misconduct relative to male advisers (i.e., the difference in differences for female and male advisers with and without misconduct). Figure $2 \mathrm{~b}$ displays the firms with the ten highest coefficient estimates. We restrict our analysis to 44 firms with at least twenty observations of female advisers receiving misconduct disclosures. 
Table 1: Summary Statistics

(a) Adviser Summary Statistics

\begin{tabular}{lcccc}
\hline Variable & \multicolumn{2}{c}{ Male } & \multicolumn{2}{c}{ Female } \\
& Obs & Mean & Obs & Mean \\
\hline Experience (years) & $4,932,478$ & 12.31 & $1,615,496$ & $9.37 * * *$ \\
Disclosures: & & & & \\
$\quad$ Disclosure (in a year) & $4,932,478$ & $1.83 \%$ & $1,615,496$ & $1.08 \% * * * *$ \\
$\quad$ Misconduct (in a year) & $4,932,478$ & $0.72 \%$ & $1,615,496$ & $0.29 \% * * *$ \\
$\quad$ Disclosure (ever) & $4,932,478$ & $14.89 \%$ & $1,615,496$ & $7.61 \% * * *$ \\
$\quad$ Misconduct (ever) & $4,932,478$ & $9.08 \%$ & $1,615,496$ & $3.00 \% * * *$ \\
Exams and Qualifications (Series): & & & & \\
$\quad$ No. Qualifications & $4,932,478$ & 2.88 & $1,615,496$ & $2.51^{* * *}$ \\
Uniform Sec. Agent St. Law (63) & $4,932,478$ & $77 \%$ & $1,615,496$ & $71 \% * * *$ \\
$\quad$ General Sec. Rep. (7) & $4,932,478$ & $68 \%$ & $1,615,496$ & $61 \% * * *$ \\
$\quad$ Inv. Co. Products Rep. (6) & $4,932,478$ & $37 \%$ & $1,615,496$ & $46 \% * * *$ \\
$\quad$ Uniform Combined St. Law (66) & $4,932,478$ & $19 \%$ & $1,615,496$ & $19 \%$ \\
$\quad$ Uniform Inv. Adviser Law (65) & $4,932,478$ & $21 \%$ & $1,615,496$ & $13 \% * * *$ \\
$\quad$ General Sec. Principal (24) & $4,932,478$ & $16 \%$ & $1,615,496$ & $10 \% * * *$ \\
Productivity: & & & & \\
$\quad$ Assets Under Management (\$mm) & 988,217 & 54.7 & 169,641 & $53.2^{* * * *}$ \\
$\quad$ Productivition (\$100k) & 560,519 & 532 & 90,572 & $503^{* * * *}$ \\
$\quad$ High Quality Indicator & $2,272,975$ & 0.45 & 559,589 & $0.32^{* * * *}$ \\
\hline
\end{tabular}

Table 1a displays the summary statistics corresponding to our panel of male and female financial advisers. Observations are at the adviser-by-year-level over the period 2005-2015. Experience measures the number of years since the adviser obtained his/her first regulatory license. Disclosure is a dummy variable indicating whether the adviser received a disclosure. Misconduct is a dummy variable indicating whether the adviser received a misconduct-related disclosure. No. Qualifications measures the number of regulatory licenses an adviser holds. The other regulatory licensing related variables (i.e. Uniform Sec. Agent St. Law) are dummy variables that indicate whether an adviser holds the particular license. Advisers can hold 61 different types of licenses. We report the 6 most common licenses. We observe adviser-level productivity data for a subset of advisers from Meridian IQ for 2016. The Meridian IQ data contain advisers' quality rating (generated by Meridian IQ), assets under management (AUM), and production (revenue). We denote statistically significant differences across male and female characteristics, ${ }^{* *} \mathrm{p}<0.01,{ }^{* *} \mathrm{p}<0.05,{ }^{*} \mathrm{p}<0.10$.

Table $1 \mathrm{~b}$ displays the incidence of disclosures/misconduct among male and female financial advisers. Observations are at the year-by-financial adviser level over the period 2005-2015. We classify the six categories listed at the top of the as adviser misconduct. The column "Current" displays the share of observations (year-by-adviser) in which the adviser received one or more of a given type of disclosure that particular year. The column "Current and Past" displays the share of observations (year-by-adviser) in which the adviser received a given type of disclosure up to and including that year. The disclosure definitions are reported in Appendix A2.

Tables $1 \mathrm{c}$ and $1 \mathrm{~d}$ display the most frequently reported allegations and products corresponding to misconduct disclosures that occurred over the period 2005-2015. We observe allegations for $91.89 \%$ of the misconductrelated disclosures. The allegation and product categories are not mutually exclusive. The "Other" category includes all other allegations/classifications that were reported with a frequency of less than $2 \%$.

Table 1e displays the settlements and damages (in \$) that were granted and requested over the period 20052015. We observe all settlements and damages paid for consumer related misconduct, which accounts for $45.80 \%$ of misconduct related disclosures. 
Table 1: Summary Statistics (contd.)

(b) Financial Adviser Disclosures and Misconduct

\begin{tabular}{lcccc}
\hline \multicolumn{1}{c}{ Disclosure } & \multicolumn{3}{c}{ Disclosure Misconduct } \\
& \multicolumn{2}{c}{ Current } & \multicolumn{2}{c}{ Current and Past } \\
& Male & Female & Male & Female \\
\hline Misconduct Related Disclosures & & & & \\
Customer Dispute - Settled & $0.39 \%$ & $0.13 \%$ & $4.74 \%$ & $1.35 \%$ \\
Employment Separation After Allegations & $0.20 \%$ & $0.12 \%$ & $1.21 \%$ & $0.43 \%$ \\
Regulatory - Final & $0.12 \%$ & $0.04 \%$ & $1.62 \%$ & $0.35 \%$ \\
Criminal - Final Disposition & $0.03 \%$ & $0.01 \%$ & $2.46 \%$ & $0.98 \%$ \\
Customer Dispute - Award/Judgment & $0.02 \%$ & $0.01 \%$ & $0.75 \%$ & $0.15 \%$ \\
Civil - Final & $0.00 \%$ & $0.00 \%$ & $0.04 \%$ & $0.01 \%$ \\
Any Misconduct Related Disclosure & $\mathbf{0 . 7 2 \%}$ & $\mathbf{0 . 2 9} \%$ & $\mathbf{9 . 0 8} \%$ & $3.01 \%$ \\
\hline Other Disclosures: & & & & \\
Financial - Final & $0.33 \%$ & $0.39 \%$ & $1.95 \%$ & $2.47 \%$ \\
Customer Dispute - Denied & $0.38 \%$ & $0.15 \%$ & $3.92 \%$ & $1.49 \%$ \\
Judgment/Lien & $0.24 \%$ & $0.15 \%$ & $1.10 \%$ & $0.76 \%$ \\
Customer Dispute - Closed-No Action & $0.09 \%$ & $0.03 \%$ & $1.20 \%$ & $0.38 \%$ \\
Financial - Pending & $0.05 \%$ & $0.07 \%$ & $0.18 \%$ & $0.24 \%$ \\
Customer Dispute - Pending & $0.07 \%$ & $0.02 \%$ & $0.36 \%$ & $0.10 \%$ \\
Customer Dispute - Withdrawn & $0.02 \%$ & $0.01 \%$ & $0.20 \%$ & $0.06 \%$ \\
Criminal - Pending Charge & $0.01 \%$ & $0.00 \%$ & $0.02 \%$ & $0.01 \%$ \\
Investigation & $0.01 \%$ & $0.00 \%$ & $0.03 \%$ & $0.01 \%$ \\
Regulatory - Pending & $0.01 \%$ & $0.00 \%$ & $0.02 \%$ & $0.00 \%$ \\
Civil - Pending & $0.00 \%$ & $0.00 \%$ & $0.02 \%$ & $0.01 \%$ \\
Customer Dispute - Final & $0.00 \%$ & $0.00 \%$ & $0.02 \%$ & $0.01 \%$ \\
Customer Dispute - Dismissed & $0.00 \%$ & $0.00 \%$ & $0.02 \%$ & $0.00 \%$ \\
Civil Bond & $0.00 \%$ & $0.00 \%$ & $0.03 \%$ & $0.01 \%$ \\
Regulatory - On Appeal & $0.00 \%$ & $0.00 \%$ & $0.00 \%$ & $0.00 \%$ \\
Criminal - On Appeal & $0.00 \%$ & $0.00 \%$ & $0.00 \%$ & $0.00 \%$ \\
Civil - On Appeal & $0.00 \%$ & $0.00 \%$ & $0.00 \%$ & $0.00 \%$ \\
\hline Total & $1.83 \%$ & $1.08 \%$ & $14.89 \%$ & $7.61 \%$ \\
\hline & & & &
\end{tabular}

(c) Reasons for Misconduct Disclosure

\begin{tabular}{lrr}
\hline & \multicolumn{2}{c}{ Gender } \\
& Male & Female \\
\hline Unsuitable & $22.8 \%$ & $18.3 \%$ \\
Misrepresentation & $18.3 \%$ & $14.6 \%$ \\
Unauthorized Activity & $14.9 \%$ & $14.1 \%$ \\
Omission of Key Facts & $11.6 \%$ & $8.1 \%$ \\
Fee/Commission Related & $8.1 \%$ & $6.0 \%$ \\
Fraud & $7.8 \%$ & $5.2 \%$ \\
Fiduciary Duty & $7.1 \%$ & $4.9 \%$ \\
Negligence & $6.4 \%$ & $4.6 \%$ \\
Risky Investments & $3.9 \%$ & $3.0 \%$ \\
Churning/ Excessive Trading & $2.9 \%$ & $1.0 \%$ \\
Other & $41.7 \%$ & $50.9 \%$ \\
\hline
\end{tabular}

(d) Products Involved in Misconduct Disclosure

\begin{tabular}{lrr}
\hline & \multicolumn{2}{c}{ Gender } \\
& Male & Female \\
\hline Insurance & $13.2 \%$ & $14.4 \%$ \\
Annuity & $8.7 \%$ & $9.7 \%$ \\
Stocks & $6.1 \%$ & $3.98 \%$ \\
Mutual Funds & $4.7 \%$ & $5.0 \%$ \\
Bonds & $2.1 \%$ & $1.6 \%$ \\
Options & $1.3 \%$ & $0.8 \%$ \\
Other/Not Listed & $69.9 \%$ & $70.3 \%$ \\
\hline
\end{tabular}

(e) Settlements/Damages

\begin{tabular}{ccrrr}
\hline \multicolumn{1}{c}{ Variable } & Obs & Mean & Std. Dev. & Median \\
\hline Male Advisers: & & & & \\
Settlement Granted & 27,469 & 549,791 & $9,199,107$ & 40,000 \\
Settlement Requested & 21,749 & $1,719,226$ & $69,458,640$ & 100,000 \\
Female Advisers: & & & & \\
$\quad$ Settlement Granted & 2,749 & 262,530 & $2,281,979$ & 32,500 \\
Settlement Requested & 2,119 & 449,282 & $3,107,101$ & 60,000 \\
\hline
\end{tabular}


Table 2: Gender and Misconduct

(a) Incidence of Misconduct

\begin{tabular}{|c|c|c|c|c|c|c|}
\hline & $(1)$ & $(2)$ & (3) & (4) & (5) & (6) \\
\hline Female & $\begin{array}{c}-0.43^{* * * *} \\
(0.025)\end{array}$ & $\begin{array}{c}-0.33^{* * * *} \\
(0.022)\end{array}$ & $\begin{array}{c}-0.32^{* * * *} \\
(0.027)\end{array}$ & $\begin{array}{l}-0.27 * * * \\
(0.030)\end{array}$ & $\begin{array}{c}-0.36 * * * \\
(0.057)\end{array}$ & $\begin{array}{c}-0.33^{* * * *} \\
(0.056)\end{array}$ \\
\hline High Rating & & & & & & $\begin{array}{c}-0.0068 \\
(0.059)\end{array}$ \\
\hline $\ln (\mathrm{AUM})$ & & & & & & $\begin{array}{l}0.033^{* *} \\
(0.016)\end{array}$ \\
\hline $\ln$ (Production) & & & & & & $\begin{array}{l}0.18^{* * * *} \\
(0.022)\end{array}$ \\
\hline Other Adviser Controls & & $\mathrm{X}$ & $\mathrm{X}$ & $\mathrm{X}$ & $\mathrm{X}$ & $\mathrm{X}$ \\
\hline Year $\times$ Firm $\times$ County F.E. & & & $\mathrm{X}$ & & $\mathrm{X}$ & $\mathrm{X}$ \\
\hline Year $\times$ Firm $\times$ County $\times$ License F.E. & & & & $\mathrm{X}$ & & \\
\hline Meridian IQ Sample & & & & & $\mathrm{X}$ & $\mathrm{X}$ \\
\hline Observations & $6,547,974$ & $6,547,974$ & $6,221,173$ & $4,465,068$ & 487,159 & 487,159 \\
\hline R-squared & 0.001 & 0.002 & 0.098 & 0.206 & 0.181 & 0.181 \\
\hline Mean of Dependent Variable & $0.61 \%$ & $0.61 \%$ & $0.61 \%$ & $0.51 \%$ & $1.05 \%$ & $1.05 \%$ \\
\hline
\end{tabular}

(b) Settlements/Damages Granted by Gender

\begin{tabular}{lccc}
\hline & $(1)$ & $(2)$ & $(3)$ \\
\hline Female & $-0.20^{* * *}$ & $-0.11^{* *}$ & $-0.14^{* * *}$ \\
& $(0.052)$ & $(0.047)$ & $(0.038)$ \\
& & & \\
Other Adviser Controls & & $\mathrm{X}$ & $\mathrm{X}$ \\
Year F.E. & & & $\mathrm{X}$ \\
County F.E. & & & $\mathrm{X}$ \\
Firm F.E. & & & $\mathrm{X}$ \\
Observations & 21,537 & 21,537 & 20,485 \\
R-squared & 0.001 & 0.041 & 0.249 \\
\hline
\end{tabular}

Table 2a displays the regression results for a linear probability model (eq. 1). Observations are at the adviser-by-year-level over the period 2005-2015. The dependent variable is a dummy variable indicating whether the adviser received a misconduct disclosure year $t$. Coefficients are in percentage points (pp). In columns (5) and (6) we restrict our analysis to advisers in the Meridian IQ sample-advisers active in 2016. Meridian IQ data contain quality rating (generated by Meridian IQ), assets under management (AUM), and production (revenue) as of 2016. Other Adviser Controls include the adviser's experience and dummy variables for the licenses the adviser holds (Series 6, 7, 24, etc.). In our most stringent specification, we include Year $\times$ Firm $\times$ County $\times$ License F.E: a fixed effect for each set of possible licenses an adviser potentially holds within a firm, location, and time. Standard errors are in parentheses and are clustered by firm. *** $\mathrm{p}<0.01, * * \mathrm{p}<0.05, * \mathrm{p}<0.10$.

Table $2 \mathrm{~b}$ displays the results for linear regression model (eq. 2). Observations are at the financial adviser-byyear-level over the period 2005-2015. We restrict the data set to observations in which the adviser received a misconduct disclosure and paid out a settlement or damages. The dependent variable is the log settlements paid out on behalf of a financial adviser as the result of a misconduct settlement or arbitration. Other adviser controls include the adviser's experience and dummy variables for the licenses that the adviser holds (Series $6,7,24$, etc.). Standard errors are in parentheses and are clustered by firm. ${ }^{* * *} \mathrm{p}<0.01, * * \mathrm{p}<0.05$, * $\mathrm{p}<0.10$. 
Table 3: Gender Punishment Gap - Labor Market Outcomes Following Misconduct

\begin{tabular}{lcccc}
\hline & \multicolumn{2}{c}{ No Misconduct } & \multicolumn{2}{c}{ Misconduct } \\
& Male & Female & Male & Female \\
\hline Remain with the Firm & $81 \%$ & $81 \%$ & $54 \%$ & $45 \%$ \\
Leave the Firm & $19 \%$ & $19 \%$ & $46 \%$ & $55 \%$ \\
Leave the Industry & $46 \%$ & $52 \%$ & $53 \%$ & $67 \%$ \\
Join a Different Firm & $54 \%$ & $48 \%$ & $47 \%$ & $33 \%$ \\
\hline
\end{tabular}

Table 3 displays the average annual job turnover among financial advisers. Observations are at the adviserby-year level. Since we track employment turnover in the subsequent year, the sample in this table covers the period 2005-2014 rather than 2005-2015. Leave the Industry is defined as an adviser not being employed as a financial adviser for at least one year; Join a Different Firm is a dummy variable that takes the value of one if the adviser is employed at a different financial advisory firm within a year. The job transitions are broken down by whether the adviser received a misconduct disclosure in the previous year. 
Table 4: Gender Punishment Gap - Employment Separations

\begin{tabular}{|c|c|c|c|c|c|c|c|c|}
\hline \multirow{2}{*}{ Misconduct } & (1) & (2) & (3) & (4) & (5) & (6) & (7) & (8) \\
\hline & $\begin{array}{c}27.6^{* * * *} \\
(1.47)\end{array}$ & $\begin{array}{c}29.0^{* * * *} \\
(1.37)\end{array}$ & $\begin{array}{c}22.3^{* * * *} \\
(1.52)\end{array}$ & $\begin{array}{c}25.7^{* \cdots *} \\
(2.22)\end{array}$ & $\begin{array}{c}34.3^{* * * *} \\
(3.23)\end{array}$ & $\begin{array}{c}8.81^{* * * *} \\
(0.89)\end{array}$ & $\begin{array}{c}8.93^{* * * *} \\
(0.88)\end{array}$ & $\begin{array}{c}28.2^{* * * *} \\
(10.5)\end{array}$ \\
\hline Misconduct $\times$ Female & $\begin{array}{l}8.32^{* * * *} \\
(2.05)\end{array}$ & $\begin{array}{l}8.07 * \cdots * * \\
(1.93)\end{array}$ & $\begin{array}{c}10.2^{* * * *} \\
(1.90)\end{array}$ & $\begin{array}{c}9.99^{* * * *} \\
(1.91)\end{array}$ & $\begin{array}{c}7.50^{* * * *} \\
(1.55)\end{array}$ & $\begin{array}{l}4.26 * * * * \\
(1.58)\end{array}$ & $\begin{array}{c}4.36 * * * \\
(1.58)\end{array}$ & $\begin{array}{c}4.44 * * * \\
(1.62)\end{array}$ \\
\hline Female & $\begin{array}{c}0.14 \\
(0.29)\end{array}$ & $\begin{array}{l}-0.54 \\
(0.34)\end{array}$ & $\begin{array}{l}-0.54^{* * *} \\
(0.15)\end{array}$ & $\begin{array}{c}-0.50 * * * * \\
(0.16)\end{array}$ & $\begin{array}{l}-0.50 * \cdots * \\
(0.15)\end{array}$ & $\begin{array}{c}-0.38 * * * \\
(0.10)\end{array}$ & $\begin{array}{l}-0.65^{* * * *} \\
(0.11)\end{array}$ & $\begin{array}{c}-0.65^{* \cdots * *} \\
(0.11)\end{array}$ \\
\hline $\begin{array}{l}\text { Allegations: } \\
\text { Unauthorized Activity }\end{array}$ & & & & & $\begin{array}{l}7.12^{* * * *} \\
(1.34)\end{array}$ & & & \\
\hline Omission of Key Facts & & & & & $\begin{array}{c}6.75^{* \cdots * *} \\
(1.76)\end{array}$ & & & \\
\hline Fee/Commission Related & & & & & $\begin{array}{c}-4.97 * * * \\
(1.45)\end{array}$ & & & \\
\hline Unsuitable & & & & & $\begin{array}{c}-18.1^{* * *} \\
(1.95)\end{array}$ & & & \\
\hline Misrepresentation & & & & & $\begin{array}{c}-14.8^{* * *} \\
(1.95)\end{array}$ & & & \\
\hline Fraud & & & & & $\begin{array}{l}8.35^{* \cdots *} \\
(2.07)\end{array}$ & & & \\
\hline \multicolumn{9}{|l|}{ Productivity: } \\
\hline High Rating & & & & & & & $\begin{array}{l}-4.05^{* * * * *} \\
(0.64)\end{array}$ & $\begin{array}{l}-3.91^{* * * *} \\
(0.64)\end{array}$ \\
\hline $\ln (\mathrm{AUM})$ & & & & & & & $\begin{array}{l}-0.43^{* * * * *} \\
(0.073)\end{array}$ & $\begin{array}{c}-0.43^{* \cdots * *} \\
(0.073)\end{array}$ \\
\hline $\ln$ (Production) & & & & & & & $\begin{array}{l}-0.24 * * * * \\
(0.072)\end{array}$ & $\begin{array}{l}-0.24 * * * * \\
(0.072)\end{array}$ \\
\hline High Rating $\times$ Misconduct & & & & & & & & $\begin{array}{c}-12.5^{* * * *} \\
(1.89)\end{array}$ \\
\hline $\ln (\mathrm{AUM}) \times$ Misconduct & & & & & & & & $\begin{array}{l}-0.77^{*} \\
(0.44)\end{array}$ \\
\hline $\ln$ (Production) $\times$ Misconduct & & & & & & & & $\begin{array}{c}0.34 \\
(0.60)\end{array}$ \\
\hline Other Adviser Controls & & $\mathrm{X}$ & $\mathrm{X}$ & $\mathrm{X}$ & $\mathrm{X}$ & $\mathrm{X}$ & $\mathrm{X}$ & $\mathrm{X}$ \\
\hline Allegation and Product Controls & & & & & $\mathrm{X}$ & & & \\
\hline Sample with Productivity Data & & & & & & $\mathrm{X}$ & $\mathrm{X}$ & $\mathrm{X}$ \\
\hline Year $\times$ Firm $\times$ County F.E. & & & $\mathrm{X}$ & & & $\mathrm{X}$ & $\mathrm{X}$ & $\mathrm{X}$ \\
\hline $\begin{array}{l}\text { Year } \times \text { Firm } \times \text { County } \times \text { License F.E. } \\
\text { Observations }\end{array}$ & 6002088 & 6002088 & 5.698 .577 & $\begin{array}{c}X \\
4093438\end{array}$ & $\begin{array}{c}X \\
4.093438\end{array}$ & 442.159 & 442,159 & 442159 \\
\hline $\begin{array}{l}\text { Observations } \\
\text { R-squared }\end{array}$ & 0.004 & 0.014 & 0.332 & 0.403 & 0.403 & 0.624 & 0.627 & 0.627 \\
\hline Mean of Dependent Variable & $19 \%$ & $19 \%$ & $19 \%$ & $19 \%$ & $19 \%$ & $10 \%$ & $10 \%$ & $10 \%$ \\
\hline
\end{tabular}

Table 4 displays the regression results corresponding to a linear probability model (eq. 3). Observations are at the adviser-by-year-level. Since we track employment turnover in the subsequent year, the sample in this table covers the period 2005-2014 rather than 2005-2015. The dependent variable is a dummy variable indicating whether a financial adviser left the firm in the following year and is scaled by 100 such that coefficients are in percentage points. Misconduct is a dummy variable indicating whether the adviser received a misconduct disclosure in a given year. The variable Female indicates the gender of the adviser. In Column (5) we include dummy variables to control for the type of misconduct corresponding to the most common allegations and products reported in Table 1. We report the coefficients for the six most common allegations. Other Adviser Controls include the adviser's experience and dummy variables for the licenses that the adviser holds (Series 6, 7, 24, etc.). In column (5) we also include Year $\times$ Firm $\times$ County $\times$ License F.E: fully saturated fixed effects for each set of possible licenses an adviser could hold within a given firm, location, and time. In columns (6)-(8) we restrict our analysis to those advisers for which we observe productivity data. The productivity data is as of 2016. High Rating is a dummy variable equal to one if the adviser has a high quality rating from Meridian IQ; $\ln (\mathrm{AUM})$ measures the adviser's assets under management; ln(Production) measures the adviser's production (revenue). Standard errors are in parentheses and are clustered by firm. $* * * \mathrm{p}<0.01, * * \mathrm{p}<0.05, * \mathrm{p}<0.10$ 
Table 5: Employment Separations and Productivity (Alternative Sample)

\begin{tabular}{|c|c|c|c|c|c|c|c|c|}
\hline & $(1)$ & $(2)$ & (3) & (4) & (5) & $(6)$ & (7) & $(8)$ \\
\hline Misconduct & $\begin{array}{c}30.18 * * * \\
(2.311)\end{array}$ & $\begin{array}{c}30.51 * * * \\
(2.289)\end{array}$ & $\begin{array}{c}23.28 * * * \\
(1.589)\end{array}$ & $\begin{array}{c}23.34 * * * \\
(1.584)\end{array}$ & $\begin{array}{c}21.79 * * * \\
(1.851)\end{array}$ & $\begin{array}{c}21.83 * * * \\
(1.848)\end{array}$ & $\begin{array}{c}21.75^{* * * *} \\
(1.809)\end{array}$ & $\begin{array}{c}21.99 * * * \\
(1.792)\end{array}$ \\
\hline Misconduct $\times$ Female & $\begin{array}{c}9.953 * * * \\
(3.220)\end{array}$ & $\begin{array}{c}9.829 * * * \\
(3.207)\end{array}$ & $\begin{array}{c}7.716 \\
(5.426)\end{array}$ & $\begin{array}{c}7.769 \\
(5.435)\end{array}$ & $\begin{array}{c}6.125 \\
(5.780)\end{array}$ & $\begin{array}{c}6.159 \\
(5.786)\end{array}$ & $\begin{array}{c}3.392 \\
(5.751)\end{array}$ & $\begin{array}{c}4.006 \\
(5.660)\end{array}$ \\
\hline Female & $\begin{array}{c}-0.751^{* * * *} \\
(0.209)\end{array}$ & $\begin{array}{c}-0.904 * * * \\
(0.204)\end{array}$ & $\begin{array}{c}0.237 \\
(0.238)\end{array}$ & $\begin{array}{c}0.193 \\
(0.238)\end{array}$ & $\begin{array}{l}0.0721 \\
(0.281)\end{array}$ & $\begin{array}{l}0.0185 \\
(0.284)\end{array}$ & $\begin{array}{l}0.0264 \\
(0.293)\end{array}$ & $\begin{array}{c}-0.168 \\
(0.287)\end{array}$ \\
\hline High Rating & & $\begin{array}{c}-4.411 * * * \\
(0.365)\end{array}$ & & & & & & $\begin{array}{c}-3.557 * * * \\
(0.373)\end{array}$ \\
\hline $\ln (\mathrm{AUM})$ & & & & $\begin{array}{c}-0.441 * * * \\
(0.0605)\end{array}$ & & & & $\begin{array}{c}-0.291 * * * \\
(0.0953)\end{array}$ \\
\hline $\ln$ (Production) & & & & & & $\begin{array}{c}-0.341 * * * \\
(0.0942)\end{array}$ & & $\begin{array}{c}-0.152 \\
(0.0960)\end{array}$ \\
\hline Adviser Controls & $\mathrm{X}$ & $\mathrm{X}$ & $\mathrm{X}$ & $\mathrm{X}$ & $\mathrm{X}$ & $\mathrm{X}$ & $\mathrm{X}$ & $\mathrm{X}$ \\
\hline Firm F.E. & $\mathrm{X}$ & $\mathrm{X}$ & $\mathrm{X}$ & $\mathrm{X}$ & $\mathrm{X}$ & $\mathrm{X}$ & $\mathrm{X}$ & $\mathrm{X}$ \\
\hline County F.E. & $\mathrm{X}$ & $\mathrm{X}$ & $\mathrm{X}$ & $\mathrm{X}$ & $\mathrm{X}$ & $\mathrm{X}$ & $\mathrm{X}$ & $\mathrm{X}$ \\
\hline Observations & 395,362 & 395,362 & 123,901 & 123,901 & 67,807 & 67,807 & 62,525 & 62,525 \\
\hline R-squared & 0.153 & 0.156 & 0.236 & 0.236 & 0.241 & 0.241 & 0.242 & 0.245 \\
\hline Mean of Dependent Variable & $12 \%$ & $12 \%$ & $9 \%$ & $9 \%$ & $8 \%$ & $8 \%$ & $8 \%$ & $8 \%$ \\
\hline
\end{tabular}

Table 5 displays the regression results corresponding to a linear probability model (eq. 3). Observations are at the financial adviser level. The dependent variable is a dummy variable indicating whether a financial adviser left the firm in 2017 and is scaled by 100 such that coefficients are in percentage points. Misconduct is a dummy variable indicating whether a financial adviser received a misconduct disclosure in the given year. We control for three different dimensions of productivity in 2016 from Meridian IQ: High Rating is a dummy variable equal to one if the adviser has a high quality rating from Meridian IQ; $\ln (A U M)$ measures the adviser's assets under management; $\ln$ (Production) measures the adviser's production (revenue). We include productivity measures in the even numbered columns $(2,4,6,8)$. In the corresponding odd numbered columns $(1,3,5$, and 7$)$ we estimate our baseline specification where we excluding productivity measures but keep the sample from adjacent columns. Other adviser controls include the adviser's experience and licenses (series 6, 7, 63, 24, etc.). Standard errors are in parentheses and are clustered by firm. ${ }^{* * *} \mathrm{p}<0.01$, $* * \mathrm{p}<0.05, * \mathrm{p}<0.10$. 
Table 6: Industry Level Gender Punishment Gap: New Employment

\begin{tabular}{|c|c|c|c|c|c|}
\hline & (1) & (2) & (3) & (4) & (5) \\
\hline Misconduct & $\begin{array}{c}-7.66 * * * \\
(2.13)\end{array}$ & $\begin{array}{c}-12.2^{* * *} \\
(1.41)\end{array}$ & $\begin{array}{c}-9.15 * * * \\
(1.09)\end{array}$ & $\begin{array}{c}-8.94 * * * \\
(1.46)\end{array}$ & $\begin{array}{c}-10.8 * * * \\
(1.93)\end{array}$ \\
\hline Misconduct $\times$ Female & $\begin{array}{c}-7.22 * * * \\
(1.80)\end{array}$ & $\begin{array}{c}-5.40 * * * \\
(1.31)\end{array}$ & $\begin{array}{c}-3.44 * * * \\
(1.22)\end{array}$ & $\begin{array}{c}-3.54 * * * \\
(1.27)\end{array}$ & $\begin{array}{c}-2.48 * * \\
(1.24)\end{array}$ \\
\hline Female & $\begin{array}{c}-6.22 * * * \\
(0.65)\end{array}$ & $\begin{array}{c}-2.42^{* * *} \\
(0.61)\end{array}$ & $\begin{array}{c}-4.04^{* * * *} \\
(0.26)\end{array}$ & $\begin{array}{c}-3.83^{* * *} \\
(0.29)\end{array}$ & $\begin{array}{c}-3.83 * * * \\
(0.29)\end{array}$ \\
\hline \multicolumn{6}{|l|}{ Allegations: } \\
\hline Unauthorized Activity & & & & & $\begin{array}{l}-3.12 \\
(1.97)\end{array}$ \\
\hline Omission of Key Facts & & & & & $\begin{array}{c}-5.00 * * * \\
(2.28)\end{array}$ \\
\hline Fee/Commission Related & & & & & $\begin{array}{c}2.80 \\
(2.34)\end{array}$ \\
\hline Unsuitable & & & & & $\begin{array}{c}8.86 * * * \\
(1.68)\end{array}$ \\
\hline Misrepresentation & & & & & $\begin{array}{l}4.66^{* *} \\
(2.06)\end{array}$ \\
\hline Fraud & & & & & $\begin{array}{c}-14.2 * * * \\
(3.27)\end{array}$ \\
\hline Adviser Controls & & $\mathrm{X}$ & $\mathrm{X}$ & $\mathrm{X}$ & $\mathrm{X}$ \\
\hline Year $\times$ Firm $\times$ County F.E. & & & $\mathrm{X}$ & & \\
\hline Year $\times$ Firm $\times$ County $\times$ License F.E. & & & & $\mathrm{X}$ & $\mathrm{X}$ \\
\hline Allegation and Product Controls & & & & & $\mathrm{X}$ \\
\hline Observations & $1,125,715$ & $1,125,715$ & $1,006,760$ & 660,127 & 660,127 \\
\hline R-squared & 0.003 & 0.101 & 0.365 & 0.464 & 0.465 \\
\hline Mean of Dependent Variable & $53 \%$ & $53 \%$ & $54 \%$ & $51 \%$ & $51 \%$ \\
\hline
\end{tabular}

Table 6 displays the regression results corresponding to a linear probability model (eq. 4). Observations are at the adviser-by-year-level over the period 2005-2014 where we restrict the sample to advisers who left their firms in a given year. Since we track advisers who left their firm in the subsequent year, the sample in this table covers the period 2005-2014 rather than 2005-2015. The dependent variable is a dummy variable indicating whether or not a financial adviser joined a new firm within one year and is scaled by 100 such that the coefficients are in percentage points. Misconduct is a dummy variable indicating whether the adviser received a misconduct disclosure in a given year. The variable Female indicates the gender of the adviser. In Column (5) we also include dummy variables to control for the type of misconduct in terms of the most common allegations and products reported in Table 1. We report the coefficients for the six most common allegations. Other Adviser Controls include the adviser's experience and dummy variables for the licenses the adviser holds (Series 6, 7, 24, etc.). In our most stringent specifications, we include Year $\times$ Firm $\times$ County $\times$ License F.E: fully saturated fixed effects for each set of possible licenses an adviser potentially holds within a firm, location, and time. Standard errors are in parentheses and are clustered by firm. $* * * \mathrm{p}<0.01, * * \mathrm{p}<0.05, * \mathrm{p}<0.10$. 
Table 7: Female Managers and the Gender Punishment Gap

(a) Gender Composition of Management, Firm Separation and Punishment Gap

\begin{tabular}{|c|c|c|c|c|c|c|c|c|}
\hline & $(1)$ & $(2)$ & (3) & (4) & (5) & (6) & $(7)$ & $(8)$ \\
\hline Misc. & $\begin{array}{c}26.8^{* * * *} \\
(1.20)\end{array}$ & $\begin{array}{c}20.1^{* * * *} \\
(1.35)\end{array}$ & $\begin{array}{c}22.9^{* * * *} \\
(2.06)\end{array}$ & $\begin{array}{c}32.3^{* * * *} \\
(3.09)\end{array}$ & $\begin{array}{c}54.1^{\cdots \cdots *} \\
(4.40)\end{array}$ & $\begin{array}{c}51.4 * * * \\
(5.30)\end{array}$ & $\begin{array}{c}57.8^{* * * *} \\
(5.97)\end{array}$ & $\begin{array}{c}62.1^{* * * *} \\
(5.22)\end{array}$ \\
\hline Misc. $\times$ Female & $\begin{array}{c}10.4 * * * * \\
(2.53)\end{array}$ & $\begin{array}{l}13.4 * * * * \\
(2.29)\end{array}$ & $\begin{array}{c}11.6^{* * * *} \\
(2.23)\end{array}$ & $\begin{array}{l}8.99 * * * * \\
(1.88)\end{array}$ & $\begin{array}{l}14.0 * \cdots * \\
(2.97)\end{array}$ & $\begin{array}{c}16.5^{* * * *} \\
(3.53)\end{array}$ & $\begin{array}{c}13.0^{* * * *} \\
(3.81)\end{array}$ & $\begin{array}{c}10.3^{* * * *} \\
(3.39)\end{array}$ \\
\hline Misc. $\times$ Pct Female Mgmt & $\begin{array}{l}10.3^{* * * *} \\
(2.20)\end{array}$ & $\begin{array}{l}11.6^{* * * *} \\
(2.12)\end{array}$ & $\begin{array}{c}13.6^{* * * *} \\
(3.09)\end{array}$ & $\begin{array}{l}11.2^{* * * *} \\
(2.96)\end{array}$ & & & & \\
\hline Misc. $\times$ Female $\times$ Pct Female Mgmt & $\begin{array}{l}-12.8^{* * * *} \\
(4.28)\end{array}$ & $\begin{array}{l}-18.5^{* * * *} \\
(3.36)\end{array}$ & $\begin{array}{l}-10.5^{* *} \\
(4.18)\end{array}$ & $\begin{array}{l}-9.17^{* *} \\
(3.90)\end{array}$ & & & & \\
\hline Misc. $\times$ Pct Female Exec & & & & & $\begin{array}{l}-23.5^{*} \\
(14.2)\end{array}$ & $\begin{array}{c}-25.4 \\
(16.8)\end{array}$ & $\begin{array}{l}-32.1^{*} \\
(18.7)\end{array}$ & $\begin{array}{l}-17.5 \\
(15.7)\end{array}$ \\
\hline Misc. $\times$ Female $\times$ Pct Female Exec & & & & & $\begin{array}{l}-41.4 * * * * \\
(14.2)\end{array}$ & $\begin{array}{l}-44.4 * * * \\
(16.2)\end{array}$ & $\begin{array}{l}-39.1^{*} \\
(20.7)\end{array}$ & $\begin{array}{l}-34.6^{*} \\
(20.3)\end{array}$ \\
\hline $\begin{array}{l}\text { Adviser Controls } \\
\text { Year } \times \text { Firm } \times \text { County F.E. }\end{array}$ & $\mathrm{X}$ & $\begin{array}{l}X \\
X\end{array}$ & $\mathrm{X}$ & $\mathrm{X}$ & $\mathrm{X}$ & $\begin{array}{l}\mathrm{X} \\
\mathrm{X}\end{array}$ & $\mathrm{X}$ & $\mathrm{X}$ \\
\hline $\begin{array}{l}\text { Year } \times \text { Firm } \times \text { County } \times \text { License F.E. } \\
\text { Allegation and Product Controls }\end{array}$ & & & $\mathrm{X}$ & $\begin{array}{l}X \\
X\end{array}$ & & & $\mathrm{X}$ & $\begin{array}{l}X \\
X\end{array}$ \\
\hline Observations & $4,839,243$ & $4,722,832$ & $3,480,225$ & $3,480,225$ & 564,905 & 541,137 & 389,112 & 389,112 \\
\hline R-squared & 0.014 & 0.315 & 0.393 & 0.394 & 0.021 & 0.145 & 0.238 & 0.239 \\
\hline Mean of Dependent Variable & $20 \%$ & $20 \%$ & $20 \%$ & $20 \%$ & $13 \%$ & $13 \%$ & $13 \%$ & $13 \%$ \\
\hline
\end{tabular}

(b) Gender Composition of Management, Firm Separation and Punishment Gap

\begin{tabular}{|c|c|c|c|c|c|c|c|c|}
\hline & (1) & (2) & (3) & (4) & (5) & (6) & (7) & (8) \\
\hline Misc & $\begin{array}{c}32.9 * * * * \\
(2.13)\end{array}$ & $\begin{array}{c}25.7 * * * * * \\
(2.40)\end{array}$ & $\begin{array}{c}28.8^{* * * *} \\
(3.20)\end{array}$ & $\begin{array}{c}35.9 * * * * \\
(3.92)\end{array}$ & $\begin{array}{c}30.3^{* * * *} \\
(1.92)\end{array}$ & $\begin{array}{c}23.0^{* * * *} \\
(2.22)\end{array}$ & $\begin{array}{c}25.5^{* * * *} \\
(3.00)\end{array}$ & $\begin{array}{c}33.3^{* * * *} \\
(3.75)\end{array}$ \\
\hline Misc. $\times$ Female & $\begin{array}{l}9.62^{* * * *} \\
(2.54)\end{array}$ & $\begin{array}{l}11.4^{* * * *} \\
(2.40)\end{array}$ & $\begin{array}{l}10.7 * * * * \\
(2.27)\end{array}$ & $\begin{array}{l}8.07 * * * * \\
(1.90)\end{array}$ & $\begin{array}{l}10.9 * * * \\
(3.35)\end{array}$ & $\begin{array}{l}14.4^{* * * * *} \\
(2.99)\end{array}$ & $\begin{array}{l}12.6 * * * * \\
(2.77)\end{array}$ & $\begin{array}{l}9.67 * * * * \\
(2.39)\end{array}$ \\
\hline Misc. $\times$ Pct Jr Female & $\begin{array}{c}-0.53^{* \cdots *} \\
(0.15)\end{array}$ & $\begin{array}{l}-0.41^{* *} \\
(0.16)\end{array}$ & $\begin{array}{l}-0.49 * * \\
(0.23)\end{array}$ & $\begin{array}{l}-0.24 \\
(0.18)\end{array}$ & $\begin{array}{l}-0.44 * * * \\
(0.14)\end{array}$ & $\begin{array}{l}-0.36^{* * *} \\
(0.15)\end{array}$ & $\begin{array}{l}-0.38 * \\
(0.21)\end{array}$ & $\begin{array}{l}-0.16 \\
(0.16)\end{array}$ \\
\hline Misc. $\times$ Female $\times$ Pct Jr Female & $\begin{array}{l}-0.20 \\
(0.25)\end{array}$ & $\begin{array}{l}-0.18 \\
(0.22)\end{array}$ & $\begin{array}{l}-0.14 \\
(0.22)\end{array}$ & $\begin{array}{l}-0.11 \\
(0.19)\end{array}$ & $\begin{array}{l}-0.16 \\
(0.26)\end{array}$ & $\begin{array}{l}-0.19 \\
(0.23)\end{array}$ & $\begin{array}{l}-0.16 \\
(0.22)\end{array}$ & $\begin{array}{l}-0.12 \\
(0.20)\end{array}$ \\
\hline Misc. $\times$ Pct Female Mgmt & & & & & $\begin{array}{c}10.3^{* * * *} \\
(2.27)\end{array}$ & $\begin{array}{l}11.6^{* * * *} \\
(2.24)\end{array}$ & $\begin{array}{c}13.1^{* \cdots *} \\
(3.04)\end{array}$ & $\begin{array}{c}11.3^{* * * *} \\
(3.05)\end{array}$ \\
\hline Misc. $\times$ Female $\times$ Pct Female Mgmt & & & & & $\begin{array}{l}-12.0 * * \\
(4.90)\end{array}$ & $\begin{array}{c}-17.6 * * * \\
(3.91)\end{array}$ & $\begin{array}{l}-10.9 * * \\
(4.38)\end{array}$ & $\begin{array}{l}-8.88^{* *} \\
(4.12)\end{array}$ \\
\hline Adviser Controls & $\mathrm{X}$ & $\mathrm{X}$ & $\mathrm{X}$ & $\mathrm{X}$ & $\mathrm{X}$ & $\mathrm{X}$ & $\mathrm{X}$ & $\mathrm{X}$ \\
\hline Year $\times$ Firm $\times$ County F.E. & & $\mathrm{X}$ & & & & $\mathrm{X}$ & & \\
\hline Year $\times$ Firm $\times$ County $\times$ License F.E. & & & $\mathrm{X}$ & $\mathrm{X}$ & & & $\mathrm{X}$ & $\mathrm{X}$ \\
\hline Allegation and Product Controls & & & & $\mathrm{X}$ & & & & $\mathrm{X}$ \\
\hline Observations & $5,014,469$ & $4,920,802$ & $3,827,301$ & $3,827,301$ & $4,325,065$ & $4,252,465$ & $3,338,750$ & $3,338,750$ \\
\hline R-squared & 0.014 & 0.305 & 0.390 & 0.390 & 0.014 & 0.296 & 0.385 & 0.386 \\
\hline Mean of Dependent Variable & $19 \%$ & $19 \%$ & $20 \%$ & $20 \%$ & $20 \%$ & $20 \%$ & $20 \%$ & $20 \%$ \\
\hline
\end{tabular}

Table 7 panels (a) and (b) present regression results corresponding to two linear probability models (eq. 6 and 7 respectively). Observations in columns (1)-(4) of panel (a) and (1)-(8) of panel (b) are at the adviser-by-year level over the period 2005-2014. Because we track individuals that left their firm in this analysis, our sample is from the period 2005-2014 rather than 2005-2015. Observations columns (5)-(8) of panel (a) are at the adviser level as of 2014. We restrict the sample to 2014 becasue we only observe the gender composition of executives (Pct Female Exec) as of 2015. The dependent variable in each specification is a dummy variable indicating whether a financial adviser left the firm in the following year and is scaled by 100 such that coefficients are in percentage points. Misconduct is a dummy variable indicating whether a financial adviser received a misconduct disclosure in the given year. Pct Female Mgmt measures the percentage of managers working for a firm in a given county and year that are female. Pct Female Exec measures the share of executives/owners that are female as of 2015. Pct Jr Female measures the share of junior employees, defined as with less than 3 years' experience, working for a firm in a given county and year that are female. In each specification we also control for the full set of interactions terms between Female, Misconduct, and our gender composition variables. For example, in column (1) of panel (a) we also control for Pct Female Mgmt and Pct Female Mgmt $\times$ Female. Other adviser controls include the adviser's experience and licenses (series $6,7,63,24$, etc.). In our most stringent specifications, we include Year $\times$ Firm $\times$ County $\times$ License F.E: fully saturated fixed effects for each set of possible licenses an adviser potentially holds within a firm, location, and time. In columns (4) and (8) of panels (a) and (b) we include dummy variables to control for the type of misconduct corresponding to the most common allegations and products reported in Table 1 . Standard errors are in parentheses and are clustered by firm. ${ }^{* * *} \mathrm{p}<0.01,{ }^{* *} \mathrm{p}<0.05,{ }^{*} \mathrm{p}<0.10$. 
Table 8: Sexual Harassment and the Gender Punishment Gap

\begin{tabular}{|c|c|c|c|c|c|c|c|c|}
\hline & (1) & (2) & (3) & (4) & (5) & (6) & (7) & $(8)$ \\
\hline Misc. & $\begin{array}{c}28.8^{* * * *} \\
(0.90)\end{array}$ & $\begin{array}{c}21.1 * * * \\
(0.95)\end{array}$ & $\begin{array}{c}23.8 * * * \\
(1.19)\end{array}$ & $\begin{array}{c}32.2 * * * \\
(1.90)\end{array}$ & $\begin{array}{c}29.0 * * * \\
(0.90)\end{array}$ & $\begin{array}{c}19.8 * * * \\
(1.04)\end{array}$ & $\begin{array}{c}22.7 * * * \\
(1.52)\end{array}$ & $\begin{array}{c}30.4^{* * * *} \\
(2.06)\end{array}$ \\
\hline Misc. $\times$ Female & $\begin{array}{c}4.10 * * * \\
(1.41)\end{array}$ & $\begin{array}{c}6.43 * * * \\
(1.30)\end{array}$ & $\begin{array}{c}6.11 * * * \\
(1.71)\end{array}$ & $\begin{array}{c}4.64 * * * \\
(1.72)\end{array}$ & $\begin{array}{l}3.31^{*} \\
(1.88)\end{array}$ & $\begin{array}{c}6.53 * * * \\
(1.75)\end{array}$ & $\begin{array}{c}7.30 * * * \\
(2.78)\end{array}$ & $\begin{array}{l}5.74^{*} \\
(2.97)\end{array}$ \\
\hline Misc. $\times$ Harassment & $\begin{array}{c}0.72 \\
(3.90)\end{array}$ & $\begin{array}{c}3.60 \\
(4.01)\end{array}$ & $\begin{array}{c}4.57 \\
(5.11)\end{array}$ & $\begin{array}{c}4.78 \\
(4.25)\end{array}$ & $\begin{array}{c}1.07 \\
(4.36)\end{array}$ & $\begin{array}{c}0.87 \\
(4.30)\end{array}$ & $\begin{array}{c}2.75 \\
(5.30)\end{array}$ & $\begin{array}{c}2.14 \\
(4.37)\end{array}$ \\
\hline Misc. $\times$ Female $\times$ Harassment & $\begin{array}{c}9.72^{* * *} \\
(3.18)\end{array}$ & $\begin{array}{c}8.01 * * * \\
(2.87)\end{array}$ & $\begin{array}{c}7.35 * * * \\
(2.62)\end{array}$ & $\begin{array}{l}5.25^{* * *} \\
(2.62)\end{array}$ & $\begin{array}{l}8.41 * * \\
(3.45)\end{array}$ & $\begin{array}{c}8.96 * * * \\
(3.13)\end{array}$ & $\begin{array}{c}9.12 * * * \\
(2.66)\end{array}$ & $\begin{array}{c}7.11 * * * \\
(2.49)\end{array}$ \\
\hline Misc. $\times$ Discrimination & & & & & $\begin{array}{l}-0.52 \\
(2.32)\end{array}$ & $\begin{array}{l}4.08 * \\
(2.10)\end{array}$ & $\begin{array}{c}3.00 \\
(2.41)\end{array}$ & $\begin{array}{l}4.36 * * \\
(2.17)\end{array}$ \\
\hline Misc. $\times$ Female $\times$ Discrimination & & & & & $\begin{array}{c}2.09 \\
(2.70)\end{array}$ & $\begin{array}{l}-1.06 \\
(2.51)\end{array}$ & $\begin{array}{l}-2.96 \\
(3.29)\end{array}$ & $\begin{array}{l}-2.96 \\
(3.36)\end{array}$ \\
\hline Adviser Controls & $\mathrm{X}$ & $\mathrm{X}$ & $\mathrm{X}$ & $\mathrm{X}$ & $\mathrm{X}$ & $\mathrm{X}$ & $\mathrm{X}$ & $\mathrm{X}$ \\
\hline Year $\times$ Firm $\times$ County F.E. & & $\mathrm{X}$ & & & & $\mathrm{X}$ & & \\
\hline Year $\times$ Firm $\times$ County $\times$ License F.E & & & $\mathrm{X}$ & $\mathrm{X}$ & & & X & $\mathrm{X}$ \\
\hline Allegation and Product Controls & & & & $\mathrm{X}$ & & & & $\mathrm{X}$ \\
\hline Observations & $6,002,088$ & $5,698,577$ & $4,093,438$ & $4,093,438$ & $6,002,088$ & $5,698,577$ & $4,093,438$ & $4,093,438$ \\
\hline R-squared & 0.014 & 0.332 & 0.403 & 0.403 & 0.014 & 0.332 & 0.403 & 0.403 \\
\hline Mean of Dependent Variable & $19 \%$ & $19 \%$ & $19 \%$ & $19 \%$ & $19 \%$ & $19 \%$ & $19 \%$ & $19 \%$ \\
\hline
\end{tabular}

Table 8 presents regression results corresponding to a linear probability model (eq. 8). Observations are at the financial adviser-by-year level over the period 2005-2014. Since we track advisers who left their firm in the subsequent year, the sample in this table covers the period 2005-2014 rather than 2005-2015. The dependent variable is a dummy variable indicating whether a financial adviser left the firm in the following year and is scaled by 100 such that coefficients are in percentage points. Misconduct is a dummy variable indicating whether a financial adviser received a misconduct disclosure in the given year. Harassment is a dummy variable indicating whether the firm has ever had a sexual harassment claim resolved through FINRA arbitration. Discrimination is a dummy variable indicating whether the firm has ever had a discrimination claim resolved through FINRA arbitration. In columns (1)-(8) we also control for the full set of Harassment, Female, and Misconduct interaction terms (i.e. Harassment, Harassment $\times$ Female); and in columns (4)-(8) we control for the full set of Discrimination, Female and Misconduct interaction terms. Other adviser controls include the adviser's experience and licenses (series 6, 7, 63, 24, etc.). In our most stringent specification, we include Year $\times$ Firm $\times$ County $\times$ License F.E: fully saturated fixed effects for each set of possible licenses an adviser potentially holds within a firm, location, and time. In columns (4) and (8) we include dummy variables to control for the type of misconduct corresponding to the most common allegations and products reported in Table 1 . Standard errors are in parentheses and are clustered by firm. ${ }^{* * *} \mathrm{p}<0.01, * * \mathrm{p}<0.05$, * $\mathrm{p}<0.10$. 
Table 9: Punishment Gap for Minority Males

(a) Misconduct

\begin{tabular}{lcccc}
\hline & $(1)$ & $(2)$ & $(3)$ & $(4)$ \\
\hline African & $0.088^{* * *}$ & $0.16^{* * *}$ & $0.096^{* * * *}$ & $0.079^{* * *}$ \\
& $(0.043)$ & $(0.043)$ & $(0.032)$ & $(0.032)$ \\
Hispanic & $0.16^{* * *}$ & $0.28^{* * *}$ & $0.096^{* * *}$ & $0.093^{* * *}$ \\
& $(0.048)$ & $(0.047)$ & $(0.026)$ & $(0.025)$ \\
Adviser Controls & & & & \\
Year $\times$ Firm $\times$ County F.E. & & $\mathrm{X}$ & $\mathrm{X}$ & $\mathrm{X}$ \\
Year $\times$ Firm $\times$ County $\times$ License F.E. & & & $\mathrm{X}$ & \\
Observations & $4,904,653$ & $4,904,653$ & $4,598,081$ & $3,114,361$ \\
R-squared & 0.000 & 0.002 & 0.111 & 0.222 \\
Mean of Dep. Var. & $0.72 \%$ & $0.72 \%$ & $0.71 \%$ & $0.59 \%$ \\
\hline
\end{tabular}

(b) Punishment Gap

\begin{tabular}{|c|c|c|c|c|c|c|c|c|}
\hline \multirow[t]{2}{*}{ Dependent Variable } & \multicolumn{4}{|c|}{ Employment Separation } & \multicolumn{4}{|c|}{ New Employment } \\
\hline & (1) & (2) & (3) & (4) & (5) & (6) & (7) & $(8)$ \\
\hline \multirow[t]{2}{*}{ Misconduct } & $28.6 * * *$ & $21.8^{* * * *}$ & $24.8 * * *$ & $32.9 * * *$ & $-12.1 * * *$ & $-9.07 * * *$ & $-8.58 * * *$ & $-10.5^{* * * *}$ \\
\hline & $(1.27)$ & $(1.39)$ & $(2.04)$ & $(3.07)$ & $(1.28)$ & (1.07) & $(1.37)$ & $(1.78)$ \\
\hline \multirow[t]{2}{*}{ Misc. $\times$ African } & $8.95^{* * *}$ & $7.58 * * *$ & $8.96 * * *$ & $7.21 * * *$ & 2.91 & 3.36 & -2.16 & -1.69 \\
\hline & $(1.91)$ & $(2.17)$ & $(2.55)$ & $(2.27)$ & $(3.08)$ & $(2.96)$ & $(3.37)$ & $(3.39)$ \\
\hline \multirow[t]{2}{*}{ Misc. $\times$ Hispanic } & $5.67 * *$ & $6.53 * *$ & $9.07 * * *$ & $6.47^{* *}$ & $-6.31 * * *$ & $-5.84 * * *$ & $-6.66 * * *$ & $-5.52 * * *$ \\
\hline & $(2.39)$ & $(2.74)$ & $(3.27)$ & $(2.72)$ & $(2.10)$ & $(1.49)$ & (1.97) & $(1.97)$ \\
\hline \multirow[t]{2}{*}{ African } & $1.45 * * *$ & $0.44 * * *$ & $0.38 * *$ & $0.38 * *$ & -1.14 & $-1.13 * * *$ & -0.80 & -0.80 \\
\hline & $(0.27)$ & $(0.15)$ & $(0.17)$ & $(0.17)$ & $(0.72)$ & $(0.38)$ & $(0.52)$ & $(0.52)$ \\
\hline Hispanic & $\begin{array}{c}1.57^{* * * *} \\
(0.51)\end{array}$ & $\begin{array}{l}0.40 * * \\
(0.19)\end{array}$ & $\begin{array}{l}0.094 \\
(0.21)\end{array}$ & $\begin{array}{c}0.11 \\
(0.21)\end{array}$ & $\begin{array}{l}2.74 * * \\
(1.23)\end{array}$ & $\begin{array}{c}1.70 * * * \\
(0.27)\end{array}$ & $\begin{array}{c}1.99 * * * \\
(0.32)\end{array}$ & $\begin{array}{c}1.98^{* * * *} \\
(0.32)\end{array}$ \\
\hline Adviser Controls & $\mathrm{X}$ & $\mathrm{X}$ & $\mathrm{X}$ & $\mathrm{X}$ & $\mathrm{X}$ & $\mathrm{X}$ & $\mathrm{X}$ & $\mathrm{X}$ \\
\hline Yr $\times$ Firm $\times$ Cnty F.E. & & $\mathrm{X}$ & & & & $\mathrm{X}$ & & \\
\hline Yr $\times$ Firm $\times$ Cnty $\times$ Lic. F.E. & & & $\mathrm{X}$ & $\mathrm{X}$ & & & $\mathrm{X}$ & $\mathrm{X}$ \\
\hline Allegation and Product Controls & & & & $\mathrm{X}$ & & & & $\mathrm{X}$ \\
\hline Observations & $4,494,607$ & $4,210,431$ & $2,853,942$ & $2,853,942$ & 842,622 & 735,946 & 454,715 & 454,715 \\
\hline R-squared & 0.015 & 0.338 & 0.412 & 0.413 & 0.101 & 0.365 & 0.464 & 0.465 \\
\hline Mean of Dep. Var & $19 \%$ & $19 \%$ & $19 \%$ & $19 \%$ & $54 \%$ & $56 \%$ & $53 \%$ & $53 \%$ \\
\hline
\end{tabular}

Table 9a displays the regression results corresponding to a linear probability model (eq. 1) where observations are restricted to male advisers and are at the adviser-by-year-level over the period 2005-2015. The dependent variable in Table $9 \mathrm{a}$ is a dummy variable indicating whether the adviser received a misconduct disclosure in a given year and is scaled by 100 such that coefficients are in percentage points.

Table 9b displays the regression results corresponding to two linear probability models (eq. 3, and 4). Observations are restricted to male advisers and are at the adviser-by-year-level over the period 2005-2014. Since we track advisers who left their firm in the subsequent year, the sample in panel (b) covers the period 2005-2014 rather than 2005-2015. The dependent variable in columns (1)-(4) of Table $9 \mathrm{~b}$ is a dummy variable indicating whether a financial adviser left the firm and is scaled by 100 such that coefficients are in percentage points. The dependent variable in columns (5)-(8) of Table $9 \mathrm{~b}$ is a dummy variable indicating whether a financial adviser joined a new firm within one year and is scaled by 100 such that coefficients are in percentage points. In columns (5)-(8) of Table 9b, we restrict the sample to advisers who left their firms in a given year.

In both panels other adviser controls include the adviser's experience and dummy variables for the licenses the adviser holds (Series $6,7,24$, etc.). In our most stringent specifications, we include Year $\times$ Firm $\times$ County $\times$ License F.E: fully saturated fixed effects for each set of possible licenses an adviser potentially holds within a firm, location, and time. In columns (4) and (8) of panel (b) we include dummy variables to control for the most common misconduct allegations and products reported in Table 1 . Standard errors are in parentheses and are clustered by firm. ${ }^{* * *} \mathrm{p}<0.01,{ }^{* *} \mathrm{p}<0.05$, $* \mathrm{p}<0.10$. 
Table 10: Minority Male Managers and Punishment Gap

(a) Male Advisers and African Male Managers

\begin{tabular}{|c|c|c|c|c|c|}
\hline & (1) & (2) & (3) & (4) & (5) \\
\hline \multirow[t]{2}{*}{ Misconduct } & $26.4^{* * *}$ & $28.1 * * *$ & $21.6^{* * *}$ & $24.7 * * *$ & $33.1 * * *$ \\
\hline & $(1.41)$ & $(1.29)$ & $(1.43)$ & (2.10) & (3.09) \\
\hline \multirow[t]{2}{*}{ Misconduct $\times$ African } & $10.2^{* * *}$ & $10.0 * * *$ & $8.60 * * *$ & $8.27 * * *$ & $6.39 * * *$ \\
\hline & $(2.37)$ & $(2.26)$ & $(2.43)$ & $(2.39)$ & $(2.21)$ \\
\hline \multirow[t]{2}{*}{ Misconduct $\times$ Pct African Mgmt } & $13.9 * *$ & $13.1^{* *}$ & $13.2^{* * *}$ & 14.1 & 12.6 \\
\hline & $(5.55)$ & $(5.38)$ & $(6.08)$ & $(8.64)$ & $(8.00)$ \\
\hline \multirow[t]{2}{*}{ Misconduct $\times$ African $\times$ Pct African Mgmt } & $-20.3 * *$ & $-20.5 * *$ & $-38.7 * * *$ & -22.4 & -15.3 \\
\hline & $(10.1)$ & $(9.80)$ & $(10.1)$ & $(18.1)$ & (16.7) \\
\hline Adviser Controls & & $\mathrm{X}$ & $\mathrm{X}$ & $\mathrm{X}$ & $\mathrm{X}$ \\
\hline Yr $\times$ Firm $\times$ Cnty F.E. & & & $\mathrm{X}$ & & \\
\hline Yr $\times$ Firm $\times$ Cnty $\times$ Lic. F.E. & & & & $\mathrm{X}$ & $\mathrm{X}$ \\
\hline Allegation and Product Controls & & & & & $\mathrm{X}$ \\
\hline Observations & $3,613,837$ & $3,613,837$ & $3,508,932$ & $2,441,227$ & $2,441,227$ \\
\hline R-squared & 0.004 & 0.016 & 0.321 & 0.404 & 0.404 \\
\hline Mean of Dependent Variable & $20 \%$ & $20 \%$ & $20 \%$ & $20 \%$ & $20 \%$ \\
\hline
\end{tabular}

(b) Male Advisers and Hispanic Male Managers

\begin{tabular}{|c|c|c|c|c|c|}
\hline & $(1)$ & $(2)$ & (3) & (4) & $(5)$ \\
\hline Misconduct & $\begin{array}{c}26.2 * * * \\
(1.32)\end{array}$ & $\begin{array}{c}27.9 * * * \\
(1.20)\end{array}$ & $\begin{array}{c}21.3 * * * \\
(1.31)\end{array}$ & $\begin{array}{c}24.2 * * * \\
(1.86)\end{array}$ & $\begin{array}{l}32.7 * * * \\
(2.90)\end{array}$ \\
\hline Misconduct $\times$ Hispanic & $\begin{array}{l}7.71 * * * \\
(2.95)\end{array}$ & $\begin{array}{l}7.13 * * * \\
(2.77)\end{array}$ & $\begin{array}{l}7.76 * * \\
(3.12)\end{array}$ & $\begin{array}{l}7.98 * * \\
(3.41)\end{array}$ & $\begin{array}{l}5.15^{*} \\
(2.86)\end{array}$ \\
\hline Misconduct $\times$ Pct Hispanic Mgmt & $\begin{array}{c}11.0 * \\
(5.75)\end{array}$ & $\begin{array}{c}10.5 * \\
(5.44)\end{array}$ & $\begin{array}{c}11.2 * \\
(5.95)\end{array}$ & $\begin{array}{c}13.4 \\
(9.40)\end{array}$ & $\begin{array}{c}10.1 \\
(8.22)\end{array}$ \\
\hline Misconduct $\times$ Hispanic $\times$ Pct Hispanic Mgmt & $\begin{array}{l}-24.1 * * \\
(9.56)\end{array}$ & $\begin{array}{c}-23.3 * * * \\
(8.94)\end{array}$ & $\begin{array}{l}-20.0 * * \\
(9.90)\end{array}$ & $\begin{array}{l}-7.84 \\
(14.5)\end{array}$ & $\begin{array}{l}-2.22 \\
(13.0)\end{array}$ \\
\hline $\begin{array}{l}\text { Adviser Controls } \\
\text { Yr } \times \text { Firm } \times \text { Cnty F.E. }\end{array}$ & & $\mathrm{X}$ & $\begin{array}{l}X \\
X\end{array}$ & $\mathrm{X}$ & $\mathrm{X}$ \\
\hline $\begin{array}{l}\text { Yr } \times \text { Firm } \times \text { Cnty } \times \text { Lic. F.E. } \\
\text { Allegation and Product Controls }\end{array}$ & & & & $\mathrm{X}$ & $\begin{array}{l}X \\
X\end{array}$ \\
\hline Observations & $3,613,837$ & $3,613,837$ & $3,508,932$ & $2,441,227$ & $2,441,227$ \\
\hline R-squared & 0.004 & 0.016 & 0.321 & 0.404 & 0.404 \\
\hline Mean of Dependent Variable & $20 \%$ & $20 \%$ & $20 \%$ & $20 \%$ & $20 \%$ \\
\hline
\end{tabular}

Table 10 displays the results for a linear probability models (eq. 6). Observations are at the adviser-by-year level over the period 2005-2014. Since we track advisers who left their firm in the subsequent year, the sample covers the period 2005-2014 rather than 2005-2015. The dependent variable in each specification is a dummy variable indicating whether a financial adviser left the firm in the following year and is scaled by 100 such that coefficients are in percentage points. Misconduct is a dummy variable indicating whether a financial adviser received a misconduct disclosure in the given year. The variable Pct African Mgmt (Pct Hispanic) measures the share of managers working for a firm in a given county and year that have names of African (Hispanic) descent. When we include the triple interaction terms, we also include the full set of interactions (i.e. in panel (a) we control for Pct African Mgmt and Pct African Mgmt $\times$ African) . Other adviser controls include the adviser's experience and dummy variables for the licenses the adviser holds (Series 6, 7, 24, etc.). In our most stringent specifications, we include Year $\times$ Firm $\times$ County $\times$ License F.E: fully saturated fixed effects for each set of possible licenses an adviser potentially holds within a firm, location, and time. In column (5) of both panels we include dummy variables to control for the most common misconduct allegations and products reported in Table 1. Standard errors are in parentheses and are clustered by firm. $* * * \mathrm{p}<0.01, * * \mathrm{p}<0.05, * \mathrm{p}<0.10$ 
Table 11: Gender and Repeat Offenses

\begin{tabular}{|c|c|c|c|c|c|c|c|c|}
\hline & (1) & (2) & (3) & (4) & (5) & (6) & (7) & (8) \\
\hline Prior Misconduct & $\begin{array}{l}2.42 * * * \\
(0.10)\end{array}$ & $\begin{array}{l}2.29 * * * \\
(0.098)\end{array}$ & $\begin{array}{l}1.91 * * * \\
(0.076)\end{array}$ & $\begin{array}{l}1.72^{* * *} \\
(0.088)\end{array}$ & $\begin{array}{l}2.09 * * * \\
(0.089)\end{array}$ & $\begin{array}{l}1.96 * * * \\
(0.084)\end{array}$ & $\begin{array}{l}1.64 * * * \\
(0.067)\end{array}$ & $\begin{array}{l}1.49 * * * \\
(0.082)\end{array}$ \\
\hline Prior Misconduct $\times$ Female & $\begin{array}{l}-0.69 * * * \\
(0.099)\end{array}$ & $\begin{array}{l}-0.69 * * * \\
(0.098)\end{array}$ & $\begin{array}{l}-0.58 * * * \\
(0.090)\end{array}$ & $\begin{array}{l}-0.56 * * * \\
(0.11)\end{array}$ & $\begin{array}{l}-0.56 * * * \\
(0.095)\end{array}$ & $\begin{array}{l}-0.55 * * * \\
(0.095)\end{array}$ & $\begin{array}{l}-0.50 * * * \\
(0.086)\end{array}$ & $\begin{array}{l}-0.46 * * * \\
(0.10)\end{array}$ \\
\hline Prior Discipline & & & & & $\begin{array}{l}3.94 * * * \\
(0.28)\end{array}$ & $\begin{array}{l}3.89 * * * \\
(0.28)\end{array}$ & $\begin{array}{l}3.49 * * * \\
(0.25)\end{array}$ & $\begin{array}{c}3.34 * * * \\
(0.35)\end{array}$ \\
\hline Prior Discipline $\times$ Female & & & & & $\begin{array}{c}-1.70 * * * \\
(0.43)\end{array}$ & $\begin{array}{c}-1.70 * * * * \\
(0.43)\end{array}$ & $\begin{array}{l}-1.17 * * * \\
(0.45)\end{array}$ & $\begin{array}{l}-1.32^{* * *} \\
(0.63)\end{array}$ \\
\hline Female & $\begin{array}{c}-0.27 * * * \\
(0.017)\end{array}$ & $\begin{array}{c}-0.22^{* * *} \\
(0.017)\end{array}$ & $\begin{array}{c}-0.23 * * * \\
(0.024)\end{array}$ & $\begin{array}{c}-0.20 * * * \\
(0.026)\end{array}$ & $\begin{array}{c}-0.27 * * * \\
(0.017)\end{array}$ & $\begin{array}{c}-0.22^{* * *} \\
(0.017)\end{array}$ & $\begin{array}{c}-0.24 * * * \\
(0.023)\end{array}$ & $\begin{array}{c}-0.20 * * * \\
(0.026)\end{array}$ \\
\hline $\begin{array}{l}\text { Adviser Controls } \\
\text { Year } \times \text { Firm } \times \text { County F.E. }\end{array}$ & & $\mathrm{X}$ & $\begin{array}{l}X \\
X\end{array}$ & $\mathrm{X}$ & & $\mathrm{X}$ & $\begin{array}{l}X \\
X\end{array}$ & $\mathrm{X}$ \\
\hline Year $\times$ Firm $\times$ County $\times$ Lic. F.E. & & & & $\mathrm{X}$ & & & & $\mathrm{X}$ \\
\hline Observations & $6,547,974$ & $6,547,974$ & $6,221,173$ & $4,465,068$ & $6,547,974$ & $6,547,974$ & $6,221,173$ & $4,465,068$ \\
\hline R-squared & 0.007 & 0.007 & 0.101 & 0.208 & 0.008 & 0.009 & 0.102 & 0.209 \\
\hline Mean of Dependent Variable & $0.61 \%$ & $0.61 \%$ & $0.61 \%$ & $0.51 \%$ & $0.61 \%$ & $0.61 \%$ & $0.61 \%$ & $0.51 \%$ \\
\hline
\end{tabular}

Table 11 displays the regression results for a linear probability model (eq. 10). Observations are at the adviser-by-year level over the period 2005-2015. The dependent variable is whether a financial adviser received a misconduct disclosure at time $t$ and is scaled by 100 such that coefficients are in percentage points. Prior Misconduct is a dummy variable indicating whether a financial adviser previously received a misconduct disclosure. Prior Discipline is a dummy variable indicating whether an adviser previously experienced an employment separation following misconduct. Other adviser controls include the adviser's experience, tests (series 6, 7, 63, 24, and investment adviser exams), and number of other qualifications. In our most stringent specification, we include Year $\times$ Firm $\times$ County $\times$ License F.E: fully saturated fixed effects for each set of possible licenses an adviser potentially holds within a firm, location, and time. Standard errors are in parentheses and are clustered by firm. ${ }^{* * *} \mathrm{p}<0.01,{ }^{* *} \mathrm{p}<0.05,{ }^{*} \mathrm{p}<0.10$. 


\title{
Online Appendix When Harry Fired Sally: The Double Standard in Punishing Misconduct
}

\author{
Mark Egan, Gregor Matvos, and Amit Seru
}




\section{A1: Additional Figures and Tables}

Figure A1: Qualifications Held by Male and Female Financial Advisers

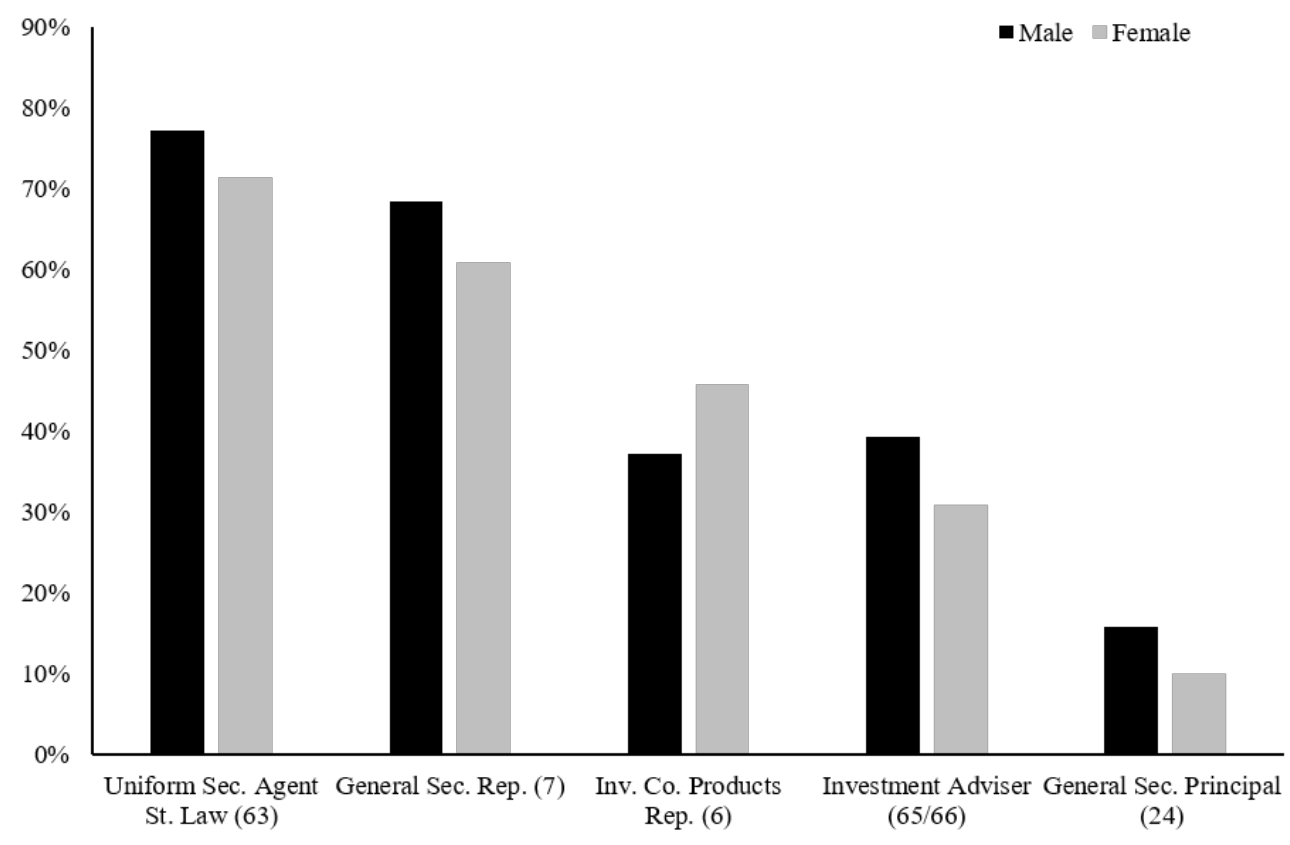

Figure A1 displays the percentage of female and male advisers that hold a particular license for the six most popular licenses. Observations are at the adviser-by-year level over the period 2005-2015. 
Figure A2: Misconduct Severity: Distribution of Settlements/Damages

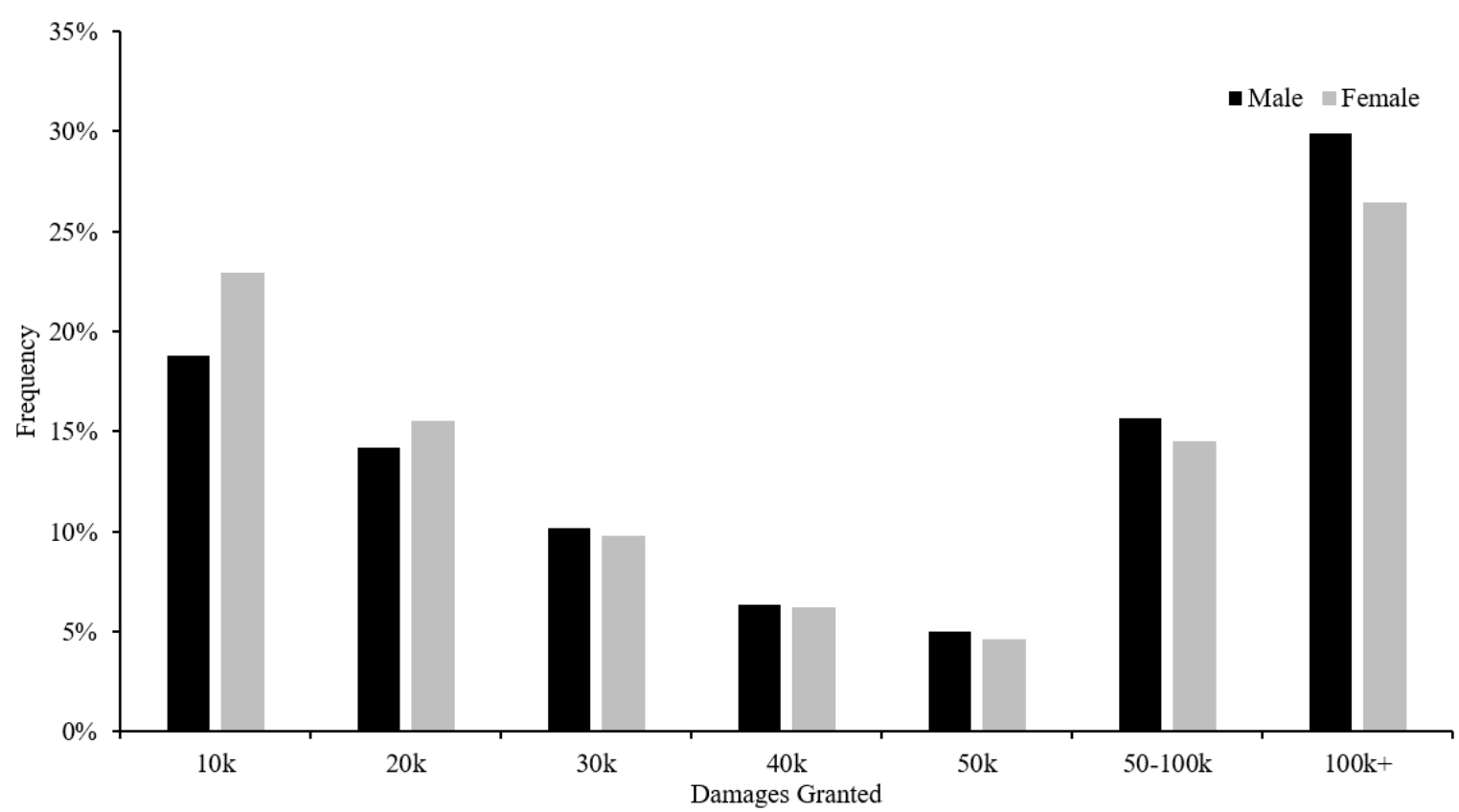

Figure A2 displays the distribution of settlements and damages paid to consumers by advisory firms for misconduct of male and female advisers over the period 2005-2015. We observe all settlements and damages paid for consumer related misconduct, which accounts for $45.80 \%$ of misconduct-related disclosures BrokerCheck database. Observations are at the financial adviser-by-year level. 
Figure A3: Annual Job Turnover - Male vs. Female Advisers

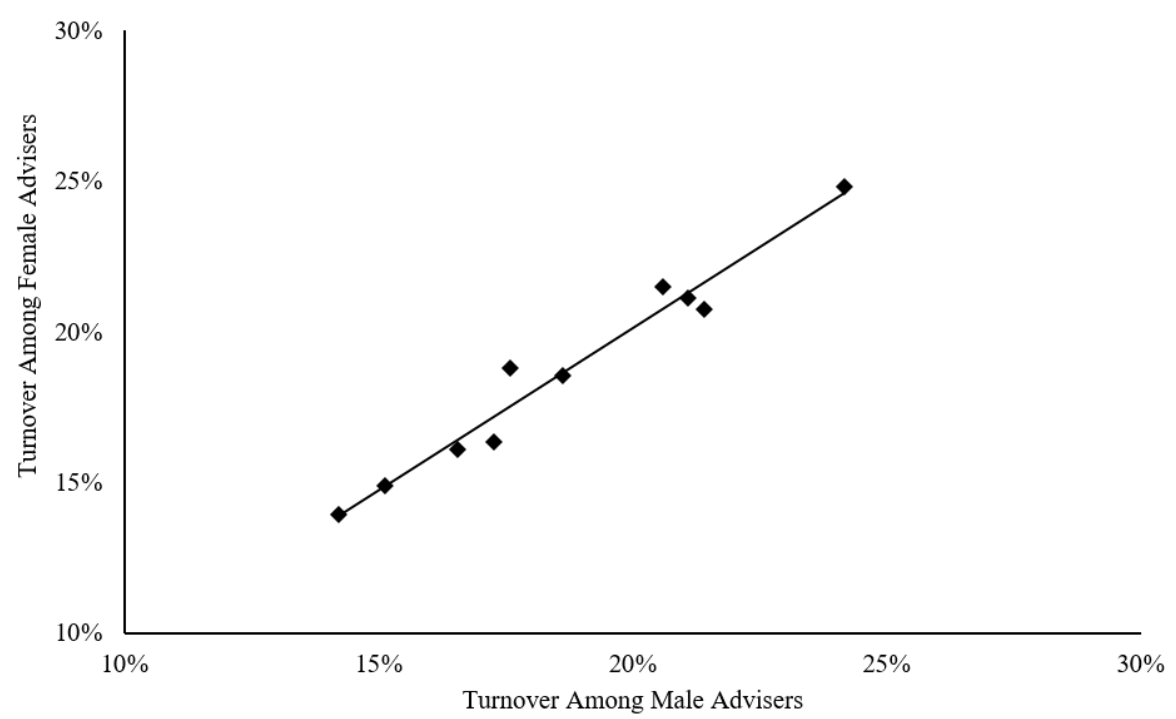

Figure A3 plots the annual average job turnover among male and female advisers over the period 2005-2014. Since we track advisers who left their firm in the subsequent year, the sample covers the period 2005-2014 rather than 2005-2015. Observations are the yearly level. The figure illustrates that average turnover rates among male and female advisers are nearly identical within a given year. This suggest that in absence of misconduct men and women leave their firms at similar rates. The correlation between average annual male and female turnover rates is 0.98 .

Figure A4: Job Turnover by Experience

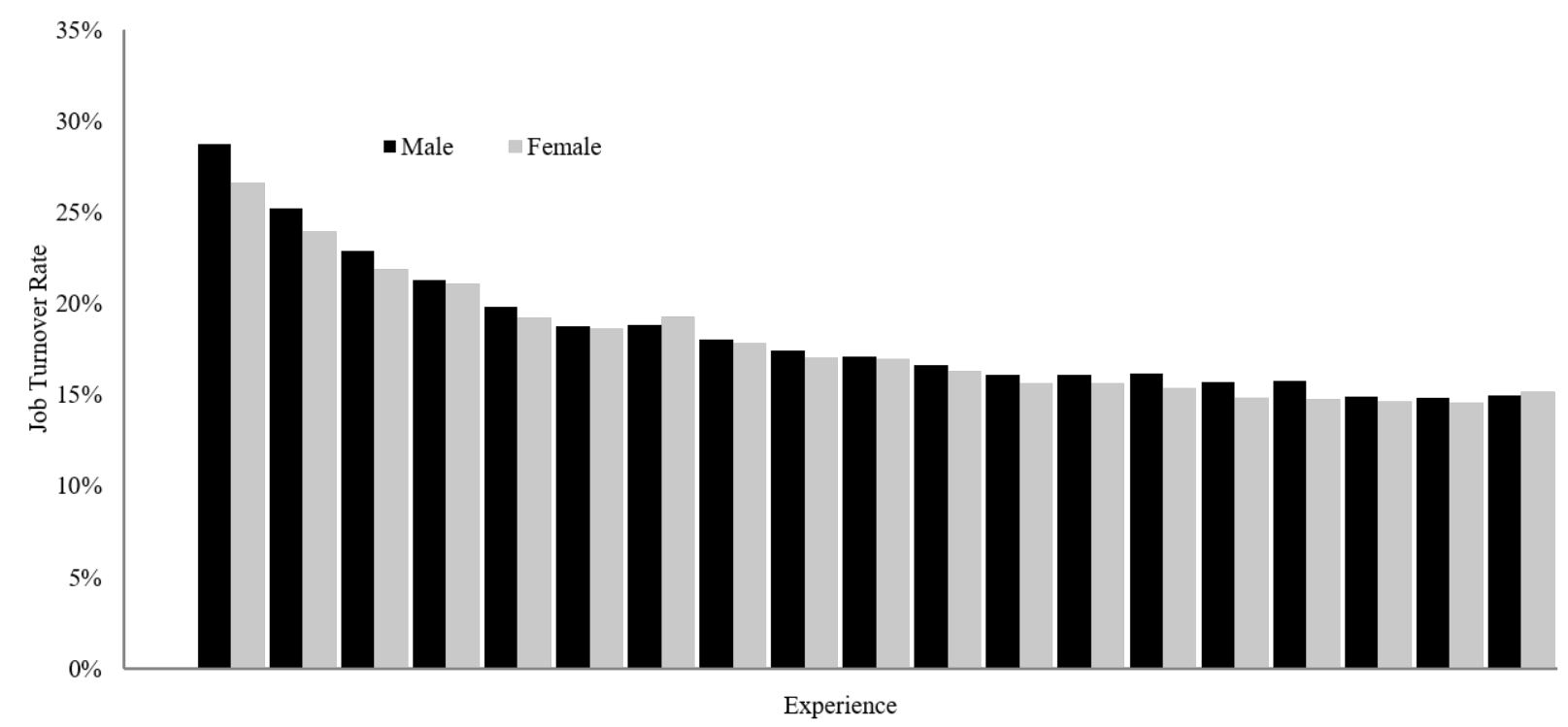

Figure A4 displays job turnover among male and female advisers conditional on advisers' experience. Experience measures the number of years since the adviser obtained his/her first regulatory license. Observations are at the adviser-by-year level over the period 2005-2014. Since we track advisers who left their firm in the subsequent year, the sample covers the period 2005-2014 rather than 2005-2015. 
Figure A5: Duration out of the Industry and Misconduct

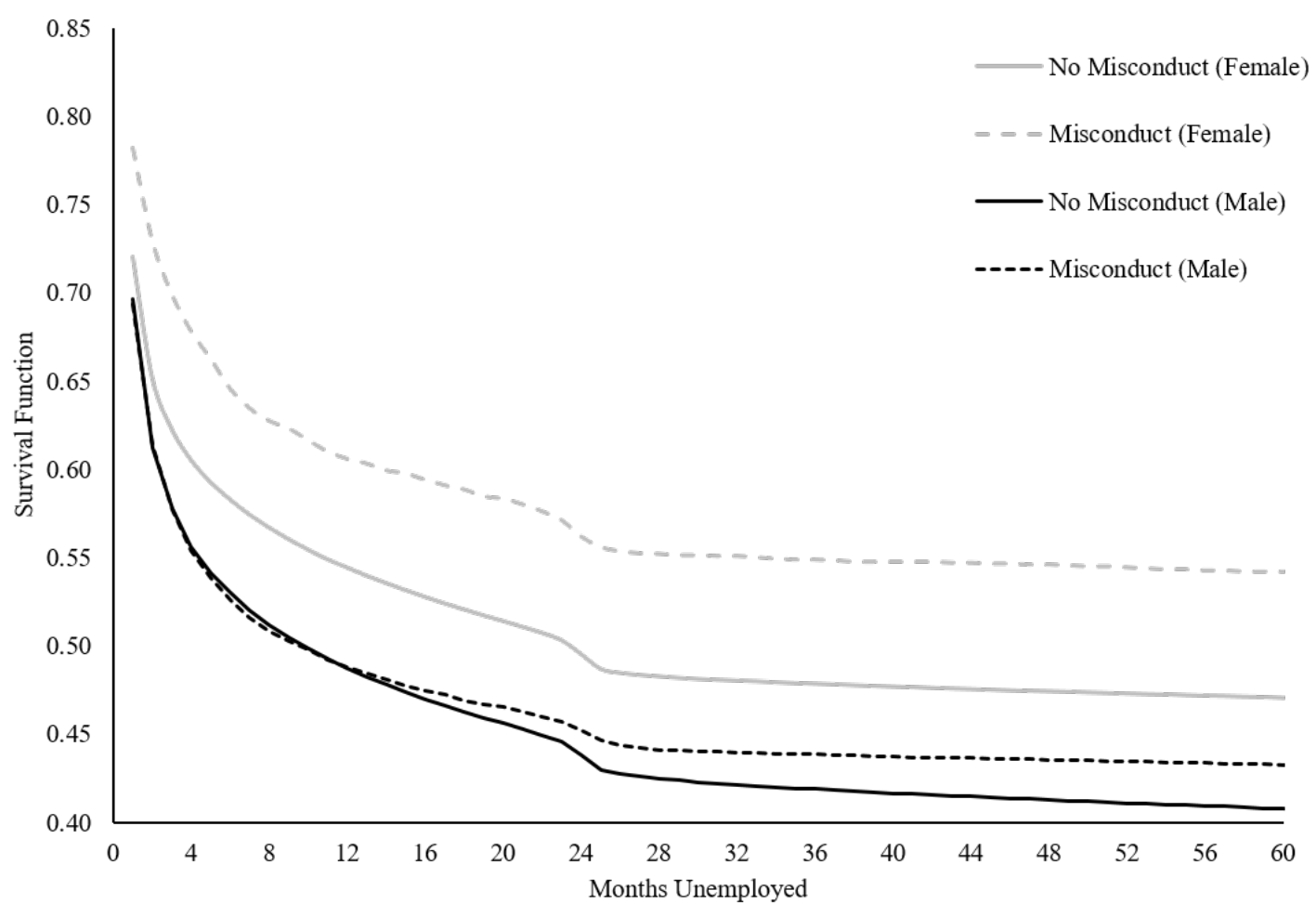

Figure A5 displays the duration out of the industry survival functions for all adviser out of the industry spells over the period 2005-2015. Out industry is defined as not being employed as a financial adviser. The solid black and gray lines display the duration out of the industry survival functions for male and female advisers who did not receive a misconduct disclosure in the year prior to their spell. The dashed lines display the duration out of the industry survival functions for male and female advisers who were reprimanded for misconduct in the year prior to the adviser's spell. 
Figure A6: Recidivism

(a) Distribution of Misconduct

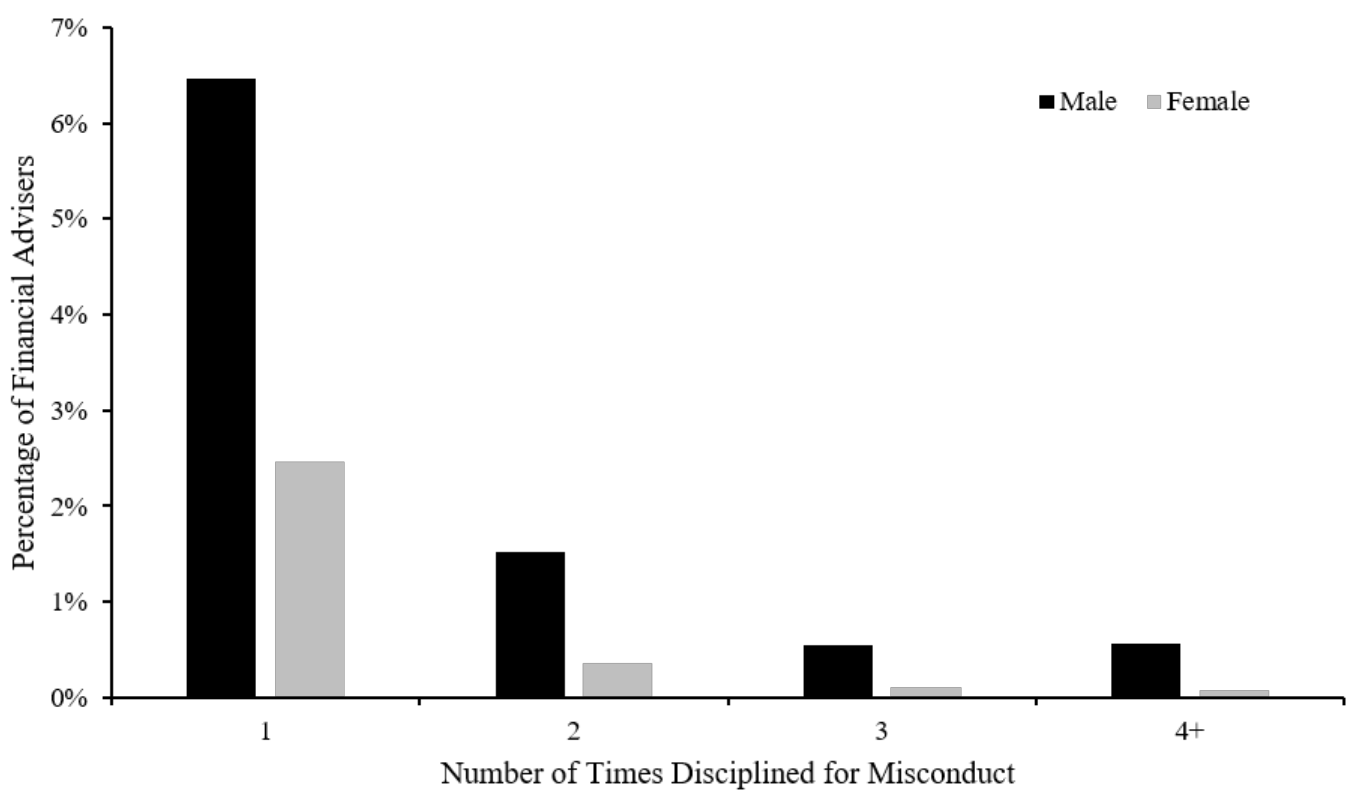

(b) Distribution of Misconduct - Repeat Offenders

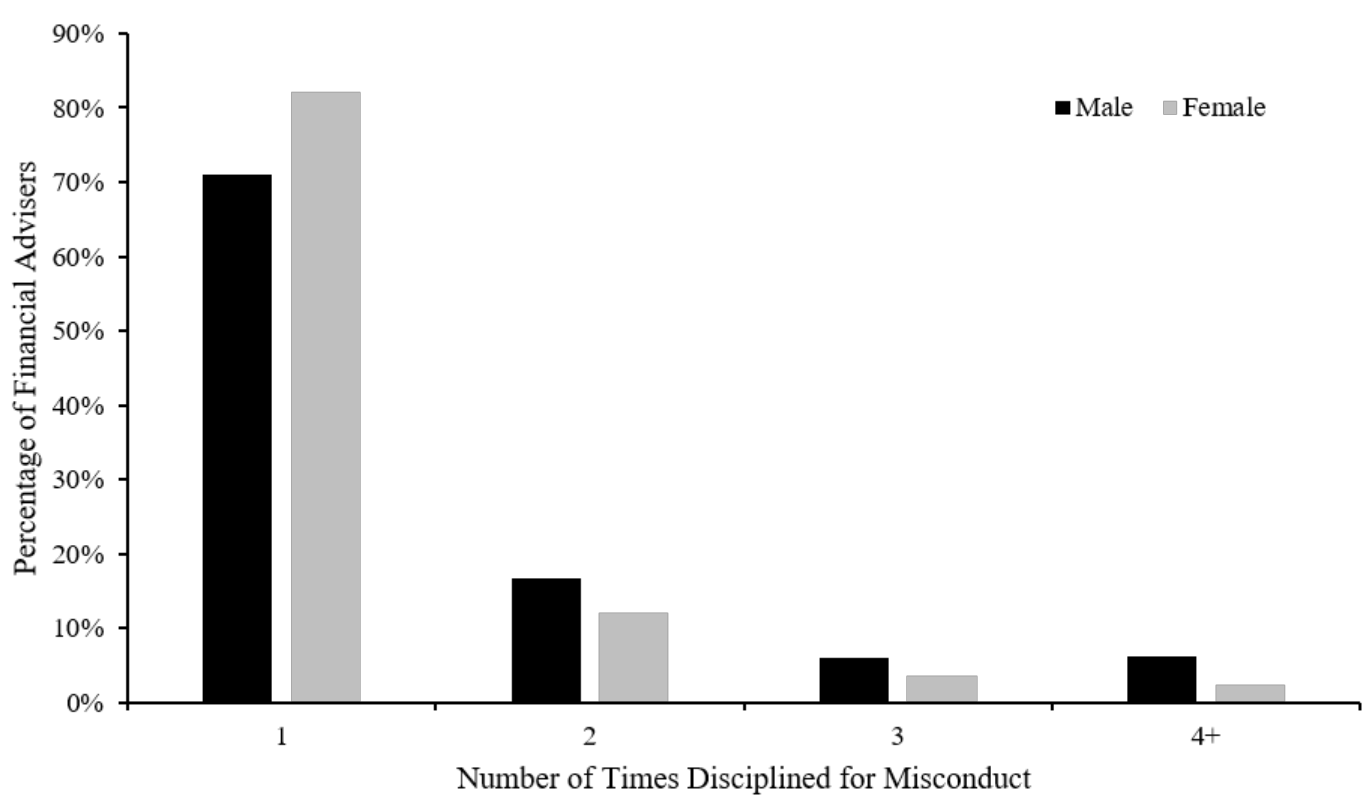

Figures A6a and A6b display the share of male and female advisers who have misconduct disclosures, and the number of misconduct disclosures. Figure A6a displays the distribution of misconduct disclosures across all advisers, and $\mathrm{A} 6 \mathrm{~b}$ displays the distribution of misconduct among advisers with at least one misconduct disclosure. Observations are at the adviser-by-year level over the period 2005-2015. 
Figure A7: Job Displacement - Male vs. Female Advisers

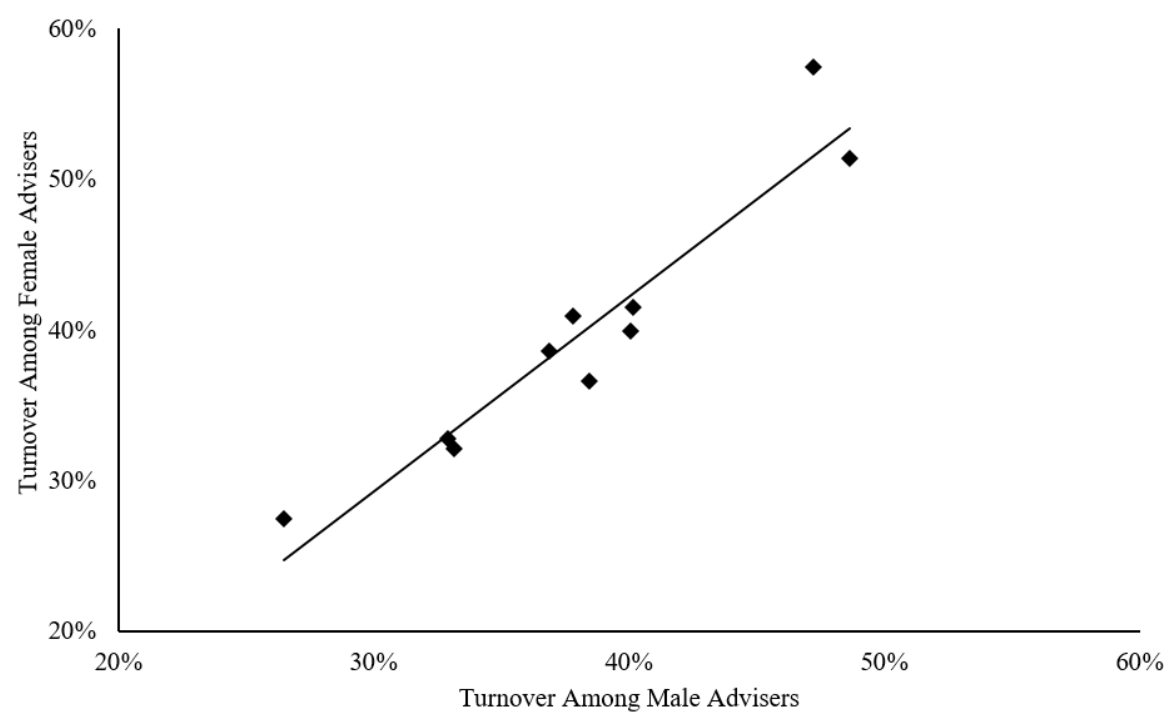

Figure A7 plots the average annual job turnover among male and female advisers at distressed firms over the period 2005-2014. Since we track advisers who left their firm in the subsequent year, the sample covers the period 2005-2014 rather than 2005-2015. We define distressed firms as firms that reduce the number of financial advisers by $10 \%$ or more in a given year. Observations are the yearly level. 
Table A1: Adviser Summary Statistics: Meridian IQ vs. Full Sample

\begin{tabular}{lcccccccc}
\hline & \multicolumn{3}{c}{ Full Data Set } & \multicolumn{3}{c}{ Meridian IQ Sample } \\
& \multicolumn{2}{c}{ Male } & \multicolumn{2}{c}{ Female } & \multicolumn{2}{c}{ Male } & Female \\
& Obs & Mean & Obs & Mean & Obs & Mean & Obs & Mean \\
\hline Experience (years) & $4,932,478$ & 12.31 & $1,615,496$ & 9.37 & $2,338,869$ & 14.38 & 589,956 & 11.20 \\
Disclosures: & & & & & & & & \\
Disclosure (in a year) & $4,932,478$ & $1.83 \%$ & $1,615,496$ & $1.08 \%$ & $2,338,869$ & $2.12 \%$ & 589,956 & $1.30 \%$ \\
Misconduct (in a year) & $4,932,478$ & $0.72 \%$ & $1,615,496$ & $0.29 \%$ & $2,338,869$ & $0.74 \%$ & 589,956 & $0.30 \%$ \\
Disclosure (ever) & $4,932,478$ & $14.89 \%$ & $1,615,496$ & $7.61 \%$ & $2,338,869$ & $19.87 \%$ & 589,956 & $10.91 \%$ \\
$\quad$ Misconduct (ever) & $4,932,478$ & $9.08 \%$ & $1,615,496$ & $3.00 \%$ & $2,338,869$ & $11.66 \%$ & 589,956 & $4.42 \%$ \\
Exams and Qualifications (Series): & & & & & & & & \\
No. Qualifications & $4,932,478$ & 2.88 & $1,615,496$ & 2.51 & $2,338,869$ & 3.16 & 589,956 & 2.81 \\
Uniform Sec. Agent St. Law (63) & $4,932,478$ & $77 \%$ & $1,615,496$ & $71 \%$ & $2,338,869$ & $81 \%$ & 589,956 & $78 \%$ \\
$\quad$ General Sec. Rep. (7) & $4,932,478$ & $68 \%$ & $1,615,496$ & $61 \%$ & $2,338,869$ & $73 \%$ & 589,956 & $66 \%$ \\
$\quad$ Inv. Co. Products Rep. (6) & $4,932,478$ & $37 \%$ & $1,615,496$ & $46 \%$ & $2,338,869$ & $40 \%$ & 589,956 & $46 \%$ \\
Uniform Combined St. Law (66) & $4,932,478$ & $19 \%$ & $1,615,496$ & $19 \%$ & $2,338,869$ & $25 \%$ & 589,956 & $25 \%$ \\
Uniform Inv. Adviser Law (65) & $4,932,478$ & $21 \%$ & $1,615,496$ & $13 \%$ & $2,338,869$ & $31 \%$ & 589,956 & $21 \%$ \\
$\quad$ General Sec. Principal (24) & $4,932,478$ & $16 \%$ & $1,615,496$ & $10 \%$ & $2,338,869$ & $16 \%$ & 589,956 & $11 \%$ \\
Employment Turnover: & & & & & & & & \\
Leave the Firm & $4,520,261$ & $19 \%$ & $1,481,827$ & $19 \%$ & $2,085,346$ & $11 \%$ & 521,665 & $10 \%$ \\
$\quad$ Leave the Industry & 847,380 & $46 \%$ & 278,335 & $52 \%$ & 219,832 & $6 \%$ & 53,321 & $9 \%$ \\
$\quad$ Join a Different Firm & 847,380 & $54 \%$ & 278,335 & $48 \%$ & 219,832 & $94 \%$ & 53,321 & $91 \%$ \\
\hline
\end{tabular}

Table A1 displays the summary statistics corresponding to our panel of male and female financial advisers in our full sample and Meridian IQ sample. Observations are at the adviser-by-year-level over the period 2005-2015. Experience measures the number of years since the adviser obtained his/her first regulatory license. Disclosure is a dummy variable indicating whether the adviser received a disclosure. Misconduct is a dummy variable indicating whether the adviser received a misconduct related disclosure. No. Qualifications measures the number of regulatory licenses an adviser holds. The other regulatory licensing related variables (i.e. Uniform Sec. Agent St. Law) are dummy variables that indicate whether an adviser holds the particular license. Advisers can hold 61 different types of licenses. We report the 6 most common licenses. Leave the Industry is defined as an adviser not being employed as a financial adviser for at least one year. Join a Different Firm is a dummy variable that takes the value of one if the adviser is employed at a different financial advisory firm within a year. 
Table A2: Alternative Gender Data

\begin{tabular}{lccc}
\hline Dependent Variable & Misconduct & Employment Separation & New Employment \\
\hline Female & $-0.29^{* * * *}$ & $-0.65^{* * *}$ & $-1.12^{* * *}$ \\
Misconduct & $(0.031)$ & $(0.15)$ & $(0.20)$ \\
& & $11.5^{* * * *}$ & 0.16 \\
Misconduct $\times$ Female & & $(0.76)$ & $(0.44)$ \\
& & $3.37^{* * *}$ & -2.06 \\
Adviser Controls & $(1.27)$ & $(1.60)$ \\
Year $\times$ Firm $\times$ County F.E. & $\mathrm{X}$ & $\mathrm{X}$ & $\mathrm{X}$ \\
Observations & $\mathrm{X}$ & $\mathrm{X}$ & $\mathrm{X}$ \\
R-squared & $3,787,172$ & $3,359,568$ & 340,136 \\
Mean of Dependent Variable & 0.113 & 0.435 & 0.240 \\
& $0.5 \%$ & $11.3 \%$ & $92 \%$ \\
\hline
\end{tabular}

Table A2 displays the regression results for three linear probability models. Observations are at the adviserby-year level over the period 2005-2015 in column (1) and over the period 2005-2014 in columns (2) and (3). Since we track advisers who left their firm in the subsequent year in columns (2) and (3), the sample covers the period 2005-2014 rather than 2005-2015. The dependent variable in column (1) is a dummy variable indicating whether or not the adviser received a misconduct disclosure in year $t$ (eq. 1) and is scaled by 100 such that coefficients are in percentage points. The dependent variable in column (2) is a dummy variable indicating whether or not a financial adviser left the firm (eq. 3) and is scaled by 100 such that coefficients are in percentage points. The dependent variable in column (3) is a dummy variable indicating whether or not a financial adviser joined a new firm within one year (eq. 4) and is scaled by 100 such that coefficients are in percentage points. In column (3), we restrict the sample to advisers who left their firms in a given year. We identify the gender of each adviser using data from Meridian IQ. Because we only observe the gender for active advisers in Meridian IQ in 2016, our ability to identify the impact of misconduct on an adviser's reemployment prospects is limited (all of the advisers in the Meridian IQ data set are active and employed as of 2016 by construction). Other adviser controls include the adviser's experience and dummy variables for the licenses the adviser holds (Series 6, 7, 24, etc.). Observations are at the adviser-by-year level over the period 2005-2015. Standard errors are in parentheses and are clustered by firm. ${ }^{* * *} \mathrm{p}<0.01,{ }^{* *} \mathrm{p}<0.05,{ }^{*} \mathrm{p}<0.10$. 
Table A3: Gender Differences in Misconduct

\begin{tabular}{lcccc}
\hline & $(1)$ & $(2)$ & $(3)$ & $(4)$ \\
\hline Female & $-0.29^{* * *}$ & $-0.24^{* * * *}$ & $-0.18^{* * *}$ & $-0.16^{* * *}$ \\
& $(0.037)$ & $(0.035)$ & $(0.019)$ & $(0.034)$ \\
Female $\times$ Pct Female Mgmt & 0.088 & & & 0.046 \\
& $(0.080)$ & & & $(0.079)$ \\
Female $\times$ Pct Jr Female & & $-0.0061^{* *}$ & & $-0.0063^{* *}$ \\
& & $(0.0029)$ & & $(0.0025)$ \\
Female $\times$ Harassment & & & $-0.28^{* * *}$ & $-0.26^{* * *}$ \\
& & & $(0.050)$ & $(0.050)$ \\
Adviser Controls & $\mathrm{X}$ & $\mathrm{X}$ & $\mathrm{X}$ & $\mathrm{X}$ \\
Year $\times$ Firm $\times$ County $\times$ License F.E. & $\mathrm{X}$ & $\mathrm{X}$ & $\mathrm{X}$ & $\mathrm{X}$ \\
Observations & $3,799,974$ & $4,166,466$ & $4,465,068$ & $3,639,155$ \\
R-squared & 0.191 & 0.187 & 0.206 & 0.178 \\
Mean of Dependent Variable & $0.51 \%$ & $0.50 \%$ & $0.51 \%$ & $0.51 \%$ \\
\hline
\end{tabular}

Table A3 presents regression results corresponding to a linear probability model. Observations are at the adviser-by-year level over the period 2005-2015. The dependent variable is a dummy variable indicating whether the adviser received a misconduct disclosure year $t$. Coefficients are in percentage points (pp). The variable Pct Jr Female measures the share of junior employees, defined as with less than 3 years' experience, working for a firm in a given county and year that are female. The variable Pct Female Mgmt measures the share of managers working for a firm in a given county and year that are female. The variable Harassment is a dummy variable indicating whether or not the firm has ever had a sexual harassment claim resolved through FINRA arbitration. Other adviser controls include the adviser's experience. In each specification we include Year $\times$ Firm $\times$ County $\times$ License F.E.: fully saturated fixed effects for each set of possible licenses an adviser potentially holds within a firm, location, and time. Standard errors are in parentheses and are clustered by firm. *** $\mathrm{p}<0.01, * * \mathrm{p}<0.05,{ }^{*} \mathrm{p}<0.10$. 
Table A4: Settlements

\begin{tabular}{|c|c|c|}
\hline & (1) & (2) \\
\hline \multicolumn{3}{|l|}{ Adviser Characteristics: } \\
\hline Female & $\begin{array}{c}0.38 \\
(0.95)\end{array}$ & $\begin{array}{c}-0.16 \\
(0.95)\end{array}$ \\
\hline Prior Misconduct & $\begin{array}{c}32.0 * * * \\
(0.64)\end{array}$ & $\begin{array}{c}31.4 * * * \\
(0.69)\end{array}$ \\
\hline \multicolumn{3}{|l|}{ Allegations: } \\
\hline Unsuitable & $\begin{array}{c}-0.76 \\
(0.55)\end{array}$ & $\begin{array}{l}0.071 \\
(0.57)\end{array}$ \\
\hline Misrepresentation & $\begin{array}{c}-1.76 * * * \\
(0.63)\end{array}$ & $\begin{array}{l}-1.28^{*} \\
(0.66)\end{array}$ \\
\hline Unauthorized Activity & $\begin{array}{l}-0.35 \\
(0.76)\end{array}$ & $\begin{array}{c}0.63 \\
(0.80)\end{array}$ \\
\hline Omission of Key Facts & $\begin{array}{c}1.01 \\
(1.07)\end{array}$ & $\begin{array}{c}-0.64 \\
(1.10)\end{array}$ \\
\hline Fee/Commission Related & $\begin{array}{c}-2.64 * * \\
(1.12)\end{array}$ & $\begin{array}{c}-2.40 * * \\
(1.12)\end{array}$ \\
\hline Fraud & $\begin{array}{c}16.9 * * * \\
(1.50)\end{array}$ & $\begin{array}{c}11.9 * * * \\
(1.41)\end{array}$ \\
\hline Fiduciary Duty & $\begin{array}{c}9.68 * * * \\
(1.21)\end{array}$ & $\begin{array}{c}11.2^{* * * *} \\
(1.21)\end{array}$ \\
\hline Negligence & $\begin{array}{c}-0.052 \\
(1.20)\end{array}$ & $\begin{array}{c}1.16 \\
(1.20)\end{array}$ \\
\hline Risky Investments & $\begin{array}{c}5.11 * * * \\
(1.35)\end{array}$ & $\begin{array}{c}3.68 * * * \\
(1.36)\end{array}$ \\
\hline Churning/ Excessive Trading & $\begin{array}{c}0.80 \\
(1.02)\end{array}$ & $\begin{array}{c}2.96^{* * * *} \\
(1.09)\end{array}$ \\
\hline Unregistered Securities & $\begin{array}{c}0.85 \\
(5.13)\end{array}$ & $\begin{array}{c}18.4 * * * \\
(6.11)\end{array}$ \\
\hline Products: & & \\
\hline Insurance & $\begin{array}{c}0.71 \\
(0.93)\end{array}$ & $\begin{array}{c}-1.56 \\
(0.97)\end{array}$ \\
\hline Annuity & $\begin{array}{c}-2.82 * * * \\
(0.94)\end{array}$ & $\begin{array}{c}-4.04 * * * \\
(0.95)\end{array}$ \\
\hline Stocks & $\begin{array}{c}-6.24 * * * \\
(0.80)\end{array}$ & $\begin{array}{c}-5.70 * * * \\
(0.84)\end{array}$ \\
\hline Mutual Funds & $\begin{array}{c}-7.62 * * * \\
(0.92)\end{array}$ & $\begin{array}{c}-5.98 * * * \\
(0.97)\end{array}$ \\
\hline Bonds & $\begin{array}{c}-3.86^{* * *} \\
(1.40)\end{array}$ & $\begin{array}{c}-3.55^{* *} \\
(1.47)\end{array}$ \\
\hline Options & $\begin{array}{c}-2.38 \\
(1.56)\end{array}$ & $\begin{array}{l}-2.56 \\
(1.68)\end{array}$ \\
\hline Year F.E. & $\mathrm{X}$ & $\mathrm{X}$ \\
\hline County F.E. & & $\mathrm{X}$ \\
\hline Firm F.E. & & $\mathrm{X}$ \\
\hline Observations & 86,108 & 82,295 \\
\hline R-squared & 0.094 & 0.170 \\
\hline
\end{tabular}

Table A4 displays the regression results for a linear regression model. Observations are at the customer dispute level and include the universe of customer disputes involving those financial advisers in our data (i.e., those financial advisers who were active over the period 2005-2015). The dependent variable measures settlements granted relative to the amount requested by the customer, $\frac{\text { Settlement }}{\text { AmountRequested }}$. The independent variable Prior Misconduct indicates whether the adviser has a past record of misconduct. We also control for the case size and other adviser controls. Other adviser controls include the corresponding adviser's experience and qualifications: Series 6, Series 7, Series 24, Series 63, Series 65/66, and number of other qualifications. Robust standard errors are in parentheses. ${ }^{* * *} \mathrm{p}<0.01,{ }^{* *} \mathrm{p}<0.05,{ }^{*} \mathrm{p}<0.10$. 
Table A5: Employment Separations (within 2 years)

\begin{tabular}{lcccc}
\hline & $(1)$ & $(2)$ & $(3)$ & $(4)$ \\
\hline Misconduct & $24.0^{* * *}$ & $26.7^{* * *}$ & $17.0^{* * *}$ & $19.2^{* * *}$ \\
Misconduct $\times$ Female & $(1.38)$ & $(1.14)$ & $(1.11)$ & $(1.43)$ \\
& $6.22^{* * *}$ & $5.93^{* * *}$ & $7.79^{* * *}$ & $7.23^{* * *}$ \\
Female & $(1.76)$ & $(1.56)$ & $(1.34)$ & $(1.30)$ \\
& 0.60 & -0.70 & $-0.86^{* * *}$ & $-0.79^{* * *}$ \\
& $(0.51)$ & $(0.60)$ & $(0.28)$ & $(0.28)$ \\
Adviser Controls & & & & \\
Year $\times$ Firm $\times$ County F.E. & & $\mathrm{X}$ & $\mathrm{X}$ & $\mathrm{X}$ \\
Year $\times$ Firm $\times$ County $\times$ License F.E. & & & $\mathrm{X}$ & $\mathrm{X}$ \\
Observations & $5,426,688$ & $5,426,688$ & $5,147,793$ & $3,698,853$ \\
R-squared & 0.002 & 0.024 & 0.371 & 0.438 \\
\hline
\end{tabular}

Table A5 presents regression results corresponding to a linear probability model. Observations are at the financial adviser-by-year-level over the period 2005-2013. Since we track advisers who left their firm in the subsequent two years, the sample covers the period 2005-2013 rather than 2005-2015. The dependent variable is a dummy variable indicating whether a financial adviser left the firm (either leaving the industry or switching firms) over a two-year window (in the given or following year). The independent variable Misconduct is a dummy variable indicating whether a financial adviser received a misconduct disclosure in the given year. Coefficients are in percentage points. Other adviser controls include the adviser's experience and licenses (series $6,7,63,24$, etc.). Standard errors are in parentheses and are clustered by firm. *** $\mathrm{p}<0.01, * \mathrm{p}<0.05, * \mathrm{p}<0.10$.

Table A6: Gender Punishment Gap In Reemployment: Duration Analysis

\begin{tabular}{lcc}
\hline & $(1)$ & $(2)$ \\
\hline & & \\
Misconduct (Male) & $0.84^{* * *}$ & $0.85^{* * *}$ \\
& $(0.0075)$ & $(0.0076)$ \\
Misconduct (Female) & $0.74^{* * *}$ & $0.75^{* * *}$ \\
& $(0.019)$ & $(0.020)$ \\
Female & $0.96^{* * *}$ & $0.96^{* * *}$ \\
& $(0.0029)$ & $(0.0029)$ \\
& & \\
Adviser Controls & $\mathrm{X}$ & $\mathrm{X}$ \\
Year F.E. & & $\mathrm{X}$ \\
Observations & $1,109,210$ & $1,109,210$ \\
\hline
\end{tabular}

Table A6 displays the estimation results corresponding to a Cox proportional hazard model (eq. A.1), discussed in Appendix A4. Observations are at the financial adviser by out of the industry spell level over the period 2005-2015. The dependent variable is the length of an out of the industry spell in months. The independent variable Misconduct is a dummy variable indicating whether the adviser received a misconduct disclosure in the year prior to his/her unemployment spell. We interact Misconduct with the gender of the adviser to allow the effect to be different for male and female advisers. Other adviser controls include the adviser's experience, tests (series 6, 7, 63, 24 and investment adviser exam), and number of other qualifications. The coefficients are reported in terms of proportional hazards such that a coefficient less than one indicates that it takes longer for an adviser to find a new job. Robust standard errors in parentheses. *** $\mathrm{p}<0.01, * \mathrm{p}<0.05, * \mathrm{p}<0.10$. 
Table A7: Branch Gender Composition, Firm Separation and Punishment Gap

\begin{tabular}{|c|c|c|c|c|c|}
\hline & (1) & (2) & (3) & (4) & (5) \\
\hline Misconduct & $\begin{array}{c}24.3 * * * \\
(1.11)\end{array}$ & $\begin{array}{c}25.7 * * * \\
(1.06)\end{array}$ & $\begin{array}{l}16.7 * * * \\
(1.29)\end{array}$ & $\begin{array}{l}17.0 * * * \\
(2.00)\end{array}$ & $\begin{array}{c}26.4 * * * \\
(2.23)\end{array}$ \\
\hline Misconduct $\times$ Female & $\begin{array}{c}10.4 * * * \\
(3.23)\end{array}$ & $\begin{array}{c}10.3 * * * \\
(3.04)\end{array}$ & $\begin{array}{c}11.8 * * * \\
(3.10)\end{array}$ & $\begin{array}{l}8.40 * * \\
(3.61)\end{array}$ & $\begin{array}{l}6.36 * * \\
(3.21)\end{array}$ \\
\hline Misconduct $\times$ Pct Female & $\begin{array}{l}19.8 * * \\
(8.27)\end{array}$ & $\begin{array}{l}19.3^{* * *} \\
(7.55)\end{array}$ & $\begin{array}{c}29.9 * * * \\
(8.80)\end{array}$ & $\begin{array}{c}42.5 * * * \\
(13.1)\end{array}$ & $\begin{array}{c}36.2 * * * \\
(10.3)\end{array}$ \\
\hline Misconduct $\times$ Female $\times$ Pct Female & $\begin{array}{l}-15.9^{*} \\
(8.16)\end{array}$ & $\begin{array}{l}-16.3^{* * *} \\
(7.51)\end{array}$ & $\begin{array}{l}-16.2^{* * *} \\
(6.76)\end{array}$ & $\begin{array}{l}-6.31 \\
(9.63)\end{array}$ & $\begin{array}{l}-5.67 \\
(8.71)\end{array}$ \\
\hline $\begin{array}{l}\text { Adviser Controls } \\
\text { Year } \times \text { Firm } \times \text { County F.E. }\end{array}$ & & $\mathrm{X}$ & $\begin{array}{l}X \\
X\end{array}$ & $\mathrm{X}$ & $\mathrm{X}$ \\
\hline $\begin{array}{l}\text { Year } \times \text { Firm } \times \text { County } \times \text { License F.E. } \\
\text { Allegation and Product Controls }\end{array}$ & & & & $\mathrm{X}$ & $\begin{array}{l}X \\
X\end{array}$ \\
\hline R-squared & $5,990,929$ & $5,990,929$ & $5,695,544$ & $4,091,147$ & $4,091,147$ \\
\hline R-squared & 0.004 & 0.014 & 0.332 & 0.403 & 0.403 \\
\hline Mean of Dependent Variable & $19 \%$ & $19 \%$ & $19 \%$ & $20 \%$ & $20 \%$ \\
\hline
\end{tabular}

Table A7 displays the regression results corresponding to a linear probability model (eq. 6). Observations are at the adviser-by-year level over the period 2005-2014. Since we track advisers who left their firm in the subsequent year, the sample covers the period 2005-2014 rather than 2005-2015 The dependent variable is a dummy variable indicating whether a financial adviser left the firm in the following year and is scaled by 100 such that coefficients are in percentage points. Misconduct is a dummy variable indicating whether a financial adviser received a misconduct disclosure in the given year. Pct Female measures the share of advisers (weighted by experience) working for a firm in a given county and year that are female. In each specification we also control for the full set of interactions terms between Female, Misconduct, and Pct Female (i.e. we control for Pct Female and Pct Female $\times$ Female). Other adviser controls include the adviser's experience and licenses (series 6, 7, 63, 24, etc.). In our most stringent specifications, we include Year $\times$ Firm $\times$ County $\times$ License F.E: fully saturated fixed effects for each set of possible licenses an adviser potentially holds within a firm, location, and time. In columns (5) we include dummy variables to control for the type of misconduct corresponding to the most common allegations and products reported in Table A24. Standard errors are in parentheses and are clustered by firm. ${ }^{* * *} \mathrm{p}<0.01,{ }^{* *} \mathrm{p}<0.05,{ }^{*} \mathrm{p}<0.10$. 
Table A8: Firm Characteristics and the Gender Punishment Gap

\begin{tabular}{|c|c|c|c|c|c|c|c|}
\hline & $(1)$ & $(2)$ & (3) & (4) & (5) & (6) & (7) \\
\hline Misc. & $\begin{array}{l}11.9 * * * * \\
(1.75)\end{array}$ & $\begin{array}{c}26.9 * * * \\
(1.88)\end{array}$ & $\begin{array}{c}23.0 * * * \\
(2.57)\end{array}$ & $\begin{array}{c}15.1 * * * \\
(3.67)\end{array}$ & $\begin{array}{c}21.1 * * * \\
(2.20)\end{array}$ & $\begin{array}{c}18.0 * * * \\
(1.53)\end{array}$ & $\begin{array}{c}20.1^{* * * *} \\
(1.36)\end{array}$ \\
\hline Misc. $\times$ Female & $\begin{array}{c}14.0 * * * * \\
(3.34)\end{array}$ & $\begin{array}{l}12.2^{* * * *} \\
(2.50)\end{array}$ & $\begin{array}{l}15.7 * * * \\
(3.72)\end{array}$ & $\begin{array}{c}15.6^{* * * *} \\
(4.67)\end{array}$ & $\begin{array}{l}16.7^{* * * *} \\
(2.79)\end{array}$ & $\begin{array}{l}11.2^{* * * *} \\
(2.25)\end{array}$ & $\begin{array}{c}13.3 * * * \\
(2.30)\end{array}$ \\
\hline Misc. $\times($ Pct Female Mgmt) & $\begin{array}{c}8.25 * * * \\
(1.87)\end{array}$ & $\begin{array}{c}5.79 * * * \\
(1.78)\end{array}$ & $\begin{array}{c}12.3 * * * \\
(2.17)\end{array}$ & $\begin{array}{c}11.0 * * * \\
(2.33)\end{array}$ & $\begin{array}{l}11.6 * * * \\
(2.10)\end{array}$ & $\begin{array}{c}11.6 * * * \\
(2.11)\end{array}$ & $\begin{array}{l}11.6 * * * \\
(2.11)\end{array}$ \\
\hline Misc. $\times$ Female $\times($ Pct Female Mgmt $)$ & $\begin{array}{c}-13.9 * * * \\
(3.11)\end{array}$ & $\begin{array}{c}-13.5 * * * \\
(3.32)\end{array}$ & $\begin{array}{c}-18.9 * * * \\
(3.41)\end{array}$ & $\begin{array}{c}-17.6 * * * \\
(3.78)\end{array}$ & $\begin{array}{l}-18.2 * * * \\
(3.25)\end{array}$ & $\begin{array}{c}-17.0 * * * \\
(3.32)\end{array}$ & $\begin{array}{c}-18.5 * * * \\
(3.35)\end{array}$ \\
\hline \multicolumn{8}{|l|}{ Firm Characteristics: } \\
\hline $\begin{array}{l}\text { Misc. } \times \text { Female } \times \\
\times \ln (\text { Branch Size })\end{array}$ & $\begin{array}{l}-0.47 \\
(0.67)\end{array}$ & & & & & & \\
\hline$\times$ Share of Advisers with Past Misc. & & $\begin{array}{l}-9.15 \\
(10.1)\end{array}$ & & & & & \\
\hline$\times$ Share of Investment Advisers & & & $\begin{array}{l}-4.57 \\
(5.64)\end{array}$ & & & & \\
\hline$\times$ Affiliated with a Bank & & & & $\begin{array}{l}-3.25 \\
(4.74)\end{array}$ & & & \\
\hline$\times$ Formation: Corporation & & & & & $\begin{array}{c}-7.36 * * \\
(2.86)\end{array}$ & & \\
\hline$\times$ Formation: LLC & & & & & & $\begin{array}{c}5.79 \\
(3.88)\end{array}$ & \\
\hline$\times$ Formation: Partnership & & & & & & & $\begin{array}{l}14.9^{*} \\
(8.16)\end{array}$ \\
\hline Full Set of Interaction Terms & $\mathrm{X}$ & $\mathrm{X}$ & $\mathrm{X}$ & $\mathrm{X}$ & $\mathrm{X}$ & $\mathrm{X}$ & $\mathrm{X}$ \\
\hline Adviser Controls & $\mathrm{X}$ & $\mathrm{X}$ & $\mathrm{X}$ & $\mathrm{X}$ & $\mathrm{X}$ & $\mathrm{X}$ & $\mathrm{X}$ \\
\hline Year $\times$ Firm $\times$ County F.E. & $\mathrm{X}$ & $\mathrm{X}$ & $\mathrm{X}$ & $\mathrm{X}$ & $\mathrm{X}$ & $\mathrm{X}$ & $\mathrm{X}$ \\
\hline Year $\times$ Firm $\times$ County & $\mathrm{X}$ & $\mathrm{X}$ & $\mathrm{X}$ & $\mathrm{X}$ & $\mathrm{X}$ & $\mathrm{X}$ & $\mathrm{X}$ \\
\hline Observations & $4,722,832$ & $4,722,832$ & $4,722,832$ & $4,722,832$ & $4,722,832$ & $4,722,832$ & $4,722,832$ \\
\hline R-squared & 0.315 & 0.315 & 0.315 & 0.315 & 0.315 & 0.315 & 0.315 \\
\hline Mean of Dependent Variable & $19.6 \%$ & $19.6 \%$ & $19.6 \%$ & $19.6 \%$ & $19.6 \%$ & $19.6 \%$ & $19.6 \%$ \\
\hline
\end{tabular}

Table A8 presents regression results corresponding to a linear probability model. Observations are at the financial adviser-by-year-level over the period 2005-2014. Since we track advisers who left their firm in the subsequent year, the sample covers the period 2005-2014 rather than 2005-2015. The dependent variable is a dummy variable indicating whether a financial adviser left the firm (either leaving the industry or switching firms) in the given year. The independent variable Misconduct is a dummy variable indicating whether a financial adviser received a misconduct disclosure in the given year. The variable Pct Female Management measures the share of managers, defined as holding a Series 24 license, working for a firm in a given county and year who are female. The variable $\ln$ (Branch Size) measures the number of advisers for a firm in a given county and year. Share of Advisers with Past Misc. measures the share of advisers working for a firm in a given county and year that have a past record of misconduct. Share of Investment Advisers measures the share of advisers with an investment adviser license (Series 65 or 66) working for a firm in a given county and year. Affiliated with a bank is a dummy variable indicating whether the firm is affiliated with a bank. The dummy variables Corporation, LLC, and Partnership indicate how the firm is set up. In each specification, we control for the full set of interaction terms (i.e. in column (1) we control for Female, $\ln ($ Branch Size), Pct Female Mgmt, Misc $\times \ln ($ Branch Size), Female $\times \ln ($ Branch Size), and Female $\times$ (Pct Female Mgmt)). Coefficients are in percentage points. Other adviser controls include the adviser's experience and licenses (series 6, 7,63, 24, etc.). Standard errors are in parentheses and are clustered by firm. *** $\mathrm{p}<0.01, * * \mathrm{p}<0.05, * \mathrm{p}<0.10$ 
Table A9: Branch Manager Gender Composition, Firm Separation and Punishment Gap

\begin{tabular}{lccccc}
\hline & $(1)$ & $(2)$ & $(3)$ & $(4)$ & $(5)$ \\
\hline Misconduct & $25.6^{* * *}$ & $27.1^{* * *}$ & $21.2^{* * *}$ & $23.9^{* * *}$ & $33.1^{* * *}$ \\
& $(1.41)$ & $(1.34)$ & $(1.37)$ & $(1.95)$ & $(3.17)$ \\
Misconduct $\times$ Female & $11.4^{* * *}$ & $10.9^{* * *}$ & $12.8^{* * *}$ & $12.5^{* * *}$ & $9.51^{* * *}$ \\
& $(2.45)$ & $(2.33)$ & $(2.30)$ & $(2.42)$ & $(2.13)$ \\
Misconduct $\times$ Pct Female Mgmt & $7.15^{* *}$ & $6.78^{* *}$ & $8.01^{* * *}$ & $10.1^{* * *}$ & $7.56^{* *}$ \\
& $(3.15)$ & $(2.90)$ & $(2.77)$ & $(3.79)$ & $(3.32)$ \\
Misconduct $\times$ Female $\times$ Pct Female Mgmt & $-16.3^{* * *}$ & $-15.0^{* * *}$ & $-17.8^{* * *}$ & $-16.2^{* * *}$ & $-12.7^{* * *}$ \\
& $(4.25)$ & $(4.19)$ & $(4.03)$ & $(5.00)$ & $(4.62)$ \\
Adviser Controls & & & & & $\mathrm{X}$ \\
Year $\times$ Firm $\times$ County F.E. & & $\mathrm{X}$ & $\mathrm{X}$ & $\mathrm{X}$ & $\mathrm{X}$ \\
Year $\times$ Firm $\times$ County $\times$ Lic. F.E. & & & & & $\mathrm{X}$ \\
Allegation and Product Controls & & & & & $\mathrm{X}$ \\
Observations & $3,531,190$ & $3,531,190$ & $3,467,897$ & $2,614,794$ & $2,614,794$ \\
R-squared & 0.003 & 0.013 & 0.293 & 0.373 & 0.374 \\
Mean of Dependent Variable & $20 \%$ & $20 \%$ & $20 \%$ & $20 \%$ & $20 \%$ \\
\hline
\end{tabular}

Table A9 presents regression results corresponding to a linear probability model (eq. 6). Observations are at the adviser-by-year level over the period 2006-2014. Here we exclude 2005 from the sample because we calculate the variable Pct Female Mgmt as of 2005 in the "pre" period. The dependent variable is a dummy variable indicating whether a financial adviser left the firm in the following year (either leaving the industry or switching firms in the given year). The dependent variable is scaled by 100 such that coefficients are in percentage points. The independent variable Misconduct is a dummy variable indicating whether a financial adviser received a misconduct disclosure in the given year. The variable Pct Female Mgmt measures the percentage of managers working for a firm in a given county and year that were female as of 2005. When we include the triple interaction terms, we also include the full set of interactions. Other adviser controls include the adviser's experience and licenses (series 6, 7, 63, 24, etc.). In column (5) we also include dummy variables to control for the type of misconduct in terms of the most common allegations and product. Standard errors are in parentheses and are clustered by firm. ${ }^{* * *} \mathrm{p}<0.01,{ }^{* *} \mathrm{p}<0.05,{ }^{*} \mathrm{p}<0.10$. 
Table A10: Executive Gender Composition, Firm Separation and Punishment Gap

\begin{tabular}{lccccc}
\hline & $(1)$ & $(2)$ & $(3)$ & $(4)$ & $(5)$ \\
\hline Misconduct & $42.3^{* * * *}$ & $43.4^{* * *}$ & $40.8^{* * * *}$ & $45.5^{* * * *}$ & $54.4^{* * *}$ \\
& $(3.93)$ & $(3.68)$ & $(4.43)$ & $(4.82)$ & $(4.12)$ \\
Misconduct $\times$ Female & $7.86^{* * *}$ & $7.33^{* * * *}$ & $8.43^{* * * *}$ & 5.60 & 4.67 \\
& $(2.61)$ & $(2.62)$ & $(2.70)$ & $(3.47)$ & $(3.09)$ \\
Misconduct $\times$ Pct Female Exec & -14.6 & -14.2 & -12.6 & -16.1 & -4.20 \\
& $(11.4)$ & $(10.7)$ & $(13.0)$ & $(14.3)$ & $(9.60)$ \\
Misconduct $\times$ Female $\times$ Pct Female Exec & $-22.0^{* *}$ & $-21.3^{* *}$ & $-25.5^{* * *}$ & $-24.1^{*}$ & -20.8 \\
& $(9.93)$ & $(10.1)$ & $(9.87)$ & $(14.4)$ & $(13.5)$ \\
Adviser Controls & & $\mathrm{X}$ & $\mathrm{X}$ & $\mathrm{X}$ & $\mathrm{X}$ \\
Year $\times$ Firm $\times$ County F.E. & & & $\mathrm{X}$ & & \\
Year $\times$ Firm $\times$ County $\times$ Lic. F.E. & & & & $\mathrm{X}$ & $\mathrm{X}$ \\
Allegation and Product Controls & $1,927,961$ & $1,994,652$ & $1,927,961$ & $1,424,652$ & $1,424,652$ \\
Observations & 0.010 & 0.018 & 0.198 & 0.287 & 0.288 \\
R-squared & $14 \%$ & $14 \%$ & $14 \%$ & $14 \%$ & $14 \%$ \\
Mean of Dependent Variable & & & & & \\
\hline
\end{tabular}

Table A10 presents regression results corresponding to a linear probability model. Observations are at the adviser level over the period 2015-2018. We examine misconduct over the period 2015-2017 and separations in the subsequent years (2016-2018). We examine the period starting in 2015 because we only see the composition of firm executives as of 2015. The dependent variable is a dummy variable indicating whether a financial adviser left the firm in the following year (either leaving the industry or switching firms in the given year). The dependent variable is scaled by 100 such that coefficients are in percentage points. The independent variable Misconduct is a dummy variable indicating whether a financial adviser received a misconduct disclosure in the given year. The variable Pct Female Exec measures the share of executives/owners that are female as of 2015. In each specification we also control for the full set of Female, Misconduct, and Pct Female Exec interaction terms (i.e. Pct Female Exec, Pct Female Exec $\times$ Female). Other adviser controls include the adviser's experience and licenses (series 6, 7, 63, 24, etc.). In our most stringent specifications, we include Year $\times$ Firm $\times$ County $\times$ License F.E: fully saturated fixed effects for each set of possible licenses an adviser potentially holds within a firm, location, and time. In column (5) we include dummy variables to control for the most common misconduct allegations and products reported in Table 1. Standard errors are in parentheses and are clustered by firm. $* * * \mathrm{p}<0.01, * * \mathrm{p}<0.05, * \mathrm{p}<0.10$. 
Table A11: Female Managers and Firm Hiring

\begin{tabular}{lcccc}
\hline & $(1)$ & $(2)$ & $(3)$ & $(4)$ \\
\hline Pct Female Mgmt & $0.77^{* * *}$ & $0.76^{* * *}$ & $0.99^{* * *}$ & $0.95^{* * *}$ \\
& $(0.12)$ & $(0.12)$ & $(0.13)$ & $(0.13)$ \\
Pct Female New Hires & $3.54^{* * *}$ & $3.54^{* * *}$ & $3.67^{* * *}$ & $3.63^{* * *}$ \\
& $(0.13)$ & $(0.13)$ & $(0.14)$ & $(0.15)$ \\
& & & & \\
Year F.E & & $\mathrm{X}$ & $\mathrm{X}$ & $\mathrm{X}$ \\
Firm F.E. & & & $\mathrm{X}$ & $\mathrm{X}$ \\
Firm $\times$ Year F.E. & 122,143 & 122,143 & 120,913 & $\mathrm{X}$ \\
Observations & 0.031 & 0.031 & 0.083 & 0.119 \\
R-squared & & & & \\
Mean of Dependent Variable & $0.75 \%$ & $0.75 \%$ & $0.75 \%$ & $0.78 \%$ \\
\hline
\end{tabular}

Table A11 displays the estimation results corresponding to a firm's hiring patterns. Observations are at the firm branch-by-year level over the period 2005-2015. The dependent variable reflects the share of new employees that were hired in a given firm, branch, and year that are female and have a past record of misconduct. The dependent variable is scaled by 100 such that coefficients are in percentage points. If the firm branch did not hire any new employees in a given year, the observation is treated as missing. The variable Pct Female Mgmt measures the share of managers working for a firm in a given county and year that are female. The variable Pct Female New Hires reflects the share of new employees that were hired in a given firm, branch, and year that are female. Robust standard errors are in parentheses. $* * * \mathrm{p}<0.01, * *$ $\mathrm{p}<0.05, * \mathrm{p}<0.10$. 
Table A12: Minority Male Managers and Female Advisers

(a) Female Advisers and African Male Managers

\begin{tabular}{|c|c|c|c|c|c|c|c|c|}
\hline & (1) & (2) & (3) & (4) & (5) & (6) & (7) & (8) \\
\hline Misc. & $\begin{array}{c}28.2^{* * *} \\
(1.33)\end{array}$ & $\begin{array}{c}21.8^{* * * * *} \\
(1.46)\end{array}$ & $\begin{array}{c}25.1^{* * * *} \\
(2.09)\end{array}$ & $\begin{array}{c}34.1^{* \ldots * k} \\
(3.12)\end{array}$ & $\begin{array}{c}26.7^{* * * *} \\
(1.19)\end{array}$ & $\begin{array}{c}19.9^{* \cdots * *} \\
(1.33)\end{array}$ & $\begin{array}{c}22.7^{* \ldots *} \\
(2.01)\end{array}$ & $\begin{array}{c}32.1^{* * * *} \\
(3.06)\end{array}$ \\
\hline Misc. $\times$ Female & $\begin{array}{c}8.07^{* * * *} \\
(1.88)\end{array}$ & $\begin{array}{c}9.81 * * * \\
(1.91)\end{array}$ & $\begin{array}{c}9.59 * * * \\
(2.01)\end{array}$ & $\begin{array}{c}7.35 \\
(1.61)\end{array}$ & $\begin{array}{c}10.3^{* \cdots * * *} \\
(2.52)\end{array}$ & $\begin{array}{c}13.3^{* * *} \\
(2.32)\end{array}$ & $\begin{array}{c}11.4 * * * \\
(2.28)\end{array}$ & $\begin{array}{c}8.99 * * * \\
(1.91)\end{array}$ \\
\hline Misc. $\times$ Pct African Mgmt & $\begin{array}{l}10.4^{* *} \\
(4.73)\end{array}$ & $\begin{array}{c}8.22 \\
(5.54)\end{array}$ & $\begin{array}{c}11.1 \\
(8.66)\end{array}$ & $\begin{array}{c}9.63 \\
(7.84)\end{array}$ & $\begin{array}{l}10.4^{* *} \\
(4.71)\end{array}$ & $\begin{array}{c}8.13 \\
(5.50)\end{array}$ & $\begin{array}{c}11.5 \\
(8.71)\end{array}$ & $\begin{array}{c}9.88 \\
(7.90)\end{array}$ \\
\hline Misc. $\times$ Female $\times$ Pct African Mgmt & $\begin{array}{l}14.0 \\
(13.9)\end{array}$ & $\begin{array}{c}9.71 \\
(13.6)\end{array}$ & $\begin{array}{c}14.4 \\
(20.7)\end{array}$ & $\begin{array}{l}4.95 \\
(20.0)\end{array}$ & $\begin{array}{c}14.3 \\
(13.9)\end{array}$ & $\begin{array}{c}11.1 \\
(13.6)\end{array}$ & $\begin{array}{c}13.7 \\
(20.4)\end{array}$ & $\begin{array}{c}4.68 \\
(19.9)\end{array}$ \\
\hline Misc. $\times$ Pct Female Mgmt & & & & & $\begin{array}{c}10.3^{* \cdots * *} \\
(2.20)\end{array}$ & $\begin{array}{c}11.6^{* * * *} \\
(2.12)\end{array}$ & $\begin{array}{c}13.6^{* * * *} \\
(3.11)\end{array}$ & $\begin{array}{c}11.2^{* * * *} \\
(2.98)\end{array}$ \\
\hline Misc. $\times$ Female $\times$ Pct Female Mgmt & & & & & $\begin{array}{c}-13.0^{* * * *} \\
(4.25)\end{array}$ & $\begin{array}{c}-18.7^{* * * * *}+ \\
(3.31)\end{array}$ & $\begin{array}{c}\left.-10.8^{* \cdots *}+12\right) \\
(4.12)\end{array}$ & $\begin{array}{c}-9.37 * * \\
(3.87)\end{array}$ \\
\hline $\begin{array}{l}\text { Adviser Controls } \\
\text { Year } \times \text { Firm } \times \text { Cour }\end{array}$ & $\mathrm{X}$ & $\mathrm{X}$ & $\mathrm{X}$ & $\mathrm{X}$ & $\mathrm{X}$ & $\mathrm{X}$ & $\mathrm{X}$ & $\mathrm{X}$ \\
\hline Year $\times$ & & & $\mathrm{X}$ & $\mathrm{X}$ & & & $\mathrm{X}$ & $\mathrm{X}$ \\
\hline Allegat & & & & $\mathrm{X}$ & & & & $\mathrm{X}$ \\
\hline Observations & $4,839,243$ & $4,722,832$ & $3,480,225$ & $3,480,225$ & $4,839,243$ & $4,722,832$ & $3,480,225$ & $3,480,225$ \\
\hline & 0.014 & 0.315 & 0.393 & 0.394 & 0.014 & 0.315 & 0.393 & 0.394 \\
\hline Mean of Dependent Variable & $20 \%$ & $20 \%$ & $20 \%$ & $20 \%$ & $20 \%$ & $20 \%$ & $20 \%$ & $20 \%$ \\
\hline
\end{tabular}

(b) Female Advisers and Hispanic Male Managers

\begin{tabular}{|c|c|c|c|c|c|c|c|c|}
\hline & (1) & (2) & (3) & (4) & (5) & (6) & (7) & (8) \\
\hline Misc. & $\begin{array}{c}28.2^{* \cdots *} \\
(1.27)\end{array}$ & $\begin{array}{c}21.6^{* * * *} \\
(1.40)\end{array}$ & $\begin{array}{c}24.8^{* * * *} \\
(1.96)\end{array}$ & $\begin{array}{c}33.9^{* * * *} \\
(3.03)\end{array}$ & $\begin{array}{c}26.6^{* * * *} \\
(1.16)\end{array}$ & $\begin{array}{c}19.8^{* * * *} \\
(1.28)\end{array}$ & $\begin{array}{c}22.3^{* * * *} \\
(1.90)\end{array}$ & $\begin{array}{c}31.8^{* * * *} \\
(2.99)\end{array}$ \\
\hline Misc. $\times$ Female & $\begin{array}{c}8.48 * \cdots \\
(1.92)\end{array}$ & $\begin{array}{c}10.4^{* * * *} \\
(1.91)\end{array}$ & $\begin{array}{c}10.4^{* * * *} \\
(2.01)\end{array}$ & $\begin{array}{c}7.99 * * * \\
(1.63)\end{array}$ & $\begin{array}{c}10.6^{* * * *} \\
(2.57)\end{array}$ & $\begin{array}{c}13.9^{* * * *} \\
(2.32)\end{array}$ & $\begin{array}{c}12.2^{2 * * *} \\
(2.31)\end{array}$ & $\begin{array}{l}9.59 \div * \cdots \\
(1.94)\end{array}$ \\
\hline Misc. $\times$ Pct Hispanic Mgmt & $\begin{array}{c}5.60 \\
(4.20)\end{array}$ & $\begin{array}{l}7.95^{*} \\
(4.51)\end{array}$ & $\begin{array}{l}13.6^{*} \\
(7.26)\end{array}$ & $\begin{array}{l}10.3^{*} \\
(5.97)\end{array}$ & $\begin{array}{c}5.07 \\
(4.10)\end{array}$ & $\begin{array}{l}7.40 * \\
(4.40)\end{array}$ & $\begin{array}{l}13.7^{*} \\
(7.21)\end{array}$ & $\begin{array}{l}10.4^{*} \\
(5.97)\end{array}$ \\
\hline Misc. $\times$ Female $\times$ Pct Hispanic Mgmt & $\begin{array}{l}-5.62 \\
(7.63)\end{array}$ & $\begin{array}{l}-11.6^{*} \\
(6.89)\end{array}$ & $\begin{array}{l}-15.4 \\
(9.49)\end{array}$ & $\begin{array}{l}-13.6 \\
(8.68)\end{array}$ & $\begin{array}{l}-5.00 \\
(7.61)\end{array}$ & $\begin{array}{l}-11.5^{*} \\
(6.86)\end{array}$ & $\begin{array}{l}-15.5^{*} \\
(9.36)\end{array}$ & $\begin{array}{l}-13.7 \\
(8.60)\end{array}$ \\
\hline Misc. $\times$ Pct Female Mgmt & & & & & $\begin{array}{c}10.2^{* * * *} \\
(2.15)\end{array}$ & $\begin{array}{c}11.5^{* * * *} \\
(2.07)\end{array}$ & $\begin{array}{c}13.6 * \cdots * * \\
(3.09)\end{array}$ & $\begin{array}{c}11.2^{* * * *} \\
(2.96)\end{array}$ \\
\hline Misc. $\times$ Female $\times$ Pct Female Mgmt & & & & & $\begin{array}{c}-12.7^{* * * *} \\
(4.25)\end{array}$ & $\begin{array}{c}-18.4^{* * * *} \\
(3.34)\end{array}$ & $\begin{array}{c}-10.5^{* * *} \\
(4.16)\end{array}$ & $\begin{array}{c}-9.20^{* * *} \\
(3.89)\end{array}$ \\
\hline Adviser & $\mathrm{X}$ & $\mathrm{X}$ & $\mathrm{X}$ & $\mathrm{X}$ & $\mathrm{X}$ & $\mathrm{X}$ & $\mathrm{X}$ & $\mathrm{X}$ \\
\hline Year $\times$ & & $\mathrm{X}$ & & & & $\mathrm{X}$ & & \\
\hline Year $x$ & & & $\mathrm{X}$ & $\mathrm{X}$ & & & $\mathrm{X}$ & $\mathrm{X}$ \\
\hline Allega & & & & $\mathrm{X}$ & & & & $\mathrm{X}$ \\
\hline Obser & $4,839,243$ & $4,722,832$ & $3,480,225$ & $3,480,225$ & $4,839,243$ & $4,722,832$ & $3,480,225$ & $3,480,225$ \\
\hline & 0.014 & 0.315 & 0.393 & 0.394 & 0.014 & 0.315 & 0.393 & 0.394 \\
\hline Mean of Dependent Variable & $20 \%$ & $20 \%$ & $20 \%$ & $20 \%$ & $20 \%$ & $20 \%$ & $20 \%$ & $20 \%$ \\
\hline
\end{tabular}

Table A12 displays the results to the linear probability models (eq. 9). Observations are at the adviser-by-year level over the period 2005-2014. Since we track advisers who left their firm in the subsequent year, the sample covers the period 2005-2014 rather than 2005-2015. The dependent variable in each specification is a dummy variable indicating whether a financial adviser left the firm in the following year and is scaled by 100 such that coefficients are in percentage points. Misconduct (abbreviated Misc.) is a dummy variable indicating whether a financial adviser received a misconduct disclosure in the given year. The variable Pct African Mgmt (Pct Hispanic Mgmt, Pct Female Mgmt) measures the share of managers working for a firm in a given county and year that have names of African descent (Hispanic descent, Female). When we include the triple interaction terms, we also include the full set of interactions (i.e. in column (1) of panel (a) we control for Pct African Mgmt and Pct African Mgmt $\times$ Female). Other adviser controls include the adviser's experience and dummy variables for the licenses the adviser holds (Series 6, 7, 24, etc.). In our most stringent specifications, we include Year $\times$ Firm $\times$ County $\times$ License F.E: fully saturated fixed effects for each set of possible licenses an adviser potentially holds within a firm, location, and time. In columns (4) and (8) of both panels we include dummy variables to control for the most common misconduct allegations and products reported in Table A24. Standard errors are in parentheses and are clustered by firm. $* * * \mathrm{p}<0.01$, $* * \mathrm{p}<0.05, * \mathrm{p}<0.10$. 
Table A13: Employment Separations - Conditioning on Productivity and Severity of Misconduct

\begin{tabular}{lcc}
\hline & $(1)$ & $(2)$ \\
\hline Misconduct & $8.812^{* * *}$ & $32.27^{* * *}$ \\
Misconduct $\times$ Female & $(0.889)$ & $(2.523)$ \\
& $4.261^{* * *}$ & $2.694^{*}$ \\
Female & $(1.583)$ & $(1.402)$ \\
& $-0.382^{* * *}$ & $-0.659^{* * *}$ \\
High Rating & $(0.102)$ & $(0.109)$ \\
& & $-4.005^{* * *}$ \\
ln(AUM) & & $(0.637)$ \\
& & $-0.431^{* * *}$ \\
ln(Production) & & $(0.0734)$ \\
& & $-0.236^{* * *}$ \\
No Settlement & & $(0.0711)$ \\
& & $27.16^{* * *}$ \\
ln(Settlement+1) & & $(3.076)$ \\
& & -0.143 \\
& & $(0.281)$ \\
Adviser Controls & $\mathrm{X}$ & $\mathrm{X}$ \\
Year $\times$ Firm $\times$ County F.E. & & $\mathrm{X}$ \\
& & \\
Observations & 442,159 & 442,159 \\
R-squared & 0.624 & 0.628 \\
\hline
\end{tabular}

Table A13 presents regression results corresponding to a linear probability model. Observations are at the financial adviser-by-year-level over the period 2005-2014. Since we track advisers who left their firm in the subsequent year, the sample covers the period 2005-2014 rather than 2005-2015. The dependent variable is a dummy variable indicating whether a financial adviser left the firm (either leaving the industry or switching firms) in the given year. The independent variable Misconduct is a dummy variable indicating whether a financial adviser received a misconduct disclosure in the given year. We control for three different dimensions of productivity in 2016 from Meridian IQ: High Rating is a dummy variable equal to one if the adviser has a high quality rating from Meridian IQ; $\ln ($ AUM) measures the adviser's assets under management ; $\ln$ (Production) measures the adviser's production (revenue). We also control for whether or not settlements or damages were paid out as a result of the misconduct (No Settlement) and the size of the settlement or damages $(\ln ($ Settlement +1$))$. Coefficients are in percentage points. Other adviser controls include the adviser's experience and licenses (series $6,7,63,24$, etc.). Standard errors are in parentheses and are clustered by firm. *** $\mathrm{p}<0.01, * * \mathrm{p}<0.05,{ }^{*} \mathrm{p}<0.10$. 
Table A14: Labor Market Outcomes following Misconduct related to Unauthorized Activity

\begin{tabular}{|c|c|c|c|c|c|c|c|c|}
\hline \multirow[t]{2}{*}{ Dependent Variable } & \multicolumn{4}{|c|}{ Employment Separation } & \multicolumn{4}{|c|}{ New Employment } \\
\hline & (1) & (2) & (3) & (4) & (5) & (6) & (7) & (8) \\
\hline Unauthorized Activity & $35.8 * * *$ & $37.0 * * *$ & $28.2^{* * *}$ & $31.0^{* * * *}$ & $-11.4 * * *$ & $-15.8 * * *$ & $-11.7 * * *$ & $-10.2^{* * *}$ \\
\hline & $(1.57)$ & $(1.45)$ & $(1.88)$ & $(2.68)$ & $(2.51)$ & $(1.73)$ & $(1.30)$ & (1.77) \\
\hline Unauthorized Act. $\times$ Female & $\begin{array}{c}10.3 * * * \\
(3.21)\end{array}$ & $\begin{array}{c}9.91 * * * \\
(3.03)\end{array}$ & $\begin{array}{c}14.5 * * * \\
(3.25)\end{array}$ & $\begin{array}{c}14.5 * * * \\
(3.53)\end{array}$ & $\begin{array}{c}-13.4 * * * \\
(2.49)\end{array}$ & $\begin{array}{c}-11.7 * * * \\
(2.67)\end{array}$ & $\begin{array}{c}-7.29 * * \\
(3.62)\end{array}$ & $\begin{array}{l}-6.58 \\
(4.98)\end{array}$ \\
\hline Female & $\begin{array}{c}0.14 \\
(0.29)\end{array}$ & $\begin{array}{l}-0.52 \\
(0.34)\end{array}$ & $\begin{array}{c}-0.52^{* * *} \\
(0.15)\end{array}$ & $\begin{array}{c}-0.48^{* * * *} \\
(0.15)\end{array}$ & $\begin{array}{c}-6.22 * * * \\
(0.65)\end{array}$ & $\begin{array}{c}-2.43^{* \cdots *} \\
(0.61)\end{array}$ & $\begin{array}{c}-4.05 * * * \\
(0.26)\end{array}$ & $\begin{array}{c}-3.83^{* * * *} \\
(0.29)\end{array}$ \\
\hline Advi & & $\mathrm{X}$ & $\mathrm{X}$ & $\mathrm{X}$ & & $\mathrm{X}$ & $\mathrm{X}$ & $\mathrm{X}$ \\
\hline $\operatorname{Yr} \times \mathrm{F}$ & & & $\mathrm{X}$ & & & & $\mathrm{X}$ & \\
\hline Znty $\times$ Lic. F.E. & & & & $\mathrm{X}$ & & & & $\mathrm{X}$ \\
\hline Obse & $5,967,836$ & $5,967,836$ & $5,665,189$ & $4,070,742$ & $1,110,014$ & $1,110,01<$ & 992,045 & 651,237 \\
\hline R-squ & 0.001 & 0.011 & 0.331 & 0.402 & 0.003 & 0.101 & 0.366 & 0.465 \\
\hline Mean of Dependent Variable & $19 \%$ & $19 \%$ & $19 \%$ & $19 \%$ & $53 \%$ & $53 \%$ & $54 \%$ & $51 \%$ \\
\hline
\end{tabular}

Table A14 displays the regression results corresponding to linear probability models (eq. 3 and 4). Observations are at the financial adviser-by-year-level over the period 2005-2014, where we exclude observations in which the adviser received a non-unauthorized activity related misconduct disclosure. Since we track advisers who left their firm in the subsequent year, the sample covers the period 2005-2014 rather than 2005-2015. The dependent variable in columns (1)-(4) is a dummy variable indicating whether a financial adviser left the firm and is scaled by 100 such that coefficients are in percentage points. The dependent variable in columns (5)-(8) is a dummy variable indicating whether a financial adviser joined a new firm within one year and is scaled by 100 such that coefficients are in percentage points. In columns (5)-(8), we restrict the sample to advisers who left their firm in a given year. Unauthorized Activity is a dummy variable indicating whether a financial adviser received a misconduct disclosure related to unauthorized activity in the given year. Other adviser controls include the adviser's experience and dummy variables for the licenses that the adviser holds (Series 6, 7, 24, etc.). In our most stringent specification, we include Year $\times$ Firm $\times$ County $\times$ License F.E: fully saturated fixed effects for each set of possible licenses an adviser potentially holds within a given firm, location, and time. Standard errors are in parentheses and are clustered by firm. ${ }^{* * *} \mathrm{p}<0.01,{ }^{* *} \mathrm{p}<0.05,{ }^{*} \mathrm{p}<0.10$. 
Table A15: Misconduct Topics (Latent Dirichlet Allocation)

\begin{tabular}{ll}
\hline Topic & Description \\
\hline 1 & Failure to comply with agency/firm/exchange rules (FINRA, NASD, NYSE) \\
2 & Failure to comply with state/federal laws: focus on legal proceedings \\
3 & Misrepresentation, failure to disclose, unsuitable investments \\
4 & Multiple allegations made against financial advisor \\
5 & Failure to comply with regulations and laws: focus on fraudulent activity \\
6 & Unauthorized, unsuitable trading \\
7 & Not investment-related \\
8 & Life insurance products, mutual funds, fixed income securities \\
9 & Improper handling of accounts/investments \\
10 & Limited Partnerships and Auction Rate Securities \\
\hline
\end{tabular}

Table A15 displays the misconduct topics recovered via Latent Dirichlet Allocation (LDA). We use LDA to cluster the misconduct disclosure descriptions into ten different categories. We only specify the number of topics to be generated (not the topics themselves). For each misconduct disclosure, LDA calculates the probability that the disclosure corresponds to each of the ten different topics. We assign each misconduct disclosure to the topic given the highest probability, provided that the assigned probability is greater than $80 \%$. We are able to definitively assign topics to roughly $30 \%$ of the misconduct disclosures. 
Table A16: Employment Separations - Conditioning on Type of Misconduct

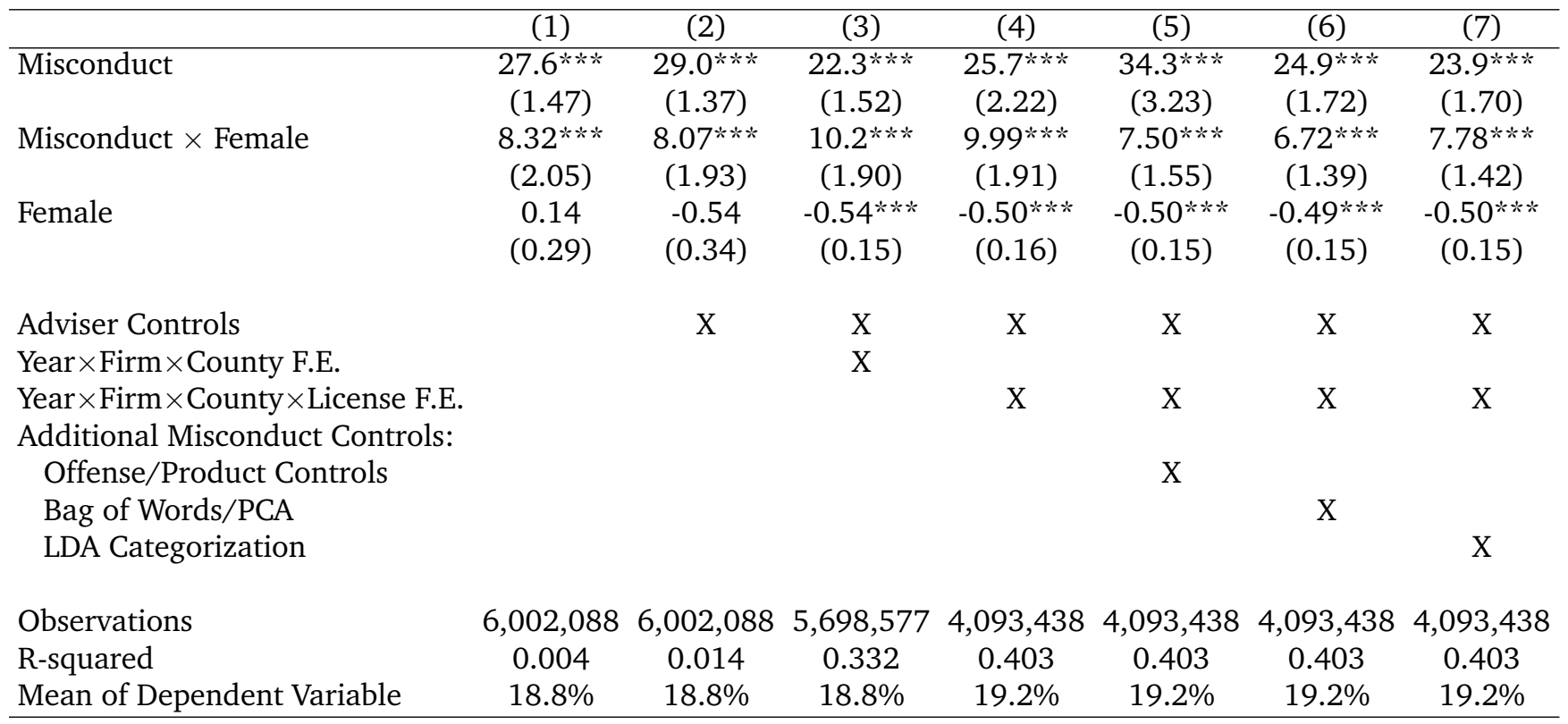

Table A16 presents regression results corresponding to a linear probability model (eq. 3). Observations are at the financial adviser-by-year-level over the period 2005-2014. Since we track advisers who left their firm in the subsequent year, the sample covers the period 2005-2014 rather than 2005-2015. The dependent variable is a dummy variable indicating whether a financial adviser left the firm (either leaving the industry or switching firms) in the given year. The independent variable Misconduct is a dummy variable indicating whether a financial adviser received a misconduct disclosure in the given year. Coefficients are in percentage points. Other adviser controls include the adviser's experience and licenses (series 6, 7, 63, 24, etc.). We include dummy variables to account for the most commmon misconduct offenses and products as reported in Table 1. Bag of Words/PCA represents pricipal components of misconduct offenses classified using the Bag of Words approach (Gentzkow, Kelly, and Taddy 2019). LDA Categorization uses Latent Dirchlet Allocation to cluster Misconduct into ten topics/categories. We include dummy variables for each of the ten topics/categories recovered through LDA (Table A15). Standard errors are in parentheses and are clustered by firm. *** $\mathrm{p}<0.01, * * \mathrm{p}<0.05, * \mathrm{p}<0.10$. 
Table A17: New Employment - Conditioning on Type of Misconduct

\begin{tabular}{|c|c|c|c|c|c|c|c|}
\hline & (1) & (2) & (3) & (4) & (5) & (6) & (7) \\
\hline Misconduct & $\begin{array}{l}-7.66 * * * \\
(2.13)\end{array}$ & $\begin{array}{l}-12.2^{* * *} \\
(1.41)\end{array}$ & $\begin{array}{l}-9.15 * * * \\
(1.09)\end{array}$ & $\begin{array}{l}-8.94 * * * \\
(1.46)\end{array}$ & $\begin{array}{l}-10.8 * * * \\
(1.93)\end{array}$ & $\begin{array}{l}-5.99 * * * \\
(1.26)\end{array}$ & $\begin{array}{l}-7.02^{* * * *} \\
(1.37)\end{array}$ \\
\hline Misconduct $\times$ Female & $\begin{array}{l}-7.22 * * * \\
(1.80)\end{array}$ & $\begin{array}{l}-5.40 * * * \\
(1.31)\end{array}$ & $\begin{array}{l}-3.44 * * * \\
(1.22)\end{array}$ & $\begin{array}{c}-3.54 * * * \\
(1.27)\end{array}$ & $\begin{array}{l}-2.48^{* *} \\
(1.24)\end{array}$ & $\begin{array}{l}-3.33 * * \\
(1.40)\end{array}$ & $\begin{array}{c}-2.84 * * \\
(1.29)\end{array}$ \\
\hline Female & $\begin{array}{l}-6.22 * * * \\
(0.65)\end{array}$ & $\begin{array}{l}-2.42 * * * \\
(0.61)\end{array}$ & $\begin{array}{l}-4.04 * * * \\
(0.26)\end{array}$ & $\begin{array}{l}-3.83 * * * \\
(0.29)\end{array}$ & $\begin{array}{l}-3.83^{* * * *} \\
(0.29)\end{array}$ & $\begin{array}{c}-3.83 * * * \\
(0.29)\end{array}$ & $\begin{array}{l}-3.83 * * * \\
(0.29)\end{array}$ \\
\hline $\begin{array}{l}\text { Adviser Controls } \\
\text { Year } \times \text { Firm } \times \text { Coun }\end{array}$ & & $\mathrm{X}$ & $\begin{array}{l}X \\
X\end{array}$ & $\mathrm{X}$ & $\mathrm{X}$ & $\mathrm{X}$ & $\mathrm{X}$ \\
\hline $\begin{array}{l}\text { Year } \times \text { Firm } \times \text { County } \times \text { License F.E. } \\
\text { Additional Misconduct Controls: }\end{array}$ & & & & $\mathrm{X}$ & $\mathrm{X}$ & $\mathrm{X}$ & $\mathrm{X}$ \\
\hline $\begin{array}{l}\text { Offense/Pro } \\
\text { Bag of Word } \\
\text { LDA Categor }\end{array}$ & & & & & $\mathrm{X}$ & $\mathrm{X}$ & $\mathrm{X}$ \\
\hline Obser & $1,125,715$ & $1,125,715$ & $1,006,760$ & 660,127 & 660,127 & 660,127 & 660,127 \\
\hline R-squ & 0.003 & 0.101 & 0.365 & 0.464 & 0.465 & 0.465 & 0.465 \\
\hline Mean of Dependent Variable & $52.8 \%$ & $52.8 \%$ & $54.0 \%$ & $51.4 \%$ & $51.4 \%$ & $51.4 \%$ & $51.4 \%$ \\
\hline
\end{tabular}

Table A17 presents regression results corresponding to a linear probability model (eq. 4). Observations are at the financial adviser-by-year-level over the period 2005-2014. Since we track advisers who left their firm in the subsequent year, the sample covers the period 2005-2014 rather than 2005-2015. We restrict the sample to those advisers who left their firm in a given year. The dependent variable is a dummy variable indicating whether a financial adviser joined a new firm within one year. The independent variable Misconduct is a dummy variable indicating whether a financial adviser received a misconduct disclosure in the given year. Coefficients are in percentage points. Other adviser controls include the adviser's experience and licenses (series 6, 7, 63, 24, etc.). We include dummy variables to account for the most common misconduct offenses and products as reported in Table 1. Bag of Words/PCA represents principal components of misconduct offenses classified using the Bag of Words approach (Gentzkow, Kelly, and Taddy 2019). LDA Categorization uses Latent Dirichlet Allocation to cluster Misconduct into ten topics/categories. We include dummy variables for each of the ten topics/categories recovered through LDA (Table A15). Standard errors are in parentheses and are clustered by firm. $* * * \mathrm{p}<0.01, * * \mathrm{p}<0.05, * \mathrm{p}<0.10$. 
Table A18: Conditioning on Career Interruptions

\begin{tabular}{lcccc}
\hline Dependent Variable & \multicolumn{3}{c}{ Employment Separation } & \multicolumn{2}{c}{ New Employment } \\
& $(1)$ & $(2)$ & $(3)$ & $(4)$ \\
\hline Female & $-0.50^{* * * *}$ & $-0.50^{* * *}$ & $-3.84^{* * *}$ & $-3.84^{* * * *}$ \\
& $(0.16)$ & $(0.16)$ & $(0.29)$ & $(0.29)$ \\
Misconduct & $34.3^{* * *}$ & $34.2^{* * *}$ & $-10.9^{* * *}$ & $-10.2^{* * *}$ \\
& $(3.23)$ & $(3.37)$ & $(1.93)$ & $(1.98)$ \\
Misconduct $\times$ Female & $7.48^{* * *}$ & $7.49^{* * *}$ & $-2.45^{* *}$ & $-2.53 * *$ \\
& $(1.54)$ & $(1.54)$ & $(1.24)$ & $(1.25)$ \\
Career Interruption & $4.03 * * *$ & $4.03^{* * *}$ & $-2.36^{* * * *}$ & $-2.30^{* * *}$ \\
& $(0.21)$ & $(0.21)$ & $(0.30)$ & $(0.30)$ \\
Career Interruption $\times$ Misconduct & & 0.72 & & $-4.49 * * *$ \\
& & $(1.58)$ & & $(1.52)$ \\
Adviser Controls & & & & \\
Year $\times$ Firm $\times$ County $\times$ License F.E. & $\mathrm{X}$ & $\mathrm{X}$ & $\mathrm{X}$ & $\mathrm{X}$ \\
Allegation and Product Controls & $\mathrm{X}$ & $\mathrm{X}$ & $\mathrm{X}$ & $\mathrm{X}$ \\
Observations & $4,093,438$ & $4,093,438$ & 660,127 & 660,127 \\
R-squared & 0.404 & 0.404 & 0.465 & 0.465 \\
Mean of Dependent Variable & $19 \%$ & $19 \%$ & $51 \%$ & $51 \%$ \\
\hline
\end{tabular}

Table A18 displays the regression results for two linear probability models (eq. 3 and 4). Observations are at the adviser-by-year-level over the period 2005-2014. Since we track advisers who left their firm in the subsequent year, the sample covers the period 2005-2014 rather than 2005-2015. The dependent variable in columns (1) and (2) is a dummy variable indicating whether a financial adviser left the firm and is scaled by 100 such that coefficients are in percentage points. The dependent variable in columns (3)-(4) is a dummy variable indicating whether a financial adviser joined a new firm within one year and is scaled by 100 such that coefficients are in percentage points. In columns (3) and (4), we restrict the sample to advisers who left their firms in a given year. Misconduct is a dummy variable indicating whether a financial adviser received a misconduct disclosure in the given year. Career interruption is a dummy variable indicating whether an adviser has previously left the financial services industry for more than six months. In each specification we include Year $\times$ Firm $\times$ County $\times$ License F.E.: fully saturated fixed effects for each set of possible licenses an adviser potentially holds within a firm, location, and time. Other adviser controls include the adviser's experience and dummy variables for the licenses that the adviser holds (Series 6, 7, 24, etc.). Allegation and product controls include dummy variables to control for the most common misconduct allegations and products reported in Table A24. Standard errors are in parentheses and are clustered by firm. $* * * * 0.01$, $* * \mathrm{p}<0.05, * \mathrm{p}<0.10$. 
Table A19: Job Turnover Among Advisers Who Eventually Engage in Misconduct

\begin{tabular}{lccc}
\hline & $(1)$ & $(2)$ & $(3)$ \\
\hline Female & $-1.72^{* * * *}$ & $-1.79^{* * *}$ & $-1.58^{* * *}$ \\
& $(0.65)$ & $(0.59)$ & $(0.35)$ \\
& & & \\
Adviser Controls & & $\mathrm{X}$ & $\mathrm{X}$ \\
Year $\times$ Firm $\times$ County F.E. & & & $\mathrm{X}$ \\
Observations & 102,915 & 102,915 & 63,124 \\
R-squared & 0.000 & 0.013 & 0.596 \\
Mean of Dependent Variable & $15.9 \%$ & $15.9 \%$ & $17.8 \%$ \\
\hline
\end{tabular}

Table A19 displays the regression results corresponding to a linear probability model (eq. 3). The dependent variable is a dummy variable indicating whether a financial adviser left the firm (either leaving the industry or switching firms) prior to incident of misconduct. Observations are at the financial adviser-by-year level over the period 2005-2014. Since we track advisers who left their firm in the subsequent year, the sample covers the period 2005-2014 rather than 2005-2015. We restrict the sample to observations corresponding to advisers who had not yet received a misconduct disclosure but who will ultimately receive one or more misconduct disclosures over the course of his/her career. Other adviser controls include the adviser's experience and dummy variables for the licenses the adviser holds (Series 6, 7, 24, etc.). Coefficients are in percentage points. Standard errors are in parentheses and are clustered by firm. ${ }^{* *} \mathrm{p}<0.01,{ }^{* *} \mathrm{p}<0.05$, * $\mathrm{p}<0.10$. 
Table A20: Job Turnover in Firms that Downsize

\begin{tabular}{lccccc}
\hline & $(1)$ & $(2)$ & $(3)$ & $(4)$ & $(5)$ \\
\hline Downsize & $22.9^{* * *}$ & $22.5^{* * *}$ & & & \\
& $(1.88)$ & $(1.91)$ & & & \\
Downsize $\times$ Female & 1.91 & $1.99^{*}$ & 0.32 & 0.21 & 0.59 \\
& $(1.02)$ & $(1.00)$ & $(0.29)$ & $(0.22)$ & $(0.37)$ \\
Female & -0.14 & $-0.86^{* * *}$ & $-0.59^{* * *}$ & $-0.61^{* *}$ & $-0.58^{* * *}$ \\
& $(0.22)$ & $(0.26)$ & $(0.17)$ & $(0.19)$ & $(0.16)$ \\
Adviser Controls & & & & & \\
Year $\times$ Firm $\times$ County $\times$ License F.E. & & $\mathrm{X}$ & $\mathrm{X}$ & $\mathrm{X}$ & $\mathrm{X}$ \\
Downsize: $5 \%+$ & & $\mathrm{X}$ & $\mathrm{X}$ & $\mathrm{X}$ \\
Downsize: $25 \%+$ & & & $\mathrm{X}$ & $\mathrm{X}$ \\
Observations & & & & & \\
R-squared & & & & & \\
Mean of Dependent Variable & $18.8 \%$ & $18.8 \%$ & $19.2 \%$ & $19.2 \%$ & $19.2 \%$ \\
\hline
\end{tabular}

Table A20 displays the results for a linear probability model. Observations are at the adviser-by-year-level over the period 2005-2014. Since we track advisers who left their firm in the subsequent year, the sample covers the period 2005-2014 rather than 2005-2015. The dependent variable is a dummy variable indicating whether a financial adviser left the firm in the following year (either leaving the industry or switching firms). The dependent variable is scaled by 100 such that coefficients are in percentage points. The independent variable Downsize is a dummy variable which indicates whether the advisers' current firm reduced the number of advisers the firm employs by some percentage over the year. In columns (1)-(3), we define Downsize as a firm that reduced its number of advisers by $10 \%$ or more. In columns (4) and (5), we redefine Downsize as a firm that reduces its number of advisers by $5 \%$ or more and $25 \%$ or more, respectively. Coefficients are in percentage points. Other adviser controls include the adviser's experience and dummy variables for the licenses the adviser holds (Series 6, 7, 24, etc.). Standard errors are in parentheses and are clustered by firm. $* * * \mathrm{p}<0.01, * * \mathrm{p}<0.05, * \mathrm{p}<0.10$. 
Table A21: Stratifying on Adviser Industry Experience

(a) Advisers with 5 or Fewer Years Industry Experience

\begin{tabular}{lccc}
\hline Dependent Variable & Misconduct & Employment Separation & New Employment \\
\hline Female & $-0.18^{* * * *}$ & $-1.14^{* * * *}$ & $-2.19^{* * * *}$ \\
Misconduct & $(0.026)$ & $(0.23)$ & $(0.28)$ \\
& & $37.2^{* * * *}$ & $-12.6^{* * * *}$ \\
Misconduct $\times$ Female & & $(3.76)$ & $(2.06)$ \\
& & $8.87^{* * * *}$ & -2.06 \\
& $(1.67)$ & $(1.32)$ \\
Adviser Controls & & & \\
Year $\times$ Firm $\times$ County F.E. & $\mathrm{X}$ & $\mathrm{X}$ & $\mathrm{X}$ \\
Observations & $1,985,627$ & $1,854,824$ & $\mathrm{X}$ \\
R-squared & 0.098 & 0.311 & 409,506 \\
Mean of Dependent Variable & $0.34 \%$ & $24 \%$ & 0.359 \\
\end{tabular}

(b) Advisers with 15 or More Years Industry Experience

\begin{tabular}{|c|c|c|c|}
\hline Dependent Variable & Misconduct & Employment Separation & New Employment \\
\hline \multirow[t]{2}{*}{ Female } & $-0.49 * * *$ & $0.23 *$ & $-6.67 * * *$ \\
\hline & $(0.033)$ & $(0.12)$ & $(0.44)$ \\
\hline \multirow[t]{2}{*}{ Misconduct } & & $18.0 * * * *$ & $-6.89 * * *$ \\
\hline & & (1.08) & (1.27) \\
\hline \multirow[t]{2}{*}{ Misconduct $\times$ Female } & & $4.45^{* * *}$ & 1.13 \\
\hline & & $(1.51)$ & $(2.53)$ \\
\hline Adviser Controls & $\mathrm{X}$ & $\mathrm{X}$ & $\mathrm{X}$ \\
\hline Year $\times$ Firm $\times$ County F.E. & $\mathrm{X}$ & $\mathrm{X}$ & $\mathrm{X}$ \\
\hline Observations & $1,887,084$ & $1,663,752$ & 209,358 \\
\hline R-squared & 0.151 & 0.411 & 0.434 \\
\hline Mean of Dependent Variable & $0.88 \%$ & $15 \%$ & $63 \%$ \\
\hline
\end{tabular}

Tables A21a and A21b display the regression results for three linear probability models. In both tables, observations are at the adviser-by-year level over the period 2005-2015 in column (1) and over the period 2005-2014 in columns (2) and (3). Since we track advisers who left their firm in the subsequent year in columns (2) and (3), the sample covers the period 2005-2014 rather than 2005-2015. In panel (a), we restrict our analysis to advisers with five or fewer years of industry experience. In panel (b), we restrict our analysis to advisers with fifteen or more years of experience. The dependent variable in column (1) is a dummy variable indicating whether the adviser received a misconduct disclosure in year $t$ (eq. 1 ) and is scaled by 100 such that coefficients are in percentage points. The dependent variable in column (2) is a dummy variable indicating whether a financial adviser left the firm (eq. 3) and is scaled by 100 such that coefficients are in percentage points. The dependent variable in column (3) is a dummy variable indicating whether a financial adviser joined a new firm within one year (eq. 4) and is scaled by 100 such that coefficients are in percentage points. In column (3), we restrict the sample to advisers who left their firms in a given year. The independent variable Misconduct is a dummy variable indicating whether a financial adviser received a misconduct disclosure in the given year. Other adviser controls include the adviser's experience and dummy variables for the licenses that the adviser holds (Series 6, 7, 24, etc.). Standard errors are in parentheses and are clustered by firm. ${ }^{* * *} \mathrm{p}<0.01,{ }^{* *} \mathrm{p}<0.05,{ }^{*} \mathrm{p}<0.10$. 
Table A22: Recidivism and Selection Correction

\begin{tabular}{lccc}
\hline & $(1)$ & $(2)$ & $(3)$ \\
\hline Female & $-0.59^{* * *}$ & $-0.97^{* * * *}$ & $-0.51^{*}$ \\
& $(0.24)$ & $(0.28)$ & $(0.27)$ \\
Adviser Controls & & & \\
Year F.E. & & $\mathrm{X}$ & $\mathrm{X}$ \\
Firm F.E. & & & $\mathrm{X}$ \\
County F.E. & & & $\mathrm{X}$ \\
Observations & 87,088 & 87,088 & 86,753 \\
R-squared & 0.000 & 0.008 & 0.090 \\
Mean of Dependent Variable & $5.3 \%$ & $5.3 \%$ & $5.3 \%$ \\
\hline
\end{tabular}

Table A22 displays the regression results for a linear probability model (eq. A.3). The dependent variable is whether a financial adviser received a misconduct disclosure at time $t$. Our sample period covers the period 2005-2015. We restrict our observations to advisers who initially engaged in misconduct and did not experience an employment separation following misconduct. We correct for potential selection using a two-step semi-parametric method described in Appendix A6. Coefficient units are percentage points. Other adviser controls include the adviser's experience and dummy variables for the licenses the adviser holds (Series 6, 7, 24, etc.). Observations are at the adviser-by-year level. Standard errors are in parentheses and are clustered by firm. ${ }^{* * *} \mathrm{p}<0.01,{ }^{* *} \mathrm{p}<0.05,{ }^{*} \mathrm{p}<0.10$.

Table A23: Gender Gap in Promotions

\begin{tabular}{lccc}
\hline & $(1)$ & $(2)$ & $(3)$ \\
\hline Misconduct & $-0.17^{* * *}$ & $-0.13^{* *}$ & -0.10 \\
Misconduct $\times$ Female & $(0.075)$ & $(0.065)$ & $(0.065)$ \\
& $-0.25^{* *}$ & $-0.18^{*}$ & -0.14 \\
Female & $(0.11)$ & $(0.10)$ & $(0.11)$ \\
& $-0.25^{* * *}$ & $-0.22^{* * *}$ & $-0.082^{* * *}$ \\
& $(0.030)$ & $(0.035)$ & $(0.023)$ \\
Adviser Controls & & & \\
Year $\times$ Firm $\times$ County F.E. & & $\mathrm{X}$ & $\mathrm{X}$ \\
Observations & $5,657,813$ & $5,657,813$ & $5,351,741$ \\
R-squared & 0.000 & 0.008 & 0.094 \\
Mean of Dependent Variable & $0.8 \%$ & $0.8 \%$ & $0.8 \%$ \\
\hline
\end{tabular}

Table A23 displays the regression results corresponding to a linear probability model. Observations are at the financial adviser-by-year-level over the period 2005-2015. The dependent variable is a dummy variable indicating whether a financial adviser passed the general securities principal exam (Series 24) at time $t$. The dependent variable is scaled by 100 such that coefficients are expressed in percentage points. We restrict our sample to those financial advisers that are not general securities principals prior to time $t$. Other adviser controls include the adviser's experience, tests (series 6, 7, 63, and investment adviser exams), and number of other qualifications. Standard errors are in parentheses and are clustered by firm. $* * * \mathrm{p}<0.01, * * \mathrm{p}<0.05$, ${ }^{*} \mathrm{p}<0.10$. 


\section{A2: Disclosure Definitions ${ }^{1}$}

Civil-Final: This type of disclosure event involves (1) an injunction issued by a court in connection with investment-related activity, (2) a finding by a court of a violation of any investment-related statute or regulation, or (3) an action brought by a state or foreign financial regulatory authority that is dismissed by a court pursuant to a settlement agreement.

Civil - Pending: This type of disclosure event involves a pending civil court action that seeks an injunction in connection with any investment-related activity or alleges a violation of any investment-related statute or regulation.

Customer Dispute - Award/Judgment: This type of disclosure event involves a final, consumer-initiated, investment-related arbitration or civil suit containing allegations of sales practice violations against the adviser that resulted in an arbitration award or civil judgment for the customer.

Customer Dispute - Settled: This type of disclosure event involves a consumer-initiated, investment-related complaint, arbitration proceeding or civil suit containing allegations of sale practice violations against the adviser that resulted in a monetary settlement to the customer.

Customer Dispute - Closed-No Action/Withdrawn/Dismissed/Denied/Final: This type of disclosure event involves (1) a consumer-initiated, investment-related arbitration or civil suit containing allegations of sales practice violations against the individual adviser that was dismissed, withdrawn, or denied; or (2) a consumer-initiated, investment-related written complaint containing allegations that the adviser engaged in sales practice violations resulting in compensatory damages of at least $\$ 5,000$, forgery, theft, or misappropriation, or conversion of funds or securities, which was closed without action, withdrawn, or denied.

Customer Dispute - Pending: This type of disclosure event involves (1) a pending consumer-initiated, investment-related arbitration or civil suit that contains allegations of sales practice violations against the adviser; or (2) a pending, consumer-initiated, investment related written complaint containing allegations that the adviser engaged in, sales practice violations resulting in compensatory damages of at least $\$ 5,000$, forgery, theft, or misappropriation, or conversion of funds or securities.

Employment Separation After Allegations: This type of disclosure event involves a situation where the adviser voluntarily resigned, was discharged, or was permitted to resign after being accused of (1) violating investment-related statutes, regulations, rules or industry standards of conduct; (2) fraud or the wrongful taking of property; or (3) failure to supervise in connection with investment-related statutes, regulations, rules, or industry standards of conduct.

Judgment/Lien: This type of disclosure event involves an unsatisfied and outstanding judgments or liens against the adviser.

\footnotetext{
${ }^{1}$ Definitions as per http://brokercheck.finra.org/
} 
Criminal - Final Disposition: This type of disclosure event involves a criminal charge against the adviser that has resulted in a conviction, acquittal, dismissal, or plea. The criminal matter may pertain to any felony or certain misdemeanor offenses, including bribery, perjury, forgery, counterfeiting, extortion, fraud, and wrongful taking of property.

Financial - Final: This type of disclosure event involves a bankruptcy, compromise with one or more creditors, or Securities Investor Protection Corporation liquidation involving the adviser or an organization the adviser controlled that occurred within the last 10 years.

Financial - Pending: This type of disclosure event involves a pending bankruptcy, compromise with one or more creditors, or Securities Investor Protection Corporation liquidation involving the adviser or an organization the adviser controlled that occurred within the last 10 years.

Investigation: This type of disclosure event involves any ongoing formal investigation by an entity such as a grand jury state or federal agency, self-regulatory organization or foreign regulatory authority. Subpoenas, preliminary or routine regulatory inquiries, and general requests by a regulatory entity for information are not considered investigations and therefore are not included in a BrokerCheck report.

Regulatory - Final: This type of disclosure event may involves (1) a final, formal proceeding initiated by a regulatory authority (e.g., a state securities agency, self-regulatory organization, federal regulatory such as the Securities and Exchange Commission, foreign financial regulatory body) for a violation of investment-related rules or regulations; or (2) a revocation or suspension of a adviser's authority to act as an attorney, accountant, or federal contractor.

Civil Bond: This type of disclosure event involves a civil bond for the adviser that has been denied, paid, or revoked by a bonding company.

Criminal - On Appeal: This type of disclosure event involves a conviction for any felony or certain misdemeanor offenses, including bribery, perjury, forgery, counterfeiting, extortion, fraud, and wrongful taking of property that is currently on appeal.

Criminal - Pending Charge: This type of disclosure event involves a formal charge for a crime involving a felony or certain misdemeanor offenses, including bribery, perjury, forgery, counterfeiting, extortion, fraud, and wrongful taking of property that is currently pending.

Regulatory - On Appeal: This type of disclosure event may involves (1) a formal proceeding initiated by a regulatory authority (e.g., a state securities agency, self-regulatory organization, federal regulator such as the Securities and Exchange Commission, foreign financial regulatory body) for a violation of investment-related rules or regulations that is currently on appeal; or (2) a revocation or suspension of a adviser's authority to act as an attorney, accountant, or federal contractor that is currently on appeal.

Regulatory - Pending: This type of disclosure event involves a pending formal proceeding initiated by a regulatory authority (e.g., a state securities agency, self-regulatory organization, federal regulatory agency such as the Securities and Exchange Commission, foreign financial regulatory body) for alleged violations of investment-related rules or regulations. 
Civil - On Appeal: This type of disclosure event involves an injunction issued by a court in connection with investment-related activity or a finding by a court of a violation of any investment-related statute or regulation that is currently on appeal. 


\section{A3: FINRA Qualifications and Exams ${ }^{2}$}

Series 1, 7, 7a, and 7b Exam: The Series 7 exam - the General Securities Representative Qualification Examination (GS) - assesses the competency of an entry-level registered representative to perform his or her job as a general securities representative. The exam measures the degree to which each candidate possesses the knowledge needed to perform the critical functions of a general securities representative, including sales of corporate securities, municipal securities, investment company securities, variable annuities, direct participation programs, options and government securities. The Series 7 exam replaced the Series 1 Exam (Registered Representative Examination).

Series 2 Exam: The Series 2 exam is the Non-Member General Securities Examination and was retired in 1996.

Series 3 Exam: The Series 3 exam -the National Commodities Futures Examination-is a National Futures Association (NFA) exam administered by FINRA

Series 4 Exam: The Series 4 - Registered Options Principal Exam (OP) The Series 4 exam-the Registered Options Principal Qualification Examination (OP) - assesses the competency of an entry-level options principal candidate to perform his or her job as a registered options principal.

Series 5 Exam: The Series 5 exam is the Interest Rate Options Exam. The Series 5 exam was retired in 2010.

Series 6 Exam: The Series 6 exam-the Investment Company and Variable Contracts Products Representative Qualification Examination (IR)—assesses the competency of an entry-level representative to perform his or her job as an investment company and variable contracts products representative. The exam measures the degree to which each candidate possesses the knowledge needed to perform the critical functions of an investment company and variable contract products representative, including sales of mutual funds and variable annuities.

Series 8, 9, 10, and 12 Exam: The General Securities Sales Supervisor Qualification Examination (Series 9 and 10) is intended to test a candidate's knowledge of securities industry rules and certain statutory provisions applicable to the supervision of sales activities at a general securities-oriented branch office. The examination question bank and question allocation is developed through a committee of securities industry professionals with experience in retail securities sales. The Series 9 and 10 exams replaced the Series 8 and Series 12 exam (NYSE Branch Manager Examination).

Series 11 Exam: The Series 11 exam-the Assistant Representative - Order Processing Examination (AR) - assesses the competency of an entry-level registered assistant representative to perform his or her job as an order-processing assistant representative.

Series 14 and 14a Exam: The Series 14 exam-the Compliance Official Qualification Examination (CO) assesses the competency of an entry-level compliance official candidate to perform his or her job as a compliance officer. The exam measures the degree to which each candidate, who will supervise 10 or more

\footnotetext{
${ }^{2}$ Definitions as per http://www.finra.org/industry/qualification-exams?bc=1 and http://www.finra.org/industry/qualificationexam-effective-dates
} 
people engaged in compliance activities or are responsible for the overall day-to-day compliance activities of the firm, possesses the knowledge needed to perform the job responsibilities.

Series 15 Exam: The Series 15 exam is the Foreign Currency Options Examination. The Series 15 exam was retired in 2008.

Series 16 Exam: The Series 16 exam—the Supervisory Analysts Qualification Examination (SA)—assesses the competency of an entry-level supervisory analyst to perform his or her job as a supervisory analyst. The exam measures the degree to which each candidate possesses the knowledge needed to perform the critical functions of a supervisory analyst, including the rules and statutory provisions applicable to the preparation and approval of research reports.

Series 17 Exam: The Series 17 exam-the United Kingdom Securities Representative Qualification Examination (IE) - an abbreviated version of the Series 7 exam, is appropriate for candidates who hold a registration in good standing with the Financial Conduct Authority (FCA) in the United Kingdom and are seeking registration in the U.S.

Series 18 Exam: The Series 18 exam is the Securities Industry Rules and Regulations Examination. The Series 18 exam was retired in 1988.

Series 21 Exam: The Series 21 exam is the NYSE Front Line Specialist Clerk Examination.

Series 22 Exam: The Series 22 exam — the Direct Participation Programs Limited Representative Examination (DR) - assesses the competency of an entry-level registered representative to perform his or her job as a direct participation programs representative.

Series 23 Exam: The Series 23-the General Securities Principal Qualification Examination-Sales Supervisor Module (GP)—assesses the competency of an entry-level general securities principal candidate to perform his or her job.

Series 24 Exam: The Series 24 exam-the General Securities Principal Qualification Examination (GP)—assesses the competency of an entry-level general securities principal candidate to perform his or her job as a general securities principal. The exam measures the degree to which each candidate possesses the knowledge needed to perform the critical functions of a general securities principal, including the rules and statutory provisions applicable to the supervisory management of a general securities broker-dealer.

Series 25 Exam: The Series 25 exam is the NYSE Trading Assistant Examination. The Series 25 exam was retired in 2016.

Series 26 Exam: The Series 26 exam—the Investment Company and Variable Contracts Products Principal Examination (IP) - assesses the competency of an entry-level investment company and variable products principal candidate to perform his or her job.

Series 27 Exam: The Series 27 exam—the Financial and Operations Principal Qualification Examination (FN) - assesses the competency of an entry-level financial and operations principal (FINOP) candidate to perform his or her job as a FINOP. The exam measures the degree to which each candidate possesses the knowledge and understanding of the financial responsibilities, rules and recordkeeping requirements of broker-dealers. 
Series 28 Exam: The Series 28 exam-the Introducing Broker-Dealer Financial and Operations Principal Qualification Examination (FI)—assesses the competency of an entry-level financial and operations principal (FINOP) candidate to perform his or her job as a FINOP in an introducing broker-dealer that does not carry customer accounts or hold customer funds or securities.

Series 30 Exam: The Series 30 exam-the NFA Branch Managers Examination-is a National Futures Association (NFA) exam administered by FINRA.

Series 31 Exam: The Series 31 exam—-the Futures Managed Funds Examination-is a National Futures Association (NFA) exam administered by FINRA.

Series 32 Exam: The Series 32 exam-the Limited Futures Examination-Regulations-is a National Futures Association (NFA) exam administered by FINRA.

Series 33 Exam: The Series 33 exam is the Financial Instruments Examination. The Series 33 exam was retired in 2005.

Series 34 Exam: The Series 34 exam-the Retail Off-Exchange Forex Examination-is a National Futures Association (NFA) exam administered by FINRA.

Series 37 Exam: The Series 37 exam-the Canada Securities Representative Qualification Examination (CD) —an abbreviated version of the Series 7 exam, is appropriate for candidates who hold a registration in good standing with Canadian securities regulatory authorities and are seeking registration in the U.S. The exam assesses the competency of the candidate to perform his or her job as a general securities representative in the U.S. It measures the degree to which each candidate possesses the knowledge needed to perform the critical functions of a general securities representative, including sales of corporate securities, investment company securities, variable annuities, direct participation programs, options and government securities.

Series 38 Exam: The Series 37 exam - the Canada Securities Representative Qualification Examination (CD) —an abbreviated version of the Series 7 exam, is appropriate for candidates who hold a registration in good standing with Canadian securities regulatory authorities and are seeking registration in the U.S. The exam assesses the competency of the candidate to perform his or her job as a general securities representative in the U.S. It measures the degree to which each candidate possesses the knowledge needed to perform the critical functions of a general securities representative, including sales of corporate securities, investment company securities, variable annuities, direct participation programs, options and government securities.

Series 39 Exam: The Series 39 exam—the Direct Participation Programs Principal Qualification Examination (DP) - assesses the competency of a direct participation program (DPP) principal candidate to perform his or her job as a DPP principal. The exam measures the degree to which each candidate possesses the knowledge needed to perform the critical functions of a DPP principal, including the rules and statutory provisions applicable to the supervisory management of a broker-dealer that limits its products to direct participation programs. 
Series 40 Exam: The Series 40 exam is the Registered Principal Examination. The Series 40 exam was retired in 1979.

Series 41 Exam: The Series 41 exam is the NYSE Allied Member Examination.

Series 42 Exam: The Series 42 exam-the Registered Options Representative Qualification Examination (OR) - assesses the competency of an entry-level registered representative to perform his or her job as an options representative. The exam measures the degree to which each candidate possesses the knowledge needed to perform the critical functions of an options representative, including handling option accounts and the understanding of equity, debt, foreign currency and index options.

Series 44 Exam: The Series 44 exam is the Pacific Exchange Inc. (PCX) Market Maker Exam.

Series 45 Exam: The Series 45 exam is the Pacific Exchange Inc. (PCX) Floor Broker Exam.

Series 46 Exam: The Series 46 exam is the Pacific Exchange Inc. (PCX) Market Maker acting as a Floor Broker Exam.

Series 48 Exam: The Series 48 exam is the AMEX Market Maker Exam.

Series 49 Exam: The Series 49 exam is the AMEX Floor Broker Exam.

Series 50 Exam: Series 50-Municipal Advisor Representative Examination—is a Municipal Securities Rulemaking Board (MSRB) exam.

Series 51 Exam: The Series 51 exam-the Municipal Fund Securities Limited Principal Qualification Examination (FP)—is a Municipal Securities Rulemaking Board (MSRB) exam.

Series 52 Exam: The Series 52 exam—-the Municipal Securities Representative Qualification Examination (MR)—is a Municipal Securities Rulemaking Board (MSRB) exam.

Series 53 Exam: The Series 53 exam—the Municipal Securities Principal Qualification Examination (MP)—is a Municipal Securities Rulemaking Board (MSRB) exam.

Series 54 Exam: The Series 54 exam is the Municipal Securities Financial and Operations Principal Examination. The exam was retired in 1989.

Series 55, Series 56 and 57 Exam: The Series 57 exam — the Securities Trader Representative Exam assesses the competency of an entry-level registered representative to perform their job as a securities trader representative. The Series 57 exam replaced the Series 55 exam (the Equity Trader Examination) and the Series 56 exam (the Proprietary Trader Examination).

Series 62 Exam: The Series 62-the Corporate Securities Representative Qualification Examination (CS)—assesses the competency of an entry-level representative to perform his or her job as a corporate securities representative. 
Series 63 Exam: The Uniform Securities Agent State Law Examination was developed by NASAA in cooperation with representatives of the securities industry and industry associations. The examination, called the Series 63 exam, is designed to qualify candidates as securities agents. The examination covers the principles of state securities regulation reflected in the Uniform Securities Act (with the amendments adopted by NASAA and rules prohibiting dishonest and unethical business practices). The examination is intended to provide a basis for state securities administrators to determine an applicant's knowledge and understanding of state law and regulations.

Series 64 Exam: The Series 65 exam is the NASAA Real Estate Securities Exam.

Series 65 Exam: The Uniform Investment Adviser Law Examination and the available study outline were developed by NASAA. The examination, called the Series 65 exam, is designed to qualify candidates as investment adviser representatives. The exam covers topics that have been determined to be necessary to understand in order to provide investment advice to clients.

Series 66 Exam: The Uniform Combined State Law Examination was developed by NASAA based on industry requests. The examination (also called the "Series 66") is designed to qualify candidates as both securities agents and investment adviser representatives. The exam covers topics that have been determined to be necessary to provide investment advice and effect securities transactions for clients.

Series 72 Exam: The Series 72 exam—-the Government Securities Representative Qualification Examination (RG) - assesses the competency of an entry-level registered representative to perform his or her job as a government securities representative. The exam measures the degree to which each candidate possesses the knowledge needed to perform the critical functions of a government securities representative, including transacting a firm's business in Treasury, government agency and mortgage-backed securities.

Series 79 Exam: The Series 79 exam — the Investment Banking Representative Exam — assesses the competency of an entry-level registered representative to perform their job as an investment banking representative.

Series 82 Exam: The Series 82 exam — the Private Securities Offerings Representative Exam — assesses the competency of an entry-level registered representative to perform their job as a private securities offerings representative.

Series 86 and 87 Exams: The Series 86/87 exam — the Research Analyst Exam — assesses the competency of an entry-level registered representative to perform their job as a research analyst.

Series 99 Exam: The Series 99 exam — the Operations Professional Exam — assesses the competency of an entry-level registered representative to perform their job as an operations professional. 


\section{A4: Gender Punishment Gap in Reemployment: Duration Analysis}

An alternative way, relative to our approach in Section III, to measure differences in reemployment prospects across genders is through the duration out of the industry. Figure A5 displays the duration out of the industry survival function for male and female advisers, cut by whether the adviser engaged in misconduct in the year prior to unemployment in the industry. As the figure illustrates, on average, the duration out of the industry spells for female advisers are longer than those for male advisers. This is the case both for advisers with misconduct in the past year and for advisers without misconduct. Roughly $50 \%$ of female advisers remain out of the industry after 24 months, while only $44 \%$ of male advisers remain out of the industry after 24 months. More relevant to differential punishment across genders is the increase in the duration out of the industry due to misconduct. The probability of long-term unemployment out of the industry following misconduct increases substantially more for female advisers than for their male counterparts.

The simple non-parametric survival analysis in Figure A5 does not account for other differences among financial advisers, such as their experience or qualifications. We formally analyze the impact of misconduct on an adviser's job search by estimating the following Cox proportional hazards model:

$$
\lambda_{i t}(\tau)=\lambda_{0}(\tau) \exp \left(\gamma_{1} \text { Female }_{i}+\gamma_{2} \text { Misc. }_{\text {it-1 }} \times \text { Male }_{i t}+\gamma_{3} \text { Misc }_{\text {.it-1 }} \times \text { Female }_{i}+\beta X_{i t}+\mu_{t}\right),
$$

where $\lambda_{i}(\tau)$ is the hazard rate of finding new employment in the industry for individual $i$ conditional on being unemployed for $\tau$ months. The hazard rate is a function of the baseline hazard $\lambda_{0}(\tau)$ and changes proportionally depending on whether the financial adviser was reprimanded for misconduct in the year preceding the unemployment out of the industry spell, Misconduct ${ }_{i t-1}$, gender, and the interaction of the two. We also control for an adviser's characteristics $X_{i t}$ and include time fixed effects $\mu_{t}$ to account for aggregate fluctuations in the employment market.

Table A6 reports the hazard ratios corresponding to our Cox proportional hazards model. Any reported hazard ratio less than one suggests that the covariate is correlated with longer duration out of the industry spells. The estimates reaffirm the results displayed in Figure A5. The results indicate that female advisers face longer duration out of the industry spells relative to male advisers. Female advisers have a $4 \%$ smaller chance of finding new employment in the industry at any given moment in time relative to male advisers. Misconduct results in longer duration out of the industry spells for both male and female advisers, but the effect is much larger for female advisers. A male adviser who had engaged in misconduct in the year prior to the start of his unemployment has a $16 \%$ smaller chance of finding new employment in the industry at any given moment in time relative to a male adviser without recent misconduct (Table A6 column 1). Conversely, a female adviser who engaged in misconduct has a $26 \%$ smaller chance of finding new employment in the industry at any given moment in time relative to a female adviser without misconduct (Table A6 column 1). 


\section{A5: Misconduct Classification Using Textual Analysis}

We use textual analysis to classify the different types of misconduct we observe in the data. For each misconduct disclosure, we observe a description of the offense, ranging from a sentence to a couple of paragraphs. We use three different textual analysis methods to analyze the description of each misconduct disclosure.

First, we manually categorize the nature of the misconduct disclosures based on the words that appear in the description of the misconduct disclosure as well as the product involved in the disclosure. Specifically, we classify misconduct into 10 different categories (i.e. fraud, unauthorized activity, etc.) as reported in Table 1(c) by manually selecting words or categories based on the most frequent words appearing in the misconduct descriptions. Using this same approach, we are also able to determine the financial product (insurance, annuity, etc.) involved in the misconduct disclosure as reported in Table 1(d).

Second, we analyze the disclosures using a Bag of Words approach (Gentzkow, Kelly, and Taddy, 2019; Bodoh-Creed, Boehnke, and Hickman 2018). Specifically, we first separate each disclosure description into sentences and words and then stem each word using Porter's Stemming Algorithm (1980). We then form a list of the 150 most common words appearing in the descriptions, ignoring articles, prepositions, and stop words. Based on these 150 most common words, we construct 150 dummy variables that indicate the presence of each word in a misconduct description, and we use principal component analysis to further reduce the dimensionality of the dummy variables to ten orthogonal vectors. We then include these principal component vectors as control variables in our baseline analysis.

Third, we analyze the disclosures using Latent Dirichlet Allocation (LDA) following Blei et al. (2003). LDA is a popular machine learning topic model that helps cluster text documents into topics. Conceptually, LDA represents each misconduct disclosure and corresponding text description as a probability distribution over topics, and each topic is a probability distribution over words. To implement the LDA, the text descriptions are first pre-processed; we use Term-Frequency Inverse-Document-Frequency (TF-IDF) to convert the documents to a matrix of "tokens," or words that occur frequently across the documents, and to generate a weight for each token. Tokens that occur frequently within individual documents receive higher weights, but these weights are lowered if they appear frequently within the collection of documents, or corpus. Text mining exercises commonly employ TF-IDF vectorizers in lieu of standard count vectorizers (which do not adjust for frequencies of tokens within the corpus) because of their ability to successfully filter words that are unlikely to provide valuable information regarding the underlying contents of the documents. In our case, we also utilize the scikit-learn 'english' stop word list for additional filtering and only keep the 1,000 most frequently occurring words in order to prevent over-fitting.

We then use LDA to cluster the disclosure descriptions into ten different categories. We only specify the number of topics to be generated (not the topics themselves); in our case, we find that using 10 topics strikes a good balance between adequately dividing the text and avoiding overlap between the generated topics. For each misconduct disclosure, LDA calculates the probability that the disclosure corresponds to each of the ten different topics. We assign each misconduct disclosure to the topic given the highest probability, provided that the assigned probability is greater than $80 \%$. We are able to definitively assign topics to roughly $30 \%$ of the misconduct disclosures. Lastly, we construct dummy variables for each topic and use them as controls in our baseline analysis. The topics and their descriptions are reported in Table A15.

We replicate our baseline analysis in using our three sets of additional control variables. First, we examine the probability male and female advisers experience an employment separation following misconduct (eq. 
3). We report the corresponding results in Table A16. Our baseline set of results are reported in columns (1)-(4), and we include our three sets of description-based misconduct control variables (described above) in columns (5)-(7). In each specification we estimate a positive and significant gender punishment gap, the coefficient on $\mathrm{Misc}_{i q j l t} \times \mathrm{Female}_{i}$. The results are similar across all seven specifications, with the gender gap ranging from 7-10pp.

We also reexamine how the reemployment prospects of male and female advisers differ following misconduct in eq. (4) and report the results in Table A17. Our baseline set of results are reported in columns (1)-(4), and we include our three sets of description-based misconduct control variables in columns (5)-(7). The results in Table A17 show that female advisers are less likely to find new employment in the industry following misconduct relative to their male counterparts, with coefficients ranging from 2.84-3.66pp in columns (5) to (7). 


\section{A6: Recidivism and Selection}

A challenge in accessing the relative recidivism propensities across genders is that we only observe recidivism among advisers who remain employed in the industry. Here, we account for sample selection using a semi-parametric two step method. In the first step we estimate the probability an adviser experience's an employment separation following his/her initial misconduct offense

$$
\text { Separation }_{i t+1}=\beta_{g} X_{i t}+\mu_{j g}+\mu_{l g}+\mu_{t g}+\varepsilon_{i t}
$$

Observations are at the adviser-by-year level; $i$ indexes an adviser of gender $g$ who worked for firm $j$ at time $t$ in county $l$. The vector of adviser controls $X_{i t}$ includes the adviser's experience and licenses (series 6, 7, 63,24 , etc.). . We also include firm, year, and county fixed effects. Furthermore, we allow the parameters to vary flexibly across genders to allow the differential treatment of men and women to vary across firms, regions, and over time. We use the predicted values from our employment separation regression (eq A.2) to calculate an adviser's propensity to experience an employment separation, $\hat{p}$.

We then re-estimate using our recidivism specification (eq. 10) where include a fourth order polynomial of $\hat{p}$ as a control function. Estimating the sample selection model semi-parametrically requires an exclusion restriction. We use the adviser's past characteristics at the time of the offense (experience, employer, location, licenses, etc.) as an exclusion restriction. This exclusion restriction requires that conditional on the adviser's current observable characteristics, the past observable characteristics that help determine whether he/she was fired following misconduct such as experience, firm, or location, are uncorrelated with recidivism.

$$
\text { Misconduct }_{i j l t}=\beta X_{i t}+\mu_{j}+\mu_{l}+\mu_{g}+\sum_{k=1}^{4} \phi_{k} \hat{p}_{i}^{k}+\eta_{i j l t}
$$

In our analysis, we restrict our observations to those advisers who initially engaged in misconduct and did not experience an employment separation following the previous misconduct. Table A22 displays the corresponding estimates where use a semi-parametric control function to address the potential selection issues. Consistent with the selection model, we restrict the data set to those advisers who engaged in misconduct but remained with their employer the following year. In each specification we estimate a negative and significant relationship between gender and misconduct. 